\title{
The Social Cognitions of Victims of Bullying: A Systematic Review
}

\author{
Sanne Kellij ${ }^{1,2,4}$ (C) Gerine M. A. Lodder ${ }^{3} \cdot$ Neeltje van den Bedem ${ }^{2} \cdot$ Berna Güroğlu $^{2,4} \cdot$ René Veenstra $^{1}$
}

Received: 30 December 2021 / Accepted: 27 January 2022 / Published online: 22 February 2022

(c) The Author(s) 2022

\begin{abstract}
The nature of the relation between victimization of bullying and social information processing is unclear. The prevention hypothesis predicts that victims focus more on negative social cues to prevent further escalation. In contrast, the reaffiliation hypothesis predicts that victims focus more on positive social cues to restore the social situation. Alternatively, the desensitization hypothesis predicts that victims become increasingly insensitive to social cues because of a numbing effect. This systematic review examines evidence for these three hypotheses on the relation between victimization and social information processing. The focus is on two phases of social information processing: encoding of social information (attending to and registration of social cues) and interpreting social information (making sense of multiple social cues simultaneously). These phases are important prerequisites for behavioral responses. The systematic search led to the inclusion of 142 articles, which were published between 1998 and 2021 and received quality assessment. The studies included on average about 1600 participants (range: 14-25,684), who were on average 11.4 years old (range: 4.1-17.0). The topics covered in the literature included attention to and accurate registration of social cues, peer perception, attribution of situations, empathy, and theory of mind. The results were most often in line with the prevention hypothesis and suggested that victimization is related to a negative social-cognitive style, as shown by a more negative perception of peers in general and more negative situational attribution. Victimization seemed unrelated to abilities to empathize or understand others, which contradicted the desensitization hypothesis. However, desensitization may only occur after prolonged and persistent victimization, which to date has been sparsely studied. The reaffiliation hypothesis could not be thoroughly examined, because most studies did not include positive social cues. In bullying prevention, it is important to consider the negative social information processing style related to victimization, because this style may impede the development of positive social interactions.
\end{abstract}

Keywords Social information processing $\cdot$ Victimization $\cdot$ Bullying $\cdot$ Attribution bias $\cdot$ Encoding $\cdot$ Empathy

\section{Introduction}

Berna Güroğlu and René Veenstra: Shared last authorship.

Sanne Kellij

s.kellij@rug.nl

1 Department of Sociology, University of Groningen, Groningen, Netherlands

2 Department of Developmental Psychology, Leiden University, Leiden, Netherlands

3 Department of Developmental Psychology, Tilburg University, Tilburg, Netherlands

4 Leiden Institute for Brain and Cognition, Leiden University Medical Center, Leiden, Netherlands
Seeing is believing, or so is the expression. People can see the same things but interpret them differently. In social situations, this can lead to misunderstandings and may, in the case of bullying, lead to unwanted negative spirals. Social cognition refers to how individuals construct their (subjective) social reality. It involves psychological and cognitive processes of how a person processes, stores, and applies information about the social world (Ostrom, 1984). When children are the victim of repeated, intentionally aggressive, or hurtful behavior from a powerful perpetrator, such as in bullying (Olweus, 1993), it is likely to affect how they experience their social world and may affect their general social cognitive tendencies. This may have long lasting consequences, even into adulthood, as victims report more mental health problems, lower levels of academic achievement, 
and poorer social relationships (Arseneault, 2018). A better understanding of the effects of victimization on social cognition of victims is needed, as social cognition likely influences (the perception of) new social interactions, and thus play a role in the victimization process. To date, it is unclear how victimization relates to different aspects of social cognition, as many studies only examine a subcomponent of this highly complex construct. Therefore, this systematic review provides an overview of the literature on the relation between victimization and different aspects of social cognition.

Bullying is a social process (Salmivalli, 2010). Both bullies and victims influence social interactions by sending and interpreting social messages. The past experiences and the social-cognitive thinking style of children influence how these social messages are received. According to the social information processing (SIP) model (Crick \& Dodge, 1994), the social-cognitive processes can be organized in six subsequent steps or phases. The first two phases refer to the selection and interpretation of social cues: encoding (which cues are registered) and interpretation (interpreting the combined meaning of all registered cues). For example, perceiving someone's facial expression without any interpretation is part of the encoding phase, whereas thinking about why someone is laughing contains a subjective component and is therefore an interpretation. A feedback loop exists between encoding and interpretation, such that interpretation can influence encoding of subsequent social cues. The last four SIP-phases refer to cognitive processes which enable an individual to form a behavioral response: goal selection, construction of possible responses, response choice, and the execution of the chosen response (Crick \& Dodge, 1994). Finally, each person has a database which includes memories, schemas, and social knowledge that influence each SIP-phase (Crick \& Dodge, 1994). For example, if people get to know each other (knowledge and memories), the interpretation of the other's intentions will improve. While the database concurrently influences the SIP-phases, it is also simultaneously updated with new experiences. The updated database, in turn, influences future encoding, interpretation, and behavioral responses, possibly leading to the development of negative spirals. Victims are likely to have difficulties in sending and interpreting social information, as they seem to have poorer social cognition and social skills (Fox $\&$ Boulton, 2005).

No matter whether it is a precursor or consequence of victimization, having difficulties in social cognition (or social intelligence, see Kaukiainen et al., 2002) may relate to being victimized. Based on the SIP-model, prior victimization experiences likely affect how victims encode, interpret, and respond to social cues as their past experiences color the interpretation of new social situations. First, victims may have a positive social-cognitive style and focus on positive social cues and interpretations to facilitate reaffiliation (Bernstein, 2003; Pickett \& Gardner, 2005), called the reaffiliation hypothesis in this review. In line with this hypothesis, socially excluded people tend to focus more on positive social cues (Buckner et al., 2010) and have better memory recall for positive events (DeWall et al., 2011). Second, instead of focusing on positive social cues, victims may develop a negative social-cognitive style and focus more on negative social cues or threat, and detect such stimuli more rapidly, to prevent subsequent negative interactions (Rapee \& Heimberg, 1997), the prevention hypothesis. In line with this, previous studies have found that anxious individuals tend to focus on negative information (Bar-Haim et al., 2007), lonely individuals expect more rejection by others (Spithoven et al., 2017), and victims of all types of events (e.g., natural disasters and crime) are prone to interpret hostile intent (van Reemst et al., 2016). Third, victims may become increasingly insensitive to social information, the desensitization hypothesis, as repeated victimization might lead to an insensitivity to all kinds of social information (Bernstein, 2003). However, to date, it is unclear what the nature of this relation is.

\section{Current Study}

The aim of the present study was to examine the relation between victimization and social cognition (encoding and interpretation) in children and adolescents through a systematic literature review. The results were interpreted in light of hypotheses that were formed on the relation between victimization and social cognition: the reaffiliation (focus on positive social cues to reaffiliate), prevention (focus on negative social cues to avoid future victimization), and desensitization (numbing or insensitivity to social cues) hypotheses.

\section{Methods}

\section{Search Strategy}

The systematic review was carried out in line with the PRISMA guidelines (Moher et al., 2009). Search terms were included for victimization and social cognition in three databases (PsycInfo, Web of Science, ERIC), see the identification block in Fig. 1 and Online Source 1. The literature search was executed in July 2018 and updated in February 2021.

\section{Study Selection}

The presented results are of the combined initial search and update. The search resulted in 7628 hits (PsycInfo: 3477, 


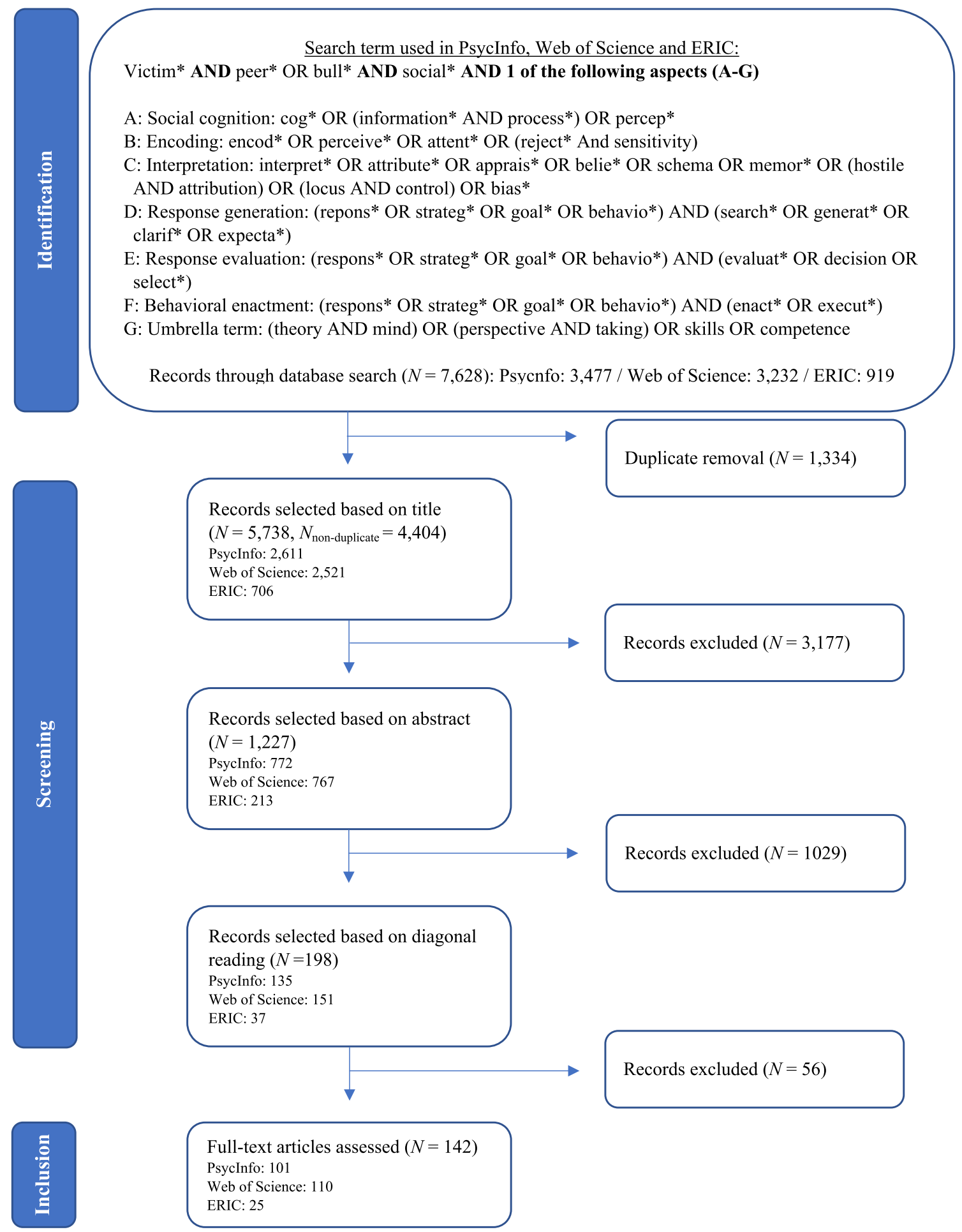

Fig. 1 Flow diagram of the selection process of the articles. In the first box you read the utilized search term and the hits per database. In the following blocks you can see the other article selection phases (title deselection, abstract reading, diagonal reading $\&$ full-text reading)

Web of Science (WoS): 3232, ERIC: 919). 1890 hits were excluded, if they had titles unrelated to the topic (e.g., other victimization types, such as gang violence), were not peerreviewed publications (to warrant study quality), or were not written in English. After removal of 1334 duplicates, 4404 articles were left (PsycInfo: 2611, WoS: 2521, ERIC: 706). In round two, the abstracts were read and articles were selected only when they referred to victimization of 
bullying or social cognition. This round resulted in 1227 articles (PsycInfo: 772, WoS: 767, ERIC: 213). In round three, diagonal reading, the articles were scanned for relevant information and selected articles that examined the relation between social cognition and victimization and had a particular focus on either encoding or interpretation. Articles were excluded if they included participants older than 18 years, or if they examined coping, attribution style (internal/external, stable/unstable, controllable/uncontrollable), general social skills, or if they examined the last four phases of the SIP-model (behavioral response). During the first search in 2018, two researchers independently did round three, the diagonal reading. Inter-rater reliability for selection in this round was $89.9 \%$ (79.3\% for the first 100 and $91.5 \%$ for the remaining articles). In case of disagreement, the researchers discussed the article and respective arguments, to come to an agreement. During the search update in 2021 one researcher read the articles because of the high inter-rater reliability obtained during the first search. Diagonal reading resulted in 198 included articles (PsycInfo: 135, WoS: 151, ERIC: 37 ).

These 198 articles were read thoroughly by the first author. An additional 56 articles (15 first search, 42 search update) were excluded (e.g., focus on rejection instead of victimization or because of participant age either being younger than 4 or older than 18). This led to an inclusion of 142 articles in the review (PsycInfo: 101, WoS: 110, ERIC: 25), published between 1998 and 2021. Studies included on average about 1600 participants (Median $=390$, range: 14-25,684), who were on average 11.4 years old (range: 4.1-17.0). Figure 1 provides the selection flow diagram. Online Source 1 contains details on the selection process.

\section{Quality Assessment}

The commonly used Newcastle-Ottawa Scale for study quality assessment (Wells et al., 2000) was adjusted for the purposes of this systematic review. Studies were evaluated on sample, measures, and method in relation to our aim: examining the relation between social cognition and victimization of bullying. Sample referred to the representativeness of the sample, the appropriateness of the sample size, the non-response, and the participant characteristics. Measures referred to the measurement of victimization as well as social cognition, and the use of control variables. Method referred to the type of study (longitudinal/crosssectional), pre-registration, the use of descriptives, and the use of statistics. The first author assessed the quality, which was replicated by the third author for $10 \%$ of the studies. The interrater reliability for this subset was satisfactory $(r=0.84, p<0.001 ;$ ICC $=0.89, p<0.001)$. The included studies received between 4 and 13 points out of the possible $16(M=8.50, S D=1.82)$, with a notable exception of one receiving 1 point (see Online Source 2a Table S3 for the quality assessment per study and Online Source $2 b$ for details). Studies most often lost points on not including effect sizes and response rates, using non-validated measures, not having a longitudinal design, and not pre-registering the study. Generally, the overall quality of the studies seems unsatisfactory, which demonstrates possible improvements for research designs.

\section{Results}

The results are organized based on the two aspects of social cognition: encoding and interpretation (first two SIP-phases) in relation to victimization of bullying. Within each SIPphase, results are categorized in subdomains, based on topics addressed in the articles. Results were interpreted in light of the reaffiliation, prevention, and desensitization hypotheses.

\section{Victimization and the Encoding of Social Information}

The articles on encoding, the first SIP-phase, examined which cues were attended to (selection) and whether cues were registered as what they objectively were (accurate registration).

\section{Selection of Social Cues}

Selection of social cues, or attention, refers to how perceptual, motor, and cognitive systems are allocated to potentially competing information-processing demands. It involves both conscious and unconscious selection to different social cues (Anderson, 2015).

Only four studies examined victimization in relation to attention (see Table 1); therefore, conclusions are preliminary. Based on the reaffiliation hypothesis, it was expected that victims would attend predominantly to positive social cues, in order to identify possibilities to restore social relationships. However, most studies focused exclusively on negative social information. One study examined differences in the attention to emotions between victims and nonvictims, but neither specified valence of emotions nor found support for victims differing in attention to others' emotions compared with peers (Hussein, 2013). Therefore, no conclusions could be drawn for the reaffiliation hypothesis.

Based on the prevention hypothesis, it was expected that victims would attend predominantly to negative social cues, to prevent further negative interactions. There was support for this hypothesis, as frequent victimization was associated with a higher likelihood to notice bullying events in real life (Jenkins \& Nickerson, 2017). Another study examined visual attention to bullying scenarios, and showed that 
Table 1 Study results on selection of cues (attention)

\begin{tabular}{|c|c|c|c|c|}
\hline Reference & Sample & Design & Measures & Results \\
\hline Hussein (2013) & 623 children, $10-12$ years, EGY & $\mathrm{CS}$ & $\begin{array}{l}\text { Victimization: PIPSQ, SR-Q } \\
\text { Attention: EAQC-R, SR-Q }\end{array}$ & $\begin{array}{l}\text { Victims/bullies/bully-victims } \\
\text { did not attend more to others' } \\
\text { emotions than non-involved } \\
\text { children }\left(\mathrm{OR}_{\text {victim }}=0.98\right. \\
p=0.70 ; \mathrm{OR}_{\text {bully }}=0.99, p=0.91 \\
\left.\text { OR }_{\text {bully-victim }} 1.04, p=0.64\right)\end{array}$ \\
\hline Jenkins and Nickerson (2017) & $\begin{array}{l}299 \text { adolescents, } 12-14 \text { years, } \\
\text { USA }\end{array}$ & $\mathrm{CS}$ & $\begin{array}{l}\text { Victimization: BPBQ, SR-Q } \\
\text { Attention: BIB, SR-Q }\end{array}$ & $\begin{array}{l}\text { Victims/defenders noticed bullying } \\
\text { events in real life more often } \\
\left(\beta_{\text {victim }}=0.21, p=0.023 ; \beta=0.19\right. \\
p=0.025) \text {, whereas bullies/assis- } \\
\text { tants/outsiders did not }(\beta \text { 's }<0.07 \\
p>0.46)\end{array}$ \\
\hline Rosen et al. (2007) & 82 children, $9-13$ years, USA & $\mathrm{CS}$ & $\begin{array}{l}\text { Victimization: PPSS, SR-Q } \\
\text { \& PaR-Q (composite score) } \\
\text { Attention: Emotional Stroop, } \\
\text { Task }\end{array}$ & $\begin{array}{l}\text { The more children were victimized, } \\
\text { the faster their reaction times } \\
\text { were to negative social words } \\
\left(R^{2}=0.35, p<0.01 ; \beta=-0.29\right. \\
p<0.01)\end{array}$ \\
\hline Troop-Gordon et al. (2019) & 72 children, 11.7 years, USA & $\mathrm{CS}$ & $\begin{array}{l}\text { Victimization: MPVS-R, } \\
\text { TR-Q, PEER, PaR-Q (com- } \\
\text { posite score) } \\
\text { Attention: Eye-tracking; time } \\
\text { focused on bully roles, Task }\end{array}$ & $\begin{array}{l}\text { Children paid most attention to the } \\
\text { bully and then the victim (Atten- } \\
\text { tion to bully: } M=5011.45 \mathrm{~ms}, \\
S D=912.76, \text { Attention to victim: } \\
M=4479.10 \mathrm{~ms}, S D=694.90, \\
\text { Attention to reinforcer: } \\
M=1547.92 \mathrm{~ms}, S D=308.52, \\
\text { Attention to defender: } \\
M=1490.81 \mathrm{~ms}, S D=364.34) \\
\text { Victimization did not significantly } \\
\text { relate to attention (time spent) } \\
\text { to any of the bullying roles } \\
\left(r_{\text {bully }}=-0.04, r_{\text {victim }}=-0.04,\right. \\
r_{\text {reinforcer }}=0.00, r_{\text {defender }}=-0.06, \\
p \text { 's }>0.05) \text {. Victims that paid } \\
\text { more attention to bullies in the } \\
\text { videos were more aggressive } \\
\text { according to peers ( } \beta_{\text {overt }}=0.38, \\
p<0.001 ; \beta_{\text {relational }}=0.43, \\
p<0.001), \text { but not accord- } \\
\text { ing to teachers }\left(\beta_{\text {teachers }}=0.20,\right. \\
p=0.099)\end{array}$ \\
\hline
\end{tabular}

$C S$ cross-sectional, $L$ longitudinal, $S R-Q$ self-report questionnaire, $P a R-Q$ parent-reported questionnaire, $T R-Q$ teacher-reported questionnaire, $P E E R=$ Peer nomination. See Table 7 for abbreviations of the questionnaires and tasks

all children spent most time looking at bullies and second most time looking at victims (Troop-Gordon et al., 2019). Thus, children focused attention mostly on the immediate threat, the bully, and not, for example, on bystanders who could possibly help. For victims, the attended social cues might affect behavior, as heightened attention for bullies by victimized children related to more aggressive behavior (Troop-Gordon et al., 2019). These findings provided indirect support for the role of threat prevention in attention to social cues in general.

A focus on threat not only became apparent in studies employing tasks with visual social cues, but also in a study examining interference of word valence on the ability to name the color of the word (emotional Stroop effect: Williams et al., 1996). Victimization experiences related to faster responses to victimization related words (Rosen et al., 2007). Faster responses to victimization related words indicate faster attendance to these social cues, which could imply that victims focus on threatening social cues. Alternatively, these results can also be interpreted in line with the desensitization hypothesis, from which it was expected that victims would attend less to social cues in general. Frequently victimized children may be more insensitive toward negative valence words, so that the valence of these words interferes less, resulting in faster reaction times. As such, whether this study provides more support for the prevention or the desensitization hypothesis remains unclear. 
Taken together, the studies on attention and victimization suggest that victims may have a heightened focus on negative or threatening social cues, as two studies gave indirect support and one study out of four clearly indicated that victims might notice social threatening events more often. Across time, this focus on negative social cues may result in numbness for negative social information, but the conclusion regarding the desensitization hypothesis is tentative, as no study investigated prolonged (persistent) victimization. So far, studies have not examined heightened attention to positive information, which means that there is not enough evidence to assess the reaffiliation hypothesis properly. Although the (scarce) evidence so far seems most in line with the prevention hypothesis, it is possible that victims use different social-cognitive styles depending on the situation and that the situations invoking reaffiliation have been omitted. For instance, situations with unknown peers might invoke reaffiliation strategies, whereas situations with familiar peers might invoke prevention or desensitization strategies.

\section{Accurate Registration}

Accurate registration of social cues is crucial for effective social interactions. Inaccurate registration of important information can lead to less adequate responses, which can come across as odd, rendering one vulnerable for victimization. Below, the general accurate registration of social cues (6 studies) and emotion recognition (12 studies) are discussed separately.

Table 2 displays the research on accurate registration of social cues and emotion recognition. Some evidence for general accurate registration points toward the desensitization hypothesis ( 1 of 6 studies), which predicts that victims would focus less on social events in general, and therefore have lower accuracy in perceiving social cues, regardless of their valence. One of the five studies indicated that victimization related to a less accurate registration of social cues in general. Children who, according to their teachers, had more victimization experiences were less accurate in telling what they saw in a picture of a social situation (Ogelman \& Seven, 2012).

Other research was in line with the prevention hypothesis ( 3 out of 6 studies), which predicts that victims would focus on negative social cues and therefore would register more cues as negative, leading to a lower registration accuracy of positive social cues. These studies showed that victims register cues with a negative bias. They underestimated the number of balls they received from other players in a digital ball tossing game (Cyberball) and overestimated the times they were excluded from the ball tossing interaction, regardless of being in- or excluded in the game (Lansu et al., 2017). Overestimation also occurred in rejection perceptions. Overt victimization, and not relational victimization, related to increased perceptions (overestimation) of peer rejection (Zimmer-Gembeck et al., 2013). Moreover, being victimized related to lower overestimation of one's own likeability (Garandeau \& Lansu, 2019). These general tendencies pointed to a negative social-cognitive style, in line with the prevention hypothesis.

One study provided some support for the reaffiliation hypothesis, which predicts that victims, in pursuit of reaffiliation, would register ambiguous social cues more positively, leading to lower registration accuracy of negative social cues. In a study where children had to identify children as being part of their own or another team, victims tended to be better at recalling their own rather than opposite team members, when they had seen pictures of the others only once before (Telzer et al., 2020). By remembering team member's identities better, they may optimize social opportunities, as they have something (although minimal) in common. In a last study peer-reported victims were compared with bullies, followers, defenders, outsiders, and non-involved children. This study provided no support for any of the hypotheses, as victims did not differ from others in their ability to recall and retell vignettes of social provocation and ambiguous scenarios (Camodeca \& Goossens, 2005). The differences between these studies might be because of the assessment of registration accuracy, as the type of task (e.g., recalling or describing) and the level of language skills needed to complete it, differed between the studies, possibly leading to diverse results.

In sum, results on accurate registration are limited and mixed, and much remains unknown, but there are first indications that victims differ in registration accuracy of social cues.

Emotions Emotion recognition is the ability to label facial expressions of others correctly. Twelve studies on accurate registration were found, of which two studies examined recognition of specific emotions, eight studies overall emotion recognition, and two studies both overall and specific emotion recognition. Most evidence indicated no significant relation between victimization and overall emotion recognition ( 8 out of 10 studies, of which 1 had mixed results depending on the task used), see Table 2 . There was no evidence for tasks with basic emotion recognition that victimization among young children (4-6 years old) related significantly to overall emotion recognition: neither for matching emotional pictures (Heinze et al., 2015; Laurent et al., 2018) nor when choosing a facial picture of how a person in a story feels (Belacchi \& Farina, 2010; Garner \& Lemerise, 2007; Heinze et al., 2015; Laurent et al., 2018). These results contradict the desensitization hypothesis, which predicts that victims are worse overall in emotion recognition, because of desensitization to others' emotions. However, the results are also not in 


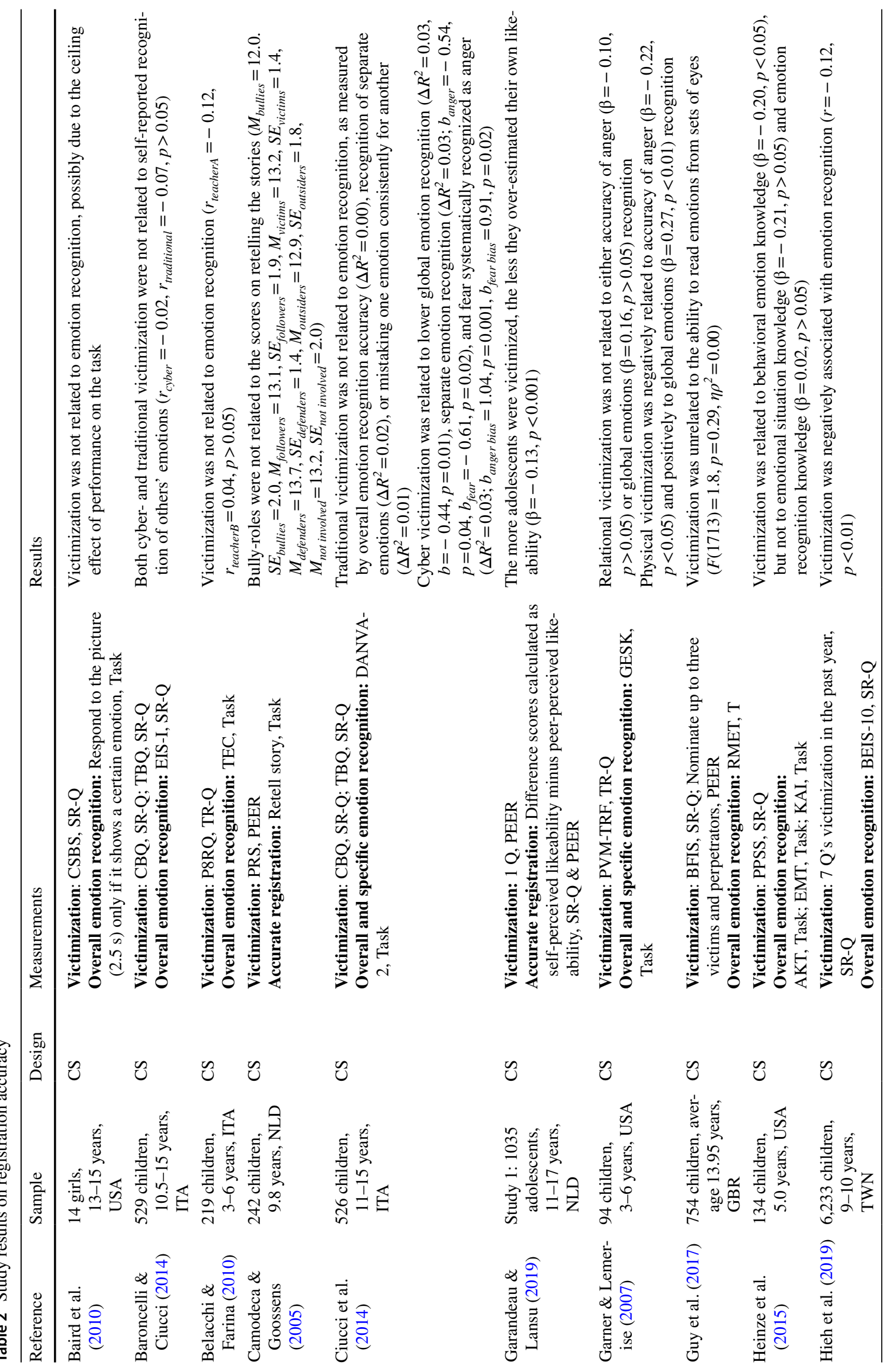




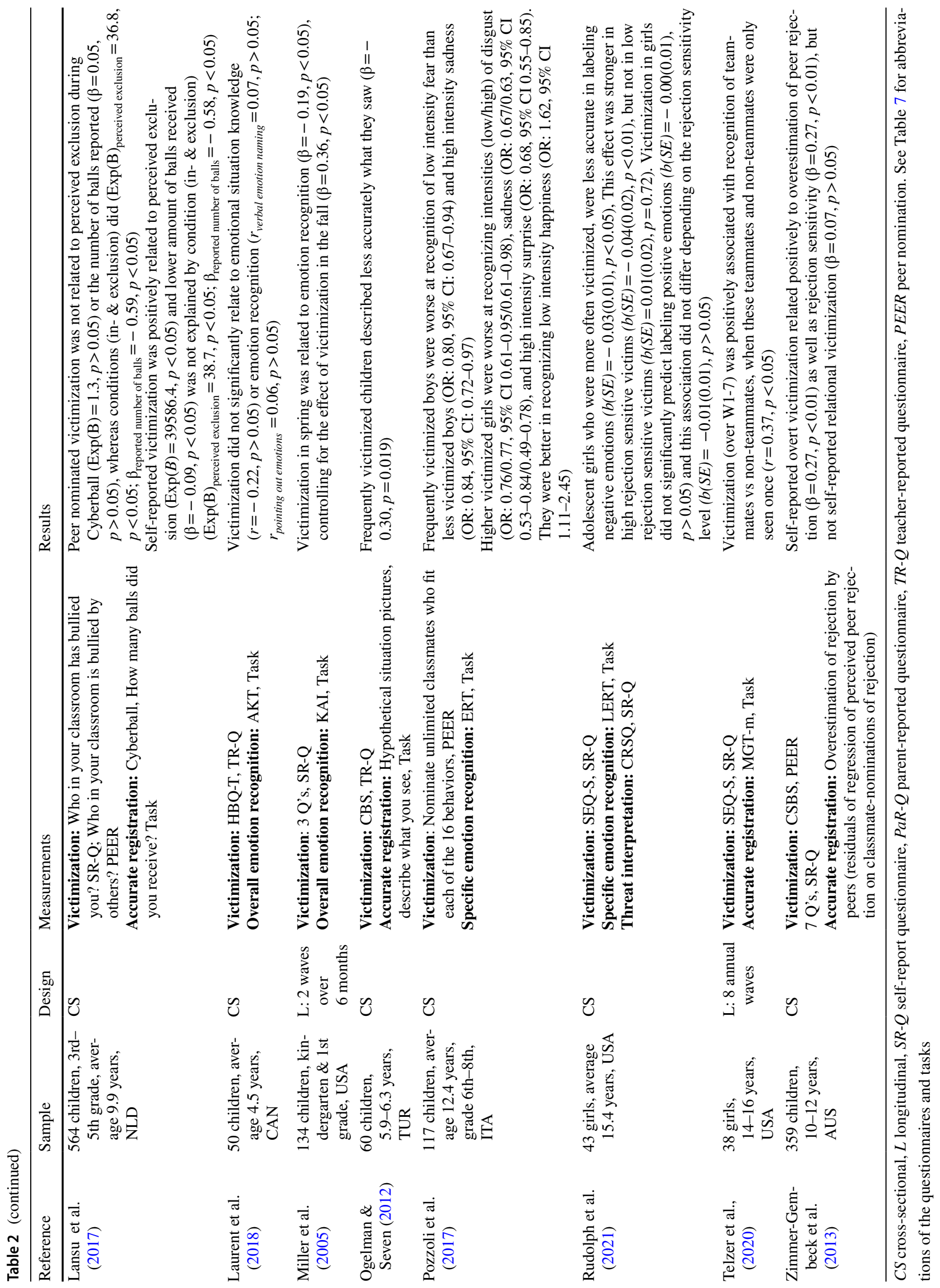


line with the prevention and reaffiliation hypothesis, which similarly predict worse overall emotion recognition: victims focusing more on negative social cues could be more open to register more expressions as negative (prevention) and vice versa, victims focusing more on positive social cues could be more open to register more expressions as positive (reaffiliation). However, the non-significant results might be due to the use of tasks that were too simple and thus unable to catch subtle differences between children or show ceiling effects. Indeed, the use of more complex measures provided different outcomes (study quality did not clearly differ between the simple and more complex tasks studies). Results on a more intricate task (labeling emotions of puppets giving visual and audio cues), indicated a positive relation between victimization and accurate labeling of emotions (Heinze et al., 2015). Additionally, physical victimization (but not relational) related to better overall emotion recognition (Garner $\&$ Lemerise, 2007). However, victimization was related to making more mistakes in labeling ten different emotions in pictures (Miller et al., 2005). Thus, the findings were mixed and also often based on relatively small sample sizes.

Among the studies on older children (10-15 years old), there were a few with larger sample sizes. The study with the largest sample size $(N=6233)$ provided evidence that victimization related negatively to self-reports of emotion recognition abilities (Hsieh et al., 2019), whereas the second study $(N=757)$ using a task (reading the mind in the eyes) did not (Guy et al., 2017). Both studies had higher quality levels in the quality assessment ( 9 and 11 points respectively). Furthermore, most other studies did not provide evidence that victimization related to overall emotion recognition (Baird et al., 2010; Baroncelli \& Ciucci, 2014; Ciucci et al., 2014), except for cyber-victimization which related to lower general emotion recognition abilities (Ciucci et al., 2014). Overall, the relation between victimization and overall emotion recognition seems not significant.

Although overall differences in emotion recognition do not seem apparent, victims may have worse abilities in emotion recognition of specific emotions. For example, emotions like fear or sadness may be recognized as anger to prevent (possible) assault (prevention hypothesis), or contrarily, emotions such as contempt may be recognized as positive and social opportunities (reaffiliation hypothesis). Four articles examined separate emotions. One study focused on younger children (4-6 years old) and found that physical and not relational victimization, related to worse recognition of angry expressions (Garner \& Lemerise, 2007). Another study on victimization type found that cyber-victimization related to making more mistakes on recognizing anger and fear (Ciucci et al., 2014), yet found no evidence for a relation with traditional victimization. A small study $(N=43$ girls), found that female victims were less accurate in labeling negative emotions, especially if they were sensitive to rejection, but no significant effects were found for labeling positive emotions (Rudolph et al., 2021). There might be gender differences, as a last study found that boys' victimization related to making more errors on recognizing fear and sadness, whereas for girls, victimization related to errors on recognizing sadness, disgust, and surprise and to less mistakes on recognizing happiness (Pozzoli et al., 2017). These studies indicate that victims might have trouble recognizing negative rather than positive emotions.

In sum, findings on registration accuracy suggest that across different types of social cues there are indications that negative social cues might be registered less accurately, which would be in line with the prevention hypothesis. If true, such misrepresentations of negative social cues would set victims at a disadvantage for appropriate responding, possibly leading to misunderstanding by others and yielding them even more vulnerable for rejection or victimization. However, the conclusions are tentative because of the small number of studies examining registration of social cues and lack of longitudinal studies investigating these links.

\section{Interpretation of Social Information}

After the selection and registration of social cues, the next step in the SIP model is the interpretation of social cues. Interpretation comprises assigning meaning to the (combination of) registered cues. For example, when you attend to and accurately register a face as happy, interpretation involves attributing a reason to why this person is smiling given the other social cues in that situation. The topics related to interpretation in the selected articles involve attribution of situations, peer perception, and the ability to understand others, which includes empathy and theory of mind (ToM).

\section{Attribution of Situations}

Attribution of situations was a popular topic in research on social cognition of victims (49 studies). Examples were interpretation of others' intentions and expectations of what would happen. Most evidence favored the prevention hypothesis, which predicts that victims have more negative interpretations of social cues because of their focus on threatening information (33 studies, of which two found it only for a specific victimization type and one only for a certain nationality), see Table 3 . With respect to attributions about bullying, victimization related to thinking that bullying is a serious problem at one's school (Choi \& Park, 2018), interpreting ambiguous scenarios more often as bullying (Calleja \& Rapee, 2020) and thinking they were being bullied more often because of their personality instead of their behavior (Morrow et al., 2019), but not to a more negative attitude toward the concept of bullying (Caravita et al., 2019; Pouwels et al., 2017). 
Other research, on non-bullying situations, found that victimization related to expecting threat (Balan et al., 2018; González-Díez et al., 2017; Hunter et al., 2010; Röder \& Müller, 2020), being rejection sensitive (Ding et al., 2020; Rowe et al., 2015; Zimmer-Gembeck, 2015; Zimmer-Gembeck \& Duffy, 2014; Zimmer-Gembeck et al., 2013, 2014), worrying about negative evaluations (Estévez et al., 2019; Giannotta et al., 2012; Gómez-Ortiz et al., 2018; Taylor et al., 2013; Zimmer-Gembeck \& Duffy, 2014), feeling rejected when receiving few likes in a social media task (Lee et al., 2020), and being more sensitive to aversive stimuli (Rudolph et al., 2016). Moreover, a longitudinal study found that adolescents with victimization experiences adopted rejection schemas more often. These maladaptive schemas, in turn, predicted later victimization (Calvete et al., 2018). Not only perceived threats of rejection, but also of hostility have been examined. Victimization experiences related to hostile intent attributions in ambiguous situations (Camodeca \& Goossens, 2005; Camodeca et al., 2003; Guy et al., 2017; Hoglund \& Leadbeater, 2007; Hung et al., 2017; Kokkinos \& Voulgaridou, 2018; Ogelman \& Seven, 2012; Perren et al., 2013; Pornari \& Wood, 2010; Schwartz et al., 1998; Yeung \& Leadbeater, 2007), as well as in provocative situations (Ziv et al., 2013). In other words, children with more victimization experiences seemed to interpret situations more often as threatening, consistent with the prevention hypothesis. In more positive situations, victims did not interpret more hostile intent (Smorti \& Ciucci, 2000). Thus, the situation (positive, ambiguous, or negative) might influence the adopted social-cognitive style.

Findings from three other studies painted a more complex picture. The specific bully-role might be important, as one study indicated that only bully-victims, but not pure victims, interpreted video fragments of ambiguous social interactions (abstract figures, animals, and humans) more often as bullying compared to non-involved children. Additionally, bully-victims interpreted even positive interactions of apes in a zoo more often as bullying compared to non-involved children (Pouwels 2016). A second study found that only relational victimization, and not physical victimization, related to interpreting situations as more negative and social threatening (Calleja \& Rapee, 2020).

However, there were several contradictory findings (14 studies). First, some studies did not find significant associations between victimization and hostile interpretation tendencies (Leff et al., 2014; Mathieson et al., 2011; Prinstein et al., 2005; Smalley \& Banerjee, 2014; Smorti \& Ciucci, 2000; van Dijk et al., 2017; Warden \& Mackinnon, 2003) or being more upset after hypothetical, ambiguous provocations (McQuade et al., 2019), or only found evidence of this association for Japanese but not for American children (Kawabata et al., 2013). Other studies found no association between victimization and fearing negative evaluation
(Kiekens et al., 2020; Pabian, 2019) or expecting and interpreting rejection (Rudolph et al., 2021; Stubbs-Richardson $\&$ May, 2020). In addition, one study found no evidence that victims interpret situations more often as emergencies when they were also asked whether they would intervene that particular situation (Jenkins \& Nickerson, 2017). Notably, the average study quality of these studies $(M=7.21$ points, $S D=1.42)$ is lower than the study quality of all studies on situation attribution $(M=8.69, S D=2.02)$, slightly suggesting that the results that were more common and in line with the prevention hypothesis might be more valid.

With regards to the reaffiliation hypothesis, in the seven studies that examined positive attributions separately from negative attributions, no evidence was found that victims interpret situations more positively or attribute less hostile intent (Garner \& Lemerise, 2007; Hung et al., 2017; Smorti \& Ciucci, 2000; Warden \& Mackinnon, 2003), nor that victims perceive more social opportunities amid school transitions (Röder \& Müller, 2020), nor judge bullying conceptually right (Caravita et al., 2019). Victims might even interpret intentions less positive compared with noninvolved children (Camodeca et al., 2003; Ziv et al., 2013).

In sum, strongest evidence was found in line with the prevention hypothesis (33 out of 49 studies): victims interpreted situations and intentions of others more negatively, hostile, or dangerous, and were more sensitive to rejection. Moreover, this negative attribution style seems to include both more negative and less positive interpretations.

\section{Peer Perception}

There were many studies that examined how victims generally perceived their peers, see Table 4 (35 studies). In line with the prevention hypothesis, most research (26 studies, of which three with partial support) indicated that victimization related to negative peer perception (Hong et al., 2019, 2021; Ladd \& Troop-Gordon, 2003; Purcell et al., 2021; Rudolph et al., 2009; Sainio et al., 2013; Salmivalli \& Isaacs, 2005; Schacter \& Juvonen, 2018; Troop-Gordon \& Ladd, 2005), less trust in peers (Betts et al., 2017), negative expectations of peer interactions (Audley et al., 2020), and negative perceptions of the social climate and interpersonal relationships (Barzeva et al., 2020; Berg \& Aber, 2015; Elsaesser et al., 2013; Gini, 2008; Harks \& Hannover, 2020; Holfeld \& Baitz, 2020; Lázaro-Visa et al., 2019; Leadbeater et al., 2015; Mertens et al., 2021; Moyano et al., 2019). Some longitudinal studies also provided evidence in this direction: Increased victimization led to increases in negative peer perception (Elsaesser et al., 2013; Troop-Gordon \& Ladd, 2005), and negative peer perception predicted subsequent victimization for girls (Sainio et al., 2013). However, cybervictimization did not explain negative peer perception over and above traditional victimization (DePaolis \& Williford, 
2019). In addition, a second study also did not find a concurrent relation between victimization and peer connectedness perceptions (Aldridge et al., 2020).

Several studies indicated that it is important to examine to which peers the perception refers. Victims attributed less favorable characteristics to non-friends than they did to friends (van Noorden et al., 2014), even more strongly than non-involved peers (van Noorden et al., 2016). This might be partially based on sympathy, as victims judged non-involved peers more positively than they judged bullies and bully-victims (van Noorden et al., 2016), again in line with the prevention hypothesis. Though victims themselves might think less of bullies, they do not necessarily think that others have similar thoughts. Being victimized was not related to thinking that hypothetical victims and classmates would dislike a hypothetical bully (Garandeau \& Lansu, 2019). However, victims themselves judged known bullies and followers more positively than unknown bullies and followers (reaffiliation hypothesis), whereas known defenders are judged less positively than unknown defenders (prevention hypothesis) (Pouwels et al., 2017). Possibly, judgements occur in reference to standards that are hold for specific peers.

Additionally, two studies indicated that the general peer perception of victims might be rigid. They found that victimization related positively to holding an entity rather than an incremental perspective on peer relationships (Rudolph, 2010) and on peers' personalities (Kaufman et al., 2020). In other words, victims seem to think that peers and relationships are set and cannot change. As victims also hold more negative perceptions of peers, it is likely that such rigid perceptions might influence how they engage in future interactions with peers.

Three studies compared victimization types. Cybervictims were less positive about peers than non-involved peers, but cyber-bully-victims were not (Guo et al., 2021). This finding was corroborated by Ding et al. (2020)), who found no differences on perceived social climate for noninvolved, traditional bully-victims and cyber-bully-victims. A last study found that bully-victims, but not pure victims, perceived their school social climate less positive than noninvolved children, whereas both victims and bully-victims perceived their peers less positive compared with bullies and non-involved peers (Bayar \& Uçanok, 2012).

Only one study was fully consistent with the reaffiliation hypothesis, and found that victimization related to believing that others keep secrets and keep promises (Rotenberg $\&$ Boulton, 2013), contrasting the study of Betts and colleagues (2017). Although trust is usually a strength in social interactions, trust might lead to more opportunities to being bullied, for example when a victim tells others their secrets. These opportunities might be especially utilized if there is a motive, such as being perceived as untrustworthy (which was how others perceived victims, Rotenberg \& Boulton, 2013). Contrasting the reaffiliation hypothesis, it seems unlikely that victims more readily like peers for superficial reasons, because participants did not like previously unknown teammates better than non-teammates (Telzer et al., 2020).

One study seemed in line with the desensitization hypothesis, as persistent victimization did not relate to peer perception (Ladd \& Troop-Gordon, 2003). A finding that did not fit any of the hypotheses was that victimization, especially for girls, related to thinking one's friends are susceptible to peer influence (Goldstein et al., 2020). Speculatively, this perception might relate to negative peer experiences where friends do not stand up for victimized youth and join in on negative behaviors of others in the peer group.

In conclusion, victims adopt more negative views of both their peers and relationships in general (26 studies in favor, 5 studies with nonsignificant results), though this tendency is less pronounced for friends and defenders. In addition, victims possibly think that peers cannot change (2 studies).

\section{Understanding others}

For successful interpretation, the ability to understand others is crucial. An important aspect is empathy, the ability to experience (affective empathy) and understand (cognitive empathy) feelings of others (Decety et al., 2012; Mehrabian \& Epstein, 1972). Related to cognitive empathy is theory of mind (ToM). ToM involves the technical ability to ascribe mental states to others, such as feelings, intentions and thoughts, and specifically the understanding that people can have different information available and thus differ in mental states (Astington, 2001). Although victims might be trying hard to understand others (to anticipate social opportunities or threats), based on the reaffiliation and the prevention hypothesis, they actually might have less abilities to experience and understand emotions and (mental) states of others. Furthermore, based on the desensitization hypothesis, persistent victimization might lead to an even lower ability to experience and understand emotions and (mental) states of others, because of desensitization. Even more, it was expected that these victims would have a deficit in the ability to understand the mental states of others, as similar to rejected peers, they might have had fewer social opportunities to develop these abilities (Banerjee et al., 2011).

Empathy In contrast with all three hypotheses, reaffiliation, prevention and desensitization, Table 5 reveals that most studies ( 29 out of 44 , of which 8 studies found some significant results for either affective, cognitive or general empathy) provide no evidence for an association between victimization and empathy (e.g., Berg \& Aber, 2015, see Online Source 3 for the 29 references). Moreover, a longitudinal study found no effect of within-person changes in empathy 


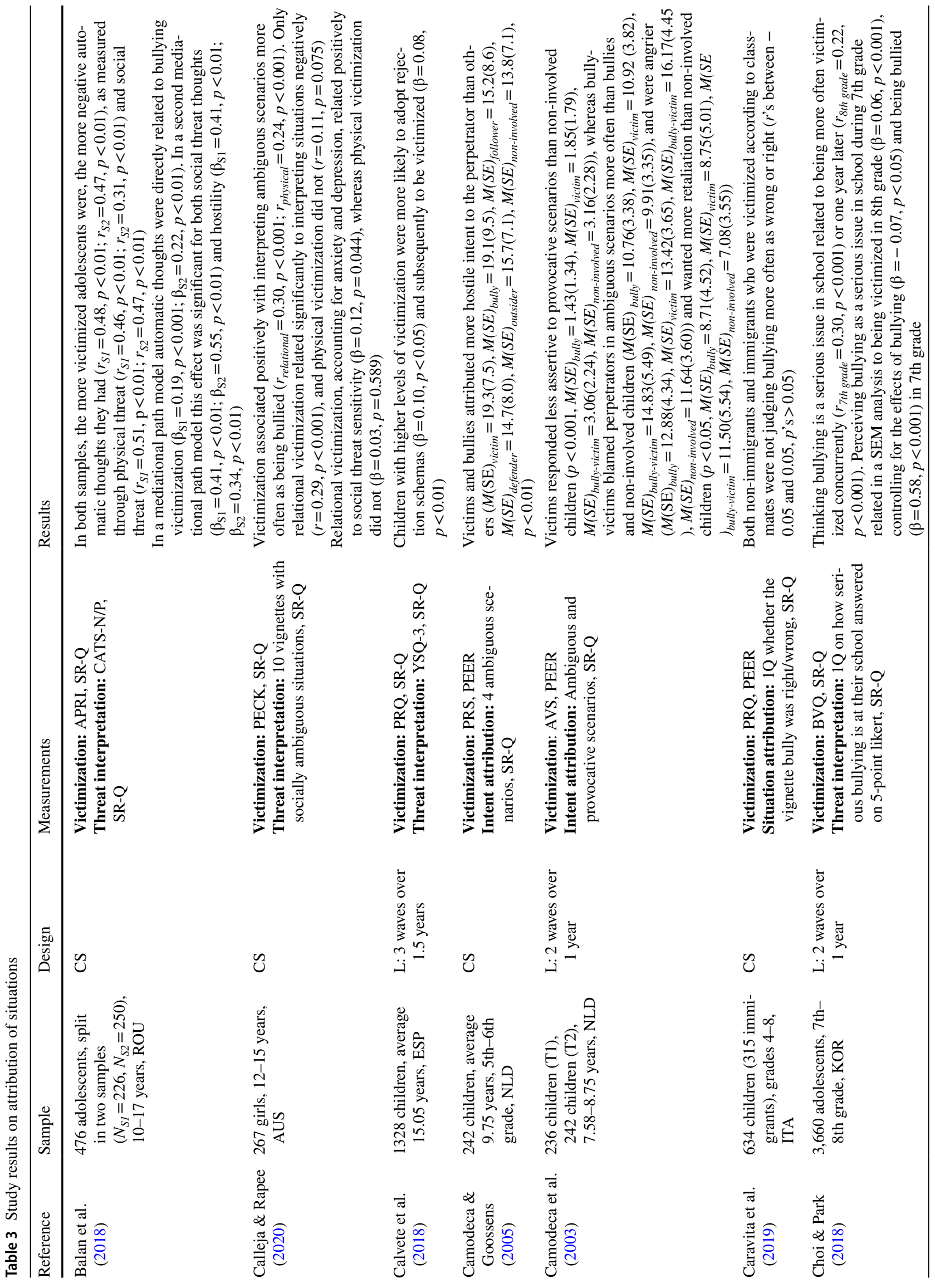




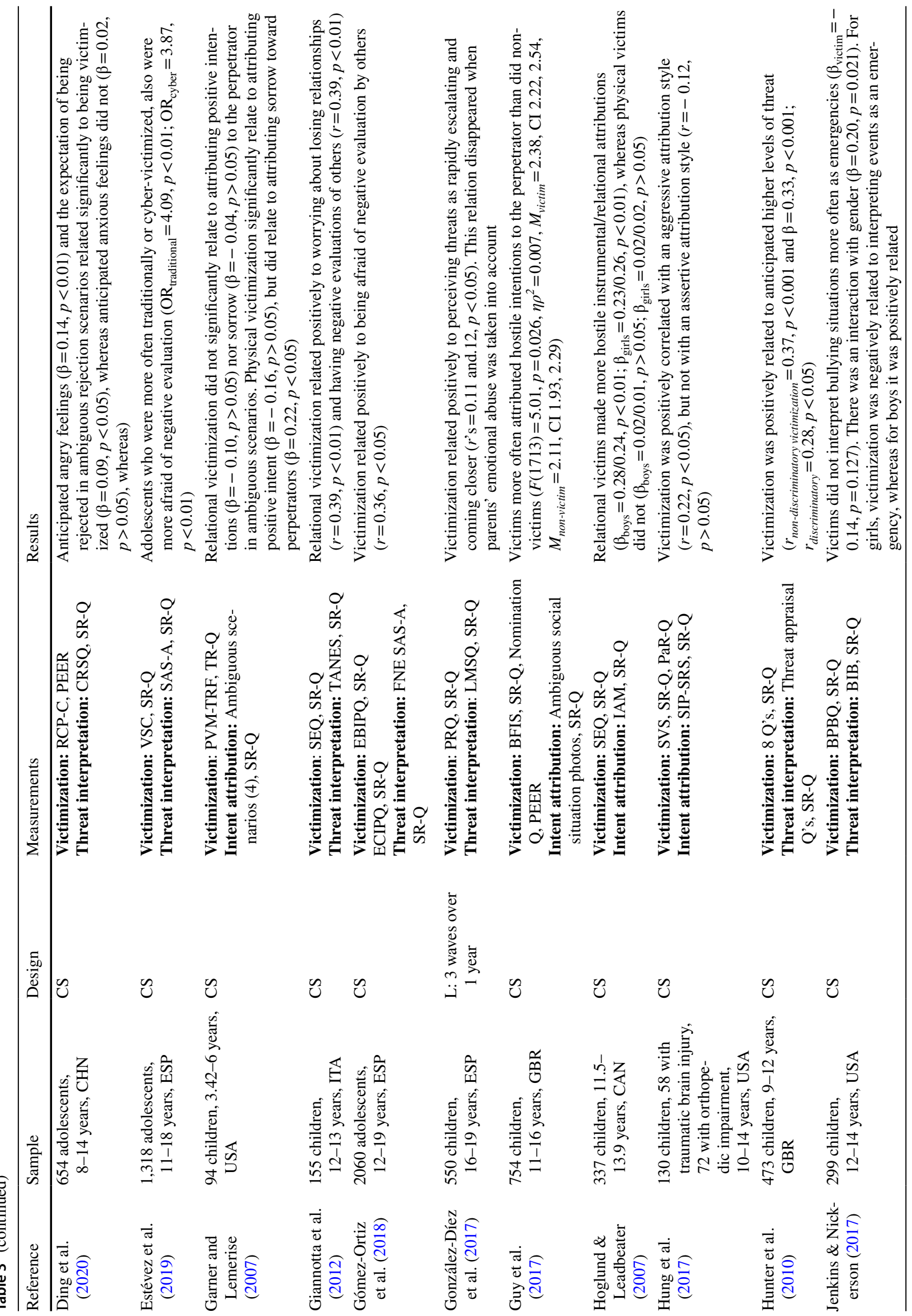




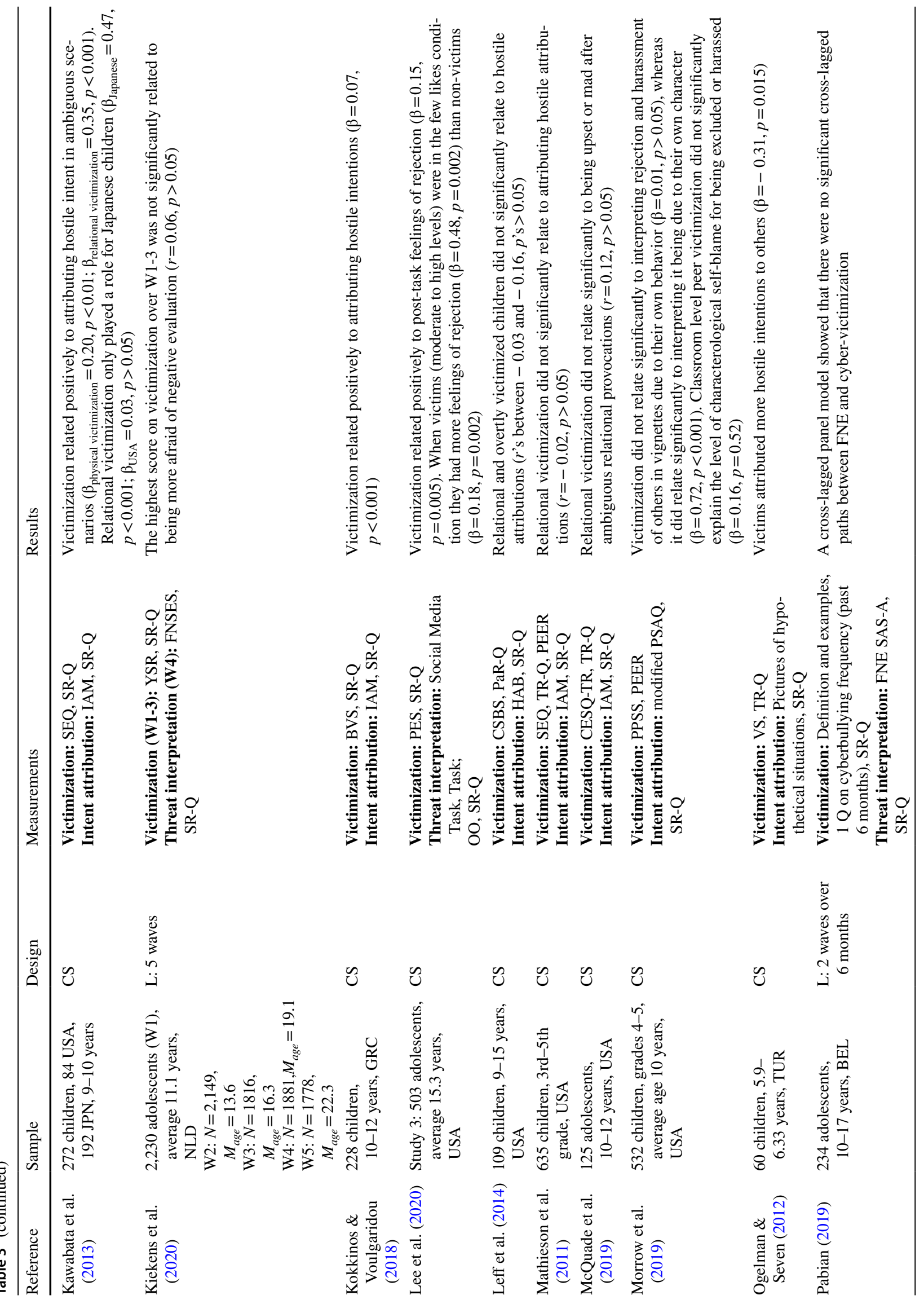




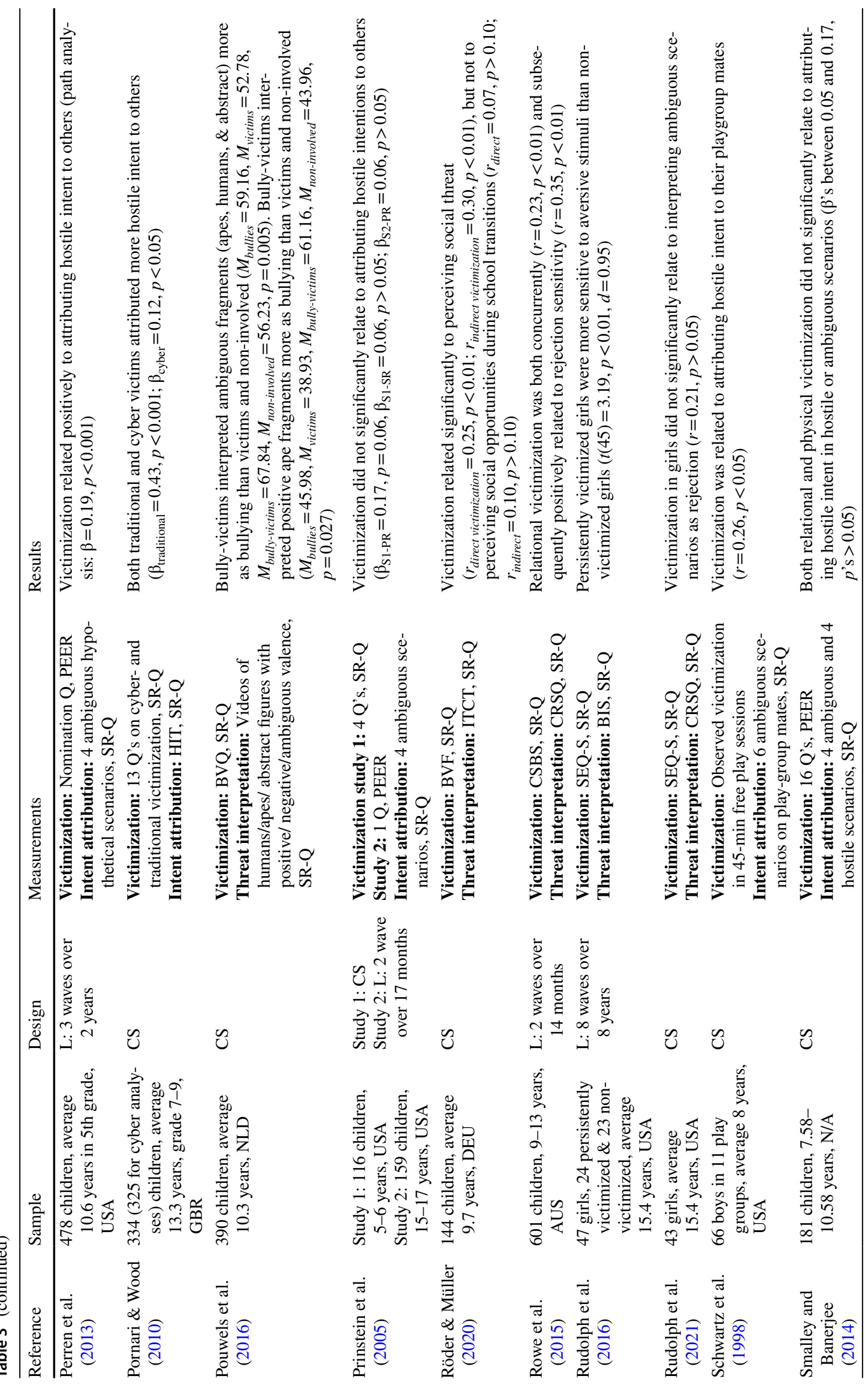




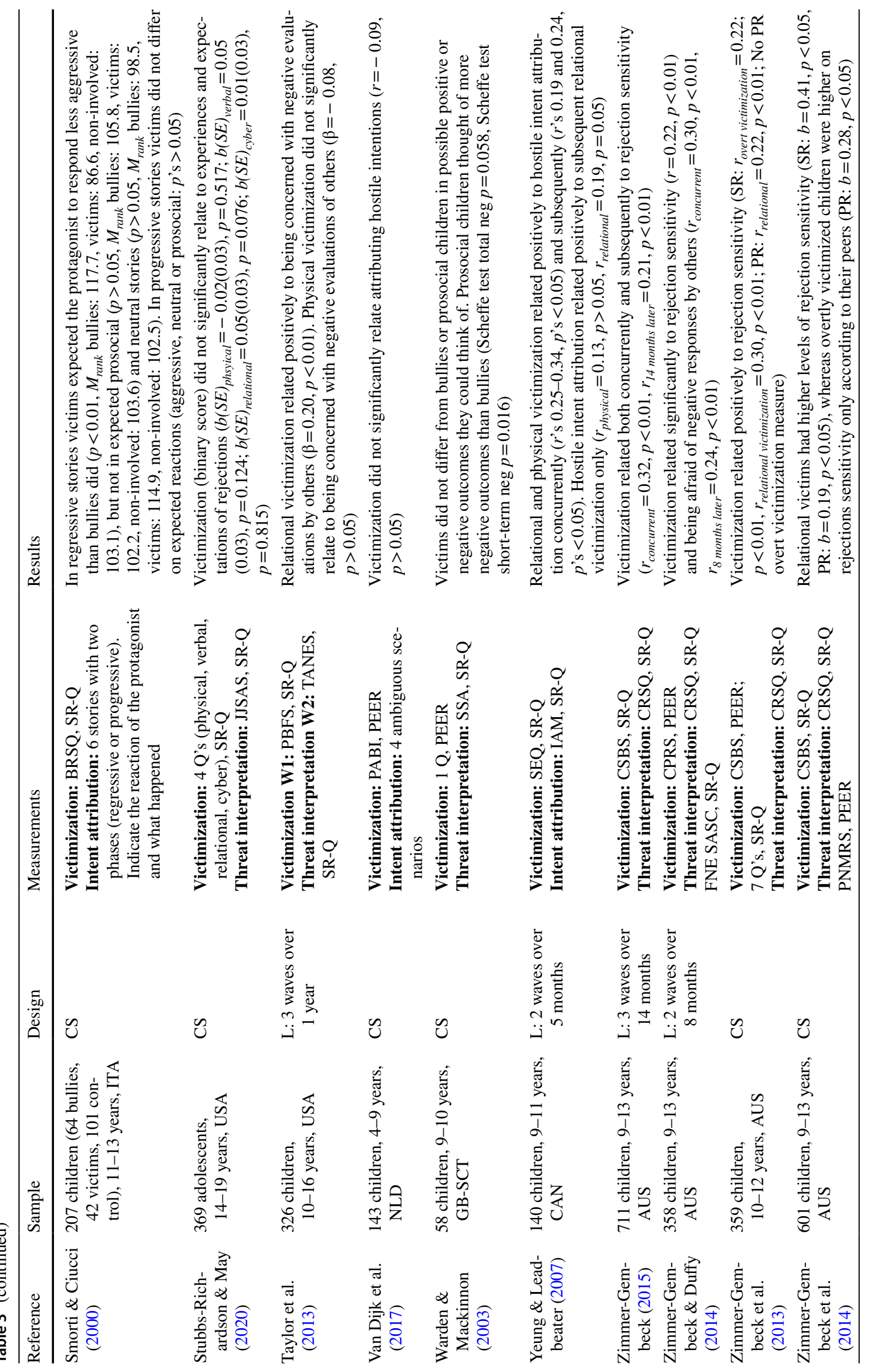


Adolescent Research Review (2022) 7:287-334

303

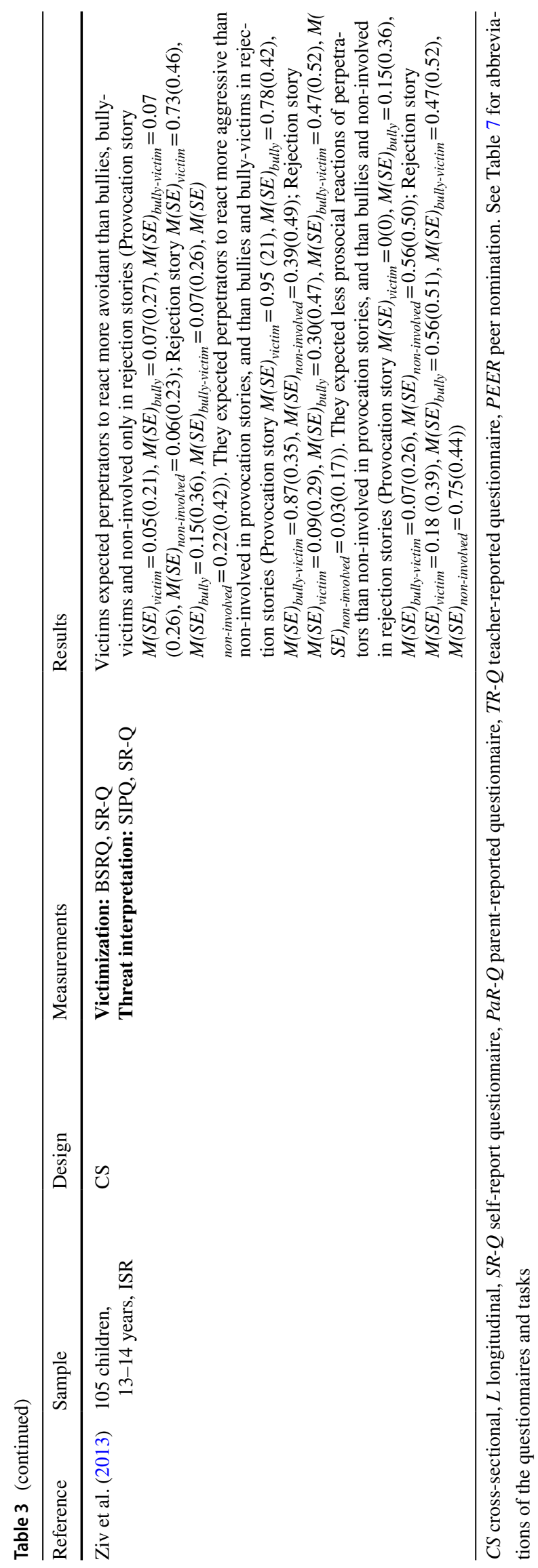

Springer 
over time on victimization (Espelage et al., 2018b). Another study examined empathy (cognitive, affective, and somatic) separately for negative and positive feelings of others, and found mixed results (Chen et al., 2021). It must be noted, however, that these significant results ( 7 of 11 correlations), were only very small in size $(r$ 's all $<0.07)$.

Nonetheless, some studies reported consistent associations between victimization and empathy. In studies examining specific bully-roles, traditional victims and not cyber-victims might have slightly higher levels of affective empathy, whereas only cyber-victims might have slightly higher levels of cognitive empathy when compared to outsiders or non-involved peers (Arató et al., 2020; Martínez et al., 2020). A third study, however, found that victims, compared to non-involved peers, had lower self-reported empathy (Mendoza-González et al., 2020). Some studies (9 out of 44), not comparing bullying roles, found that victimization related to less affective empathy (Chan \& Wong, 2015), less cognitive empathy (Nasaescu et al., 2018; Williford et al., 2016) and less general empathy (Farrell et al., 2018; Jenkins et al., 2016, 2017; Malti et al., 2010; Pistella et al., 2020; Yudes et al., 2020). Nevertheless, other research reported a positive association of victimization (13 out of 44 , of which 5 also reported some ns associations with (subtypes of) empathy), with affective empathy (Hood \& Duffy, 2018; Kokkinos \& Kipritsi, 2012; Nasaescu et al., 2018; Rodríguez-Hidalgo et al., 2018, 2019; van Noorden et al., 2016), cognitive empathy (Arató et al., 2020; Lázaro-Visa et al., 2019; Rodríguez-Hidalgo et al., 2018; van der Ploeg et al., 2017), and general empathy (Donat et al., 2020; Yang et al., 2020). Furthermore, one study found a between-person effect for general empathy and victimization (Espelage et al., 2018b). It is possible that the contradicting findings happened because of capitalization of chance. Studies with significant associations mostly utilized small samples or found small to very small effect sizes. The quality of studies with non-significant and significant findings was quite $\operatorname{similar}\left(M_{n s}=8.11, S D=1.89\right.$ versus $\left.M_{s i g}=8.91, S D=1.54\right)$, providing support for the expectation that these results were a capitalization of chance. Furthermore, the studies with positive associations also did not differ from the studies finding negative associations, with respect to quality assessment $\left(M_{p o s}=8.85, S D=1.46 ; M_{\text {neg }}=8.90, S D=1.66\right)$. The studies with more power provided no or little evidence that victimization related to empathic abilities. However, there is a difference between empathic abilities and motivation to use empathic abilities. Only one study investigated motivationrelated aspects and found that, although victims did not differ from non-victims in empathic abilities, they showed less cognitive and affective empathy for bullies and bully-victims than for non-involved peers (van Noorden et al., 2017). In other words, victims might be able to empathize with others, but not willing to do so with everyone.
Theory of Mind Table 6 shows that the few studies (9) examining victimization in relation to ToM skills (i.e., the ability to ascribe mental states to others) showed diverse results. Some studies found no evidence for an association between victimization and ToM skills (4 out of 9), either first or second order false belief (Caravita et al., 2010; Espelage et al., 2018; Monks et al., 2005; Renouf et al., 2010), which is in line with the findings on empathy. Two studies found mixed results, showing evidence that victims score worse than bullies and non-involved children on cognitive, but not emotional ToM aspects (Gasser \& Keller, 2009; Gini, 2006). Furthermore, three other studies indicated that victimization related to ToM skills negatively (Hsieh et al., 2019; van Dijk et al., 2017), with some evidence that a relative ToM deficit leads to future victimization (Shakoor et al., 2012). Overall, the association between ToM skills and victimization seems either absent or (negative and) small in magnitude.

\section{Discussion}

Social cognition, and hence how victims experience their social world, is likely affected by bullying, but the nature of this relation was unclear. Victims may become more sensitive to threat attempting to prevent or counteract new bullying situations (prevention hypothesis). However, children may also become more sensitive to positive cues while they try to restore their social situation (reaffiliation hypothesis). Finally, persistent victimization may cause a numbing effect on social cue processing to prevent the negative experience of victimization (desensitization hypothesis). The results of this systematic review on the literature on social cognition of victims across childhood and adolescence, mostly align with the prevention hypothesis. The review suggests that victims might have heightened attention to negative or threatening social cues, a less accurate registration of cues, and worse negative emotion recognition (encoding). Furthermore, victims perceived peers more negatively, attributed more hostile intent, and were more sensitive for rejection (interpretation). However, they did not differ in empathic skills. These results indicate that, regardless of whether the social-cognitive style is a precursor or consequence of victimization (or both), there might be a risk for negative spirals, in which negative interpretations may affect future experiences. According to SIP theory, encoding and interpretation of information and previous experiences have consequences for the displayed behavior (Table 7). As victims seem to have a negative social-cognitive style, they likely align their behavior accordingly. Indeed, victims' social-cognitive style seems related to later aggressive behavior (Troop-Gordon et al., 2019; Yeung \& Leadbeater, 2007). If victims display more negative and perhaps unexpected 


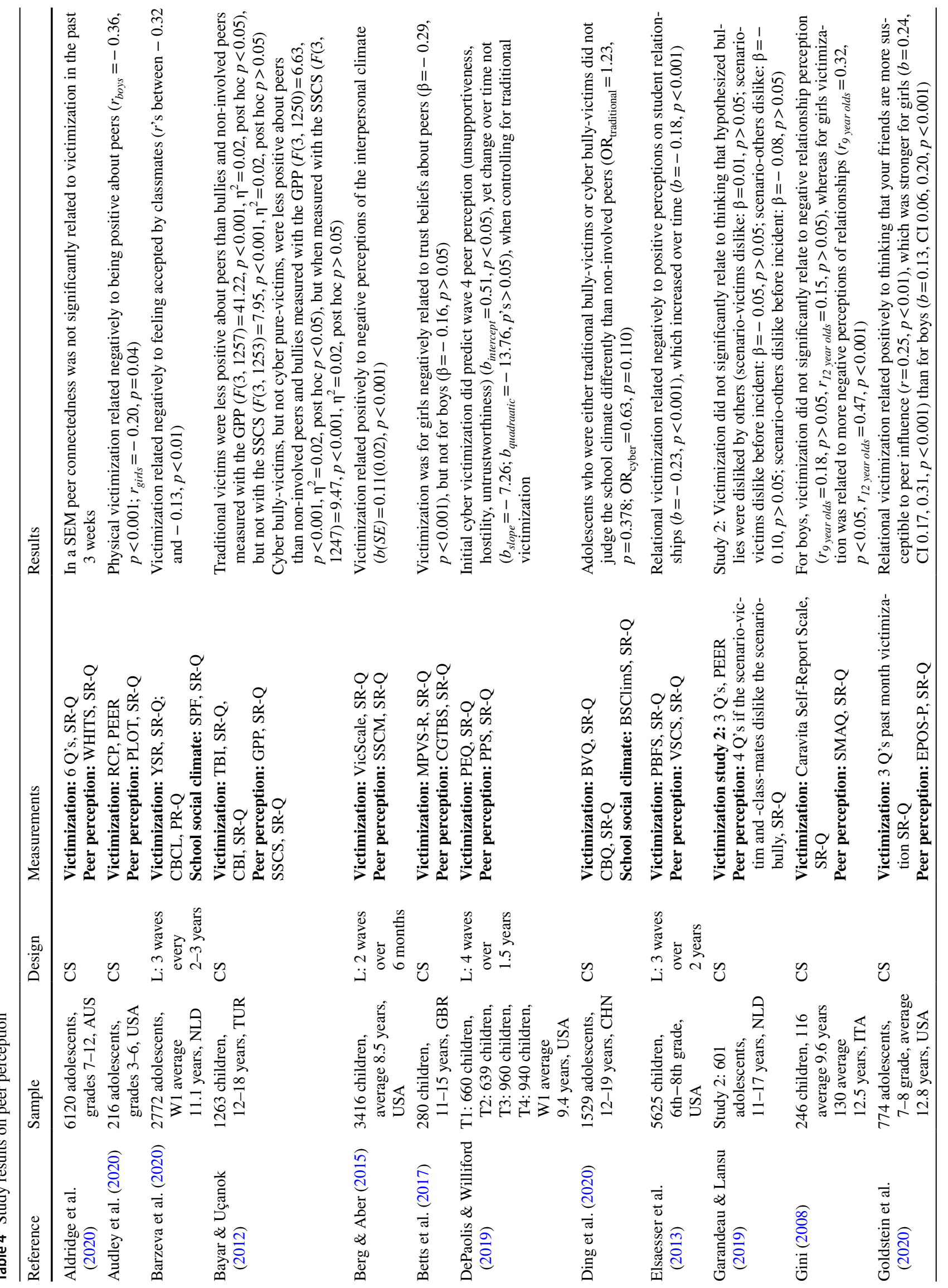




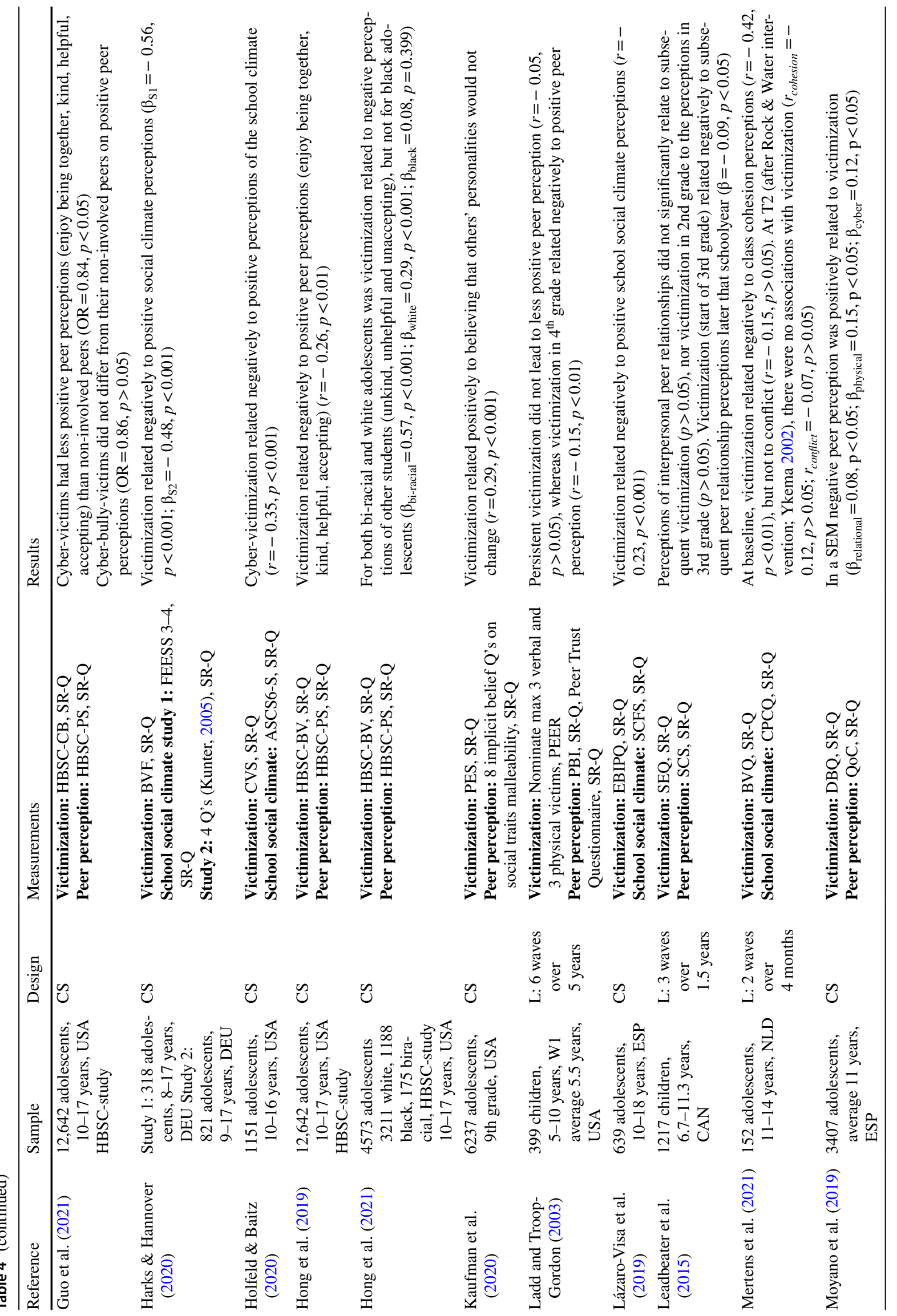




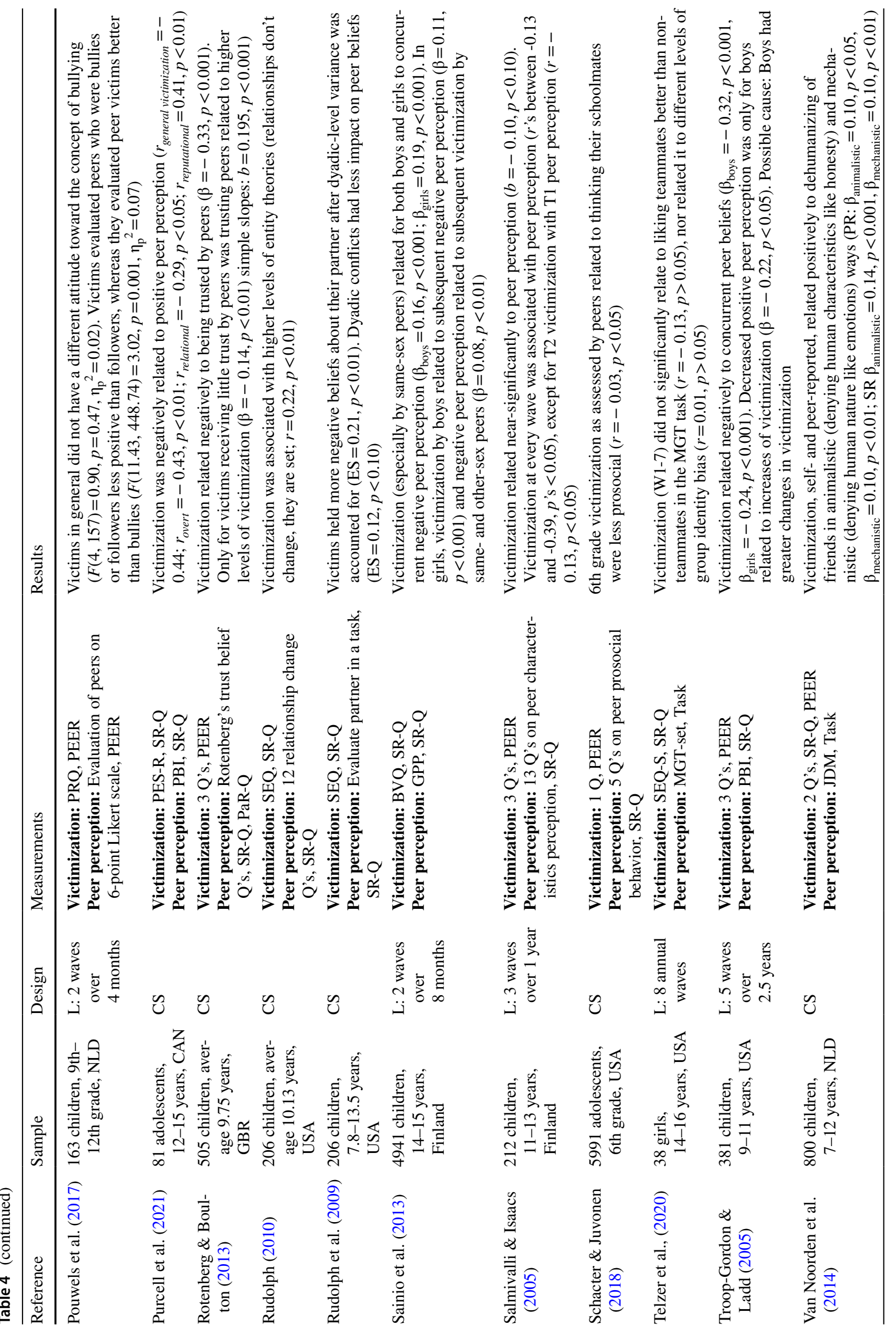




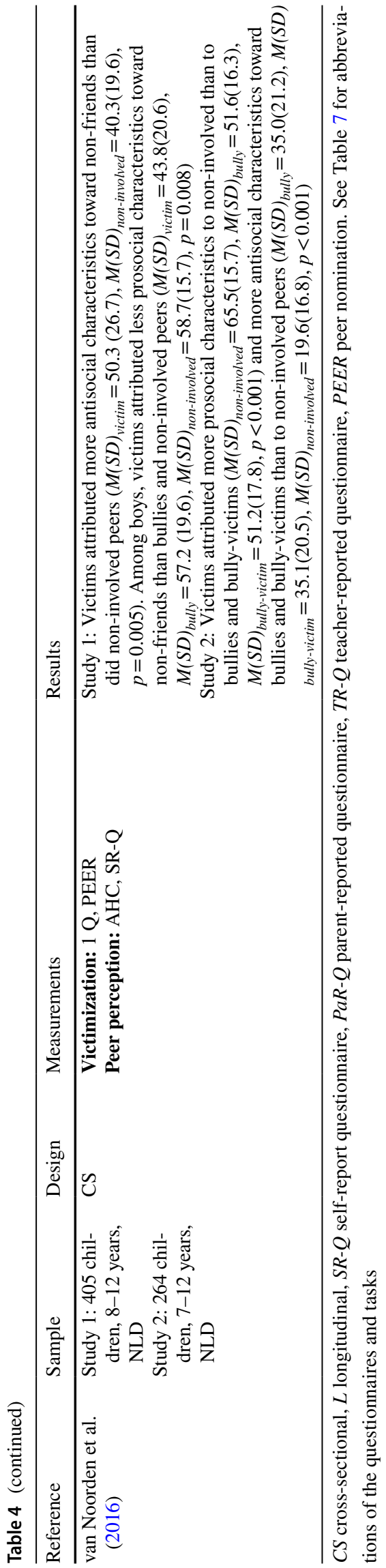

behavior, it could lead to a downward spiral of victimization, as such behaviors may evoke bullying (Thornberg, 2010).

Although most evidence (56.3\% of all articles, and $71.4 \%$ of articles only on peer perception and attribution of situations) was in favor of the prevention hypothesis, a considerable number of studies found insignificant or mixed results. Specifically, most studies indicated that victims did not differ from non-victims in their ability to recognize emotions in general, understand others' mental states and empathize with others' emotions. Some methodological issues in these studies should be considered. First, the utilized tasks might be improved. Emotion recognition tasks adopted by researchers are usually quite simple, for example, using basic emotions such as anger, happiness, sadness, and surprise that can be easily differentiated, or using long presentation and response times. Moreover, the questionnaires on empathy were often self-reported. Therefore, they required considerable self-reflection on one's own empathic abilities and possibly assessed whether children try to empathize with others instead of the ability to empathize. Last on the used tasks, ToM tasks were often quite simple, measuring first and second order ToM, which skills are usually mastered by most 5-year-olds (Perner \& Wimmer, 1985), whereas the studies examined 7- to 9-year-olds. If severe problems arise in basic emotion recognition, basic empathy, or basic ToM skills, this may affect social functioning, as, for example, has been found for people with autism spectrum disorders (Trevisan \& Birmingham, 2016). When no differences are found in basic or easy tasks, it does not guarantee that victims have no trouble with emotion recognition of shortlived or complex emotions, when different cues are shown simultaneously, or when people try to hide their emotions, such as in real life. A second possible methodological issue involves that in real life registration of social cues happens automatically. Having to report and explicitly think about it, might lead to different results in the lab compared with real-life social situations. Simple designs might thus not capture relevant (ecological valid) differences in victims. A last methodological issue relates to assessments of having versus using skills. The literature mostly focusses on having skills to understand others and not on whether these skills are used in social interactions. One study reported that victims did not differ from non-victims in empathic abilities, but reported lower levels of empathy for bullies and bullyvictims than for non-involved peers (van Noorden et al., 2017). This finding is important as it indicates a difference between motivation and ability. Therefore, the motivational aspect should be considered when examining empathy, ToM, or social skills in further research.

While most evidence favored the prevention hypothesis, there was little evidence in favor of the reaffiliation hypothesis. To some extent this may be a consequence of few 
studies examining more positive aspects of SIP. Researchers examining the interpretation SIP-phase focus mainly on negative interpretations, leaving the reaffiliation hypothesis understudied. Examining positive SIP aspects can help changing toward a more positive framework, with factors for personal growth to improve victims' resiliency, instead of focusing on (SIP) tendencies that may be detrimental. Similar to the reaffiliation hypothesis, the desensitization hypothesis is also understudied. Only two studies explicitly examined persistency of victimization. One study found that differences in longevity of victimization over five years did not relate significantly to positive peer beliefs, whereas the most recent victimization level related to less positive peer beliefs (Ladd \& Troop-Gordon, 2003). The second study found that persistent victims were more sensitive to aversive stimuli than non-victims (Rudolph et al., 2016). Given the (limited) results, it cannot be discerned whether victimization recency or persistency is most influential on SIP. Studies on differences between recency and persistency of victimization in relation to SIP can also help unraveling the timing that SIP-styles take to change. Furthermore, it can help unravel whether victims perhaps move through different social-cognitive-styles as victimization persists. Initially, victims may try to reaffiliate, but when victimization does not cease, they may switch to the prevention style and if victimization persists for even longer periods, they may yet switch to the desensitization style.

\section{Theoretical and Practical Implications}

The prevention hypothesis was best supported in this review and stated that victims focus more on negative events or interpretations to be able to better prevent future negative experiences. These negative interpretations may be a precursor of initial victimization or play a role in maintaining victimization when one responds defensive or aggressive after such interpretations. Alternatively, these interpretations may be a result of previous victimization and thus be very realistic. It can be beneficial in ambiguous social situations, as this allows victims to avoid the situation and thus prevent social exclusion. Longitudinal studies examining victimization and intent attribution may provide more clarity on the causality of this relation.

Anti-bullying interventions can benefit from these insights, as social-cognitive factors are not commonly addressed in interventions (Ttofi \& Farrington, 2011). Raising awareness about social-cognitive styles may break the downward spiral of victimization and result in changes in behavioral responses, as making automatic thoughts explicit is a core principle of cognitive behavioral therapy (Leahy \& Rego, 2012). Moreover, as bullying is a social process and multiple parties are involved (Salmivalli, 2010), it could be beneficial to teach children how to use perspective taking skills and to acknowledge differences in perspectives (Imuta et al., 2016). This might lead to a better understanding of and more sympathy for one another, and to more prosocial behavior (Allen \& Kinsey, 2013). For victims this could help to reevaluate their focus of attention, interpretations, and behavioral responses. Such changes in SIP of victims might reduce vulnerabilities or risk factors for future victimization. For non-involved peers, it could lead to better understanding of victims and higher levels of empathy, which likely leads them to respond differently.

\section{Limitations of the Literature and Future Directions}

A first limitation of the current review involves the examined victims in the included studies. Most of the time victims of bullying were examined as a homogeneous group. However, the victim group is quite heterogeneous with respect to whether victims also bully others (Lereya et al., 2015) and whether the victimization is long- or short-term (Kaufman et al., 2018). The conclusions might not hold for all types of victims, as there might be different processes at play for the different types of victims. There is some research investigating the interpretation SIP-phase of bully-victims. Some studies found that bully-victims had more negative interpretations of ambiguous scenarios than victims (Camodeca et al., 2003; Pouwels et al., 2016), whereas other studies found no evidence for a difference between victims and bully-victims (Bayar \& Uçanok, 2012; Guy et al., 2017), and a last study found that it depended on the situation whether bully-victims had more negative interpretations (Ziv et al., 2013). Such studies typically did not address victimization duration, nor individual differences over time. Long-term victimization merits more attention, as it is related to indicators of both biological (Giletta et al., 2018) and mental stress (Hong et al., 2018). Moreover, long-term victims in schools with low levels of bullying (healthy context) have increased levels of mental health problems compared with long-term victims in schools with high levels of bullying (Huitsing et al., 2019). With increasingly more schools employing anti-bullying interventions, there is a strong and urgent need to identify factors that will improve interventions for longterm victims.

A second limitation of this review is that the role of development in social-cognitive abilities is hardly examined. As experience is used throughout all SIP-phases, it is expected that younger children have less experience in processing social information, and with more experience they will develop more advanced social-cognitive abilities. Consequences of victimization on the development of social-cognitive abilities can also be expected based on the desensitization hypothesis. With persistent victimization, social cognition of victims may become less focused on social cues, which may have consequences for the further 


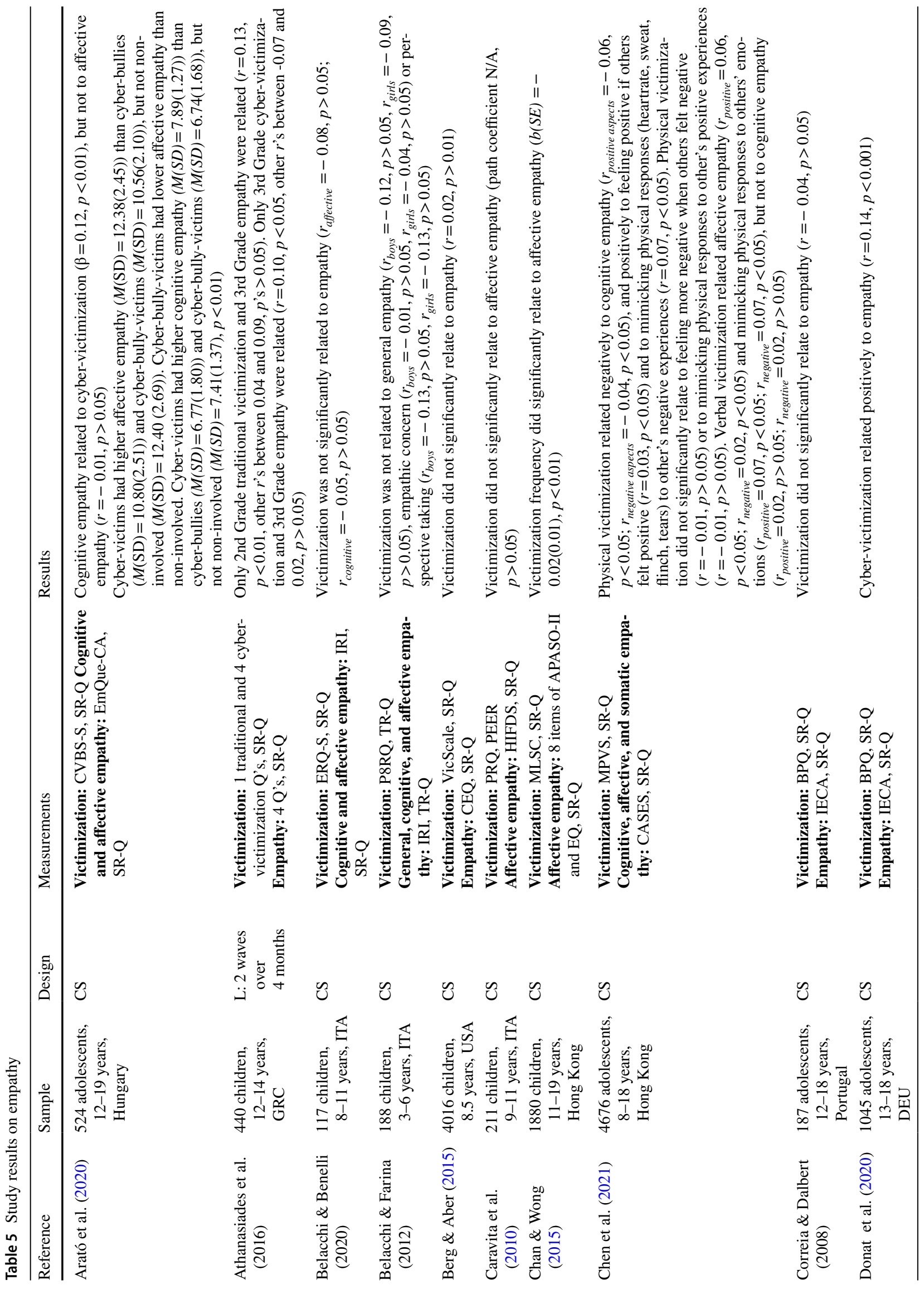




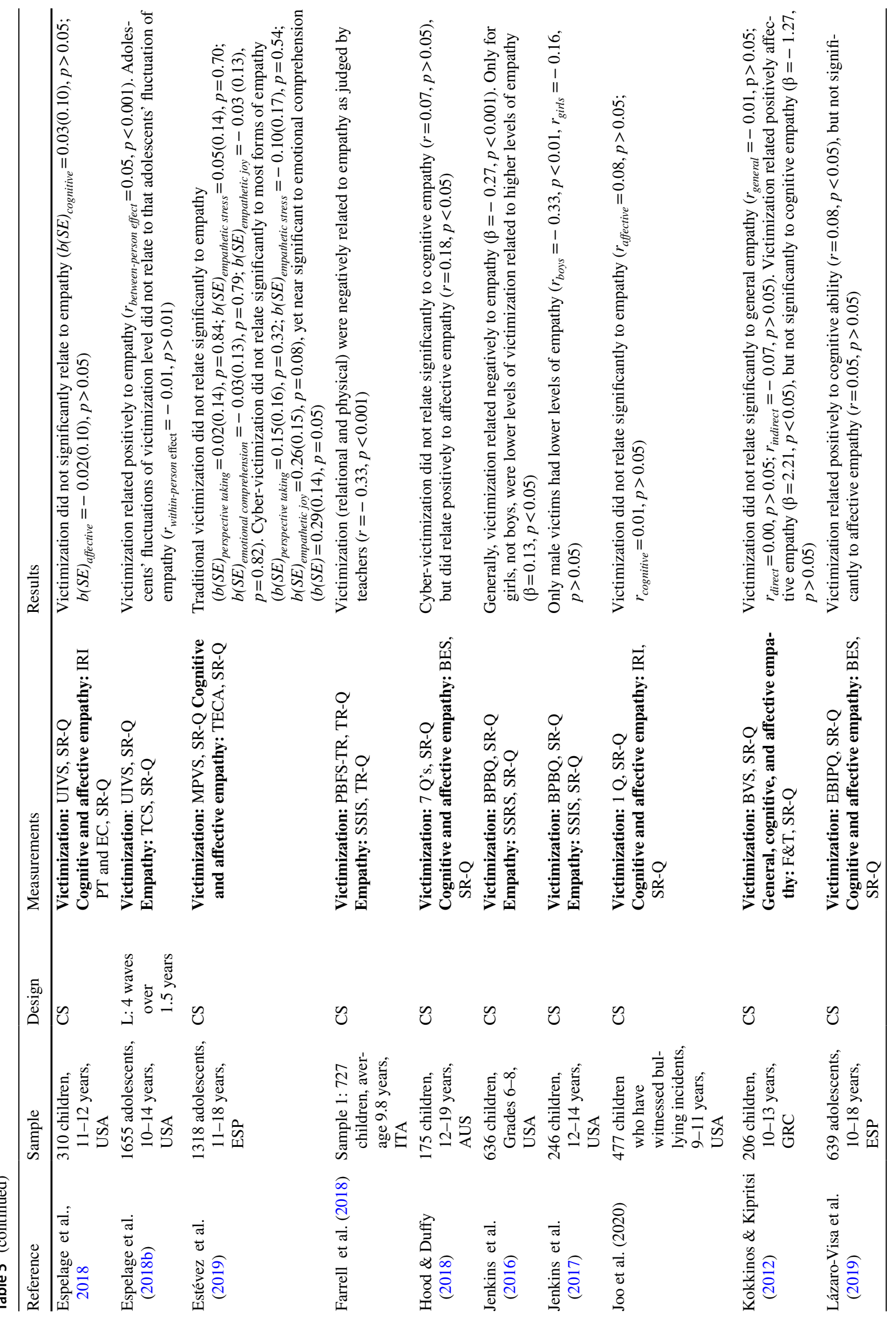




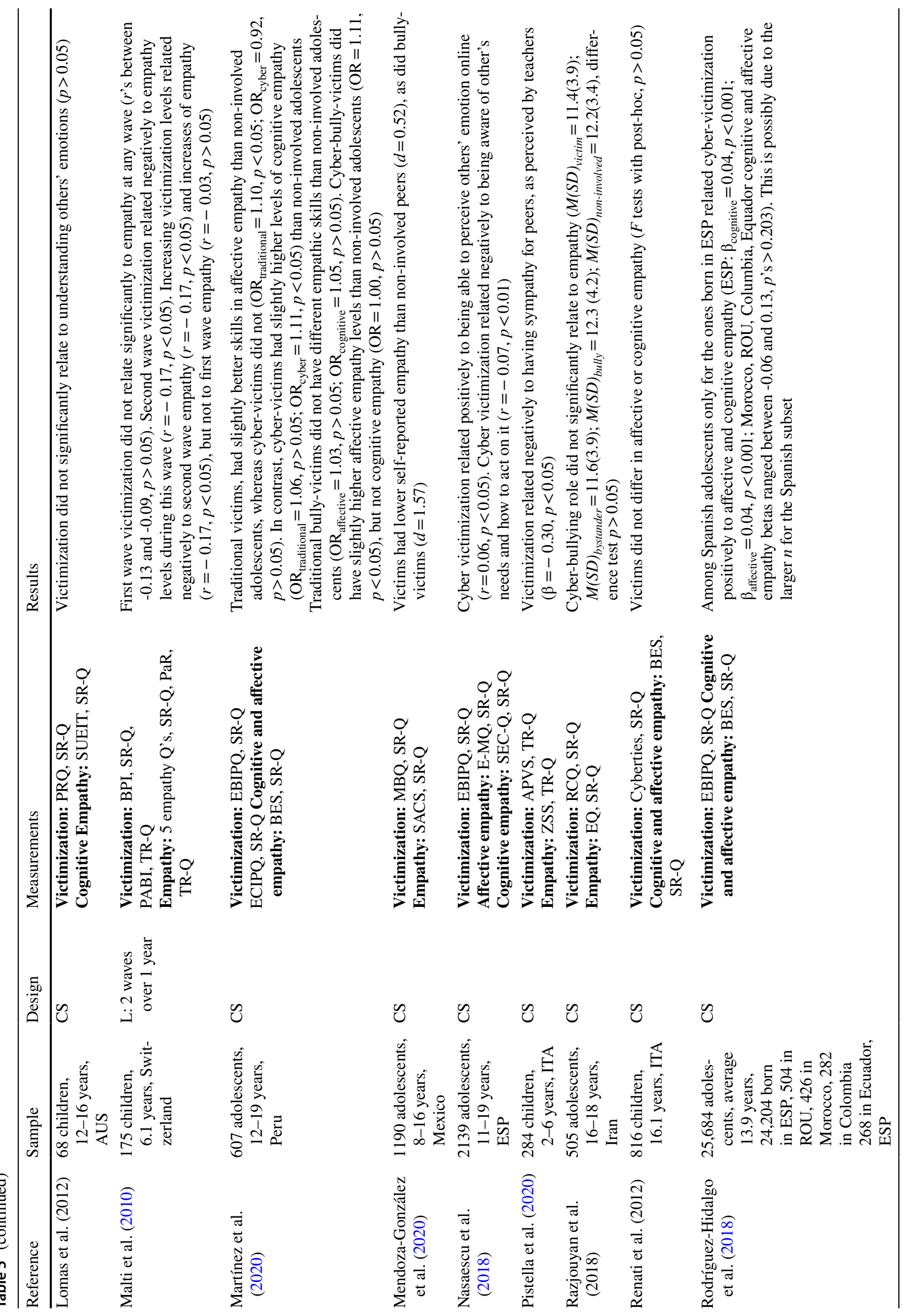




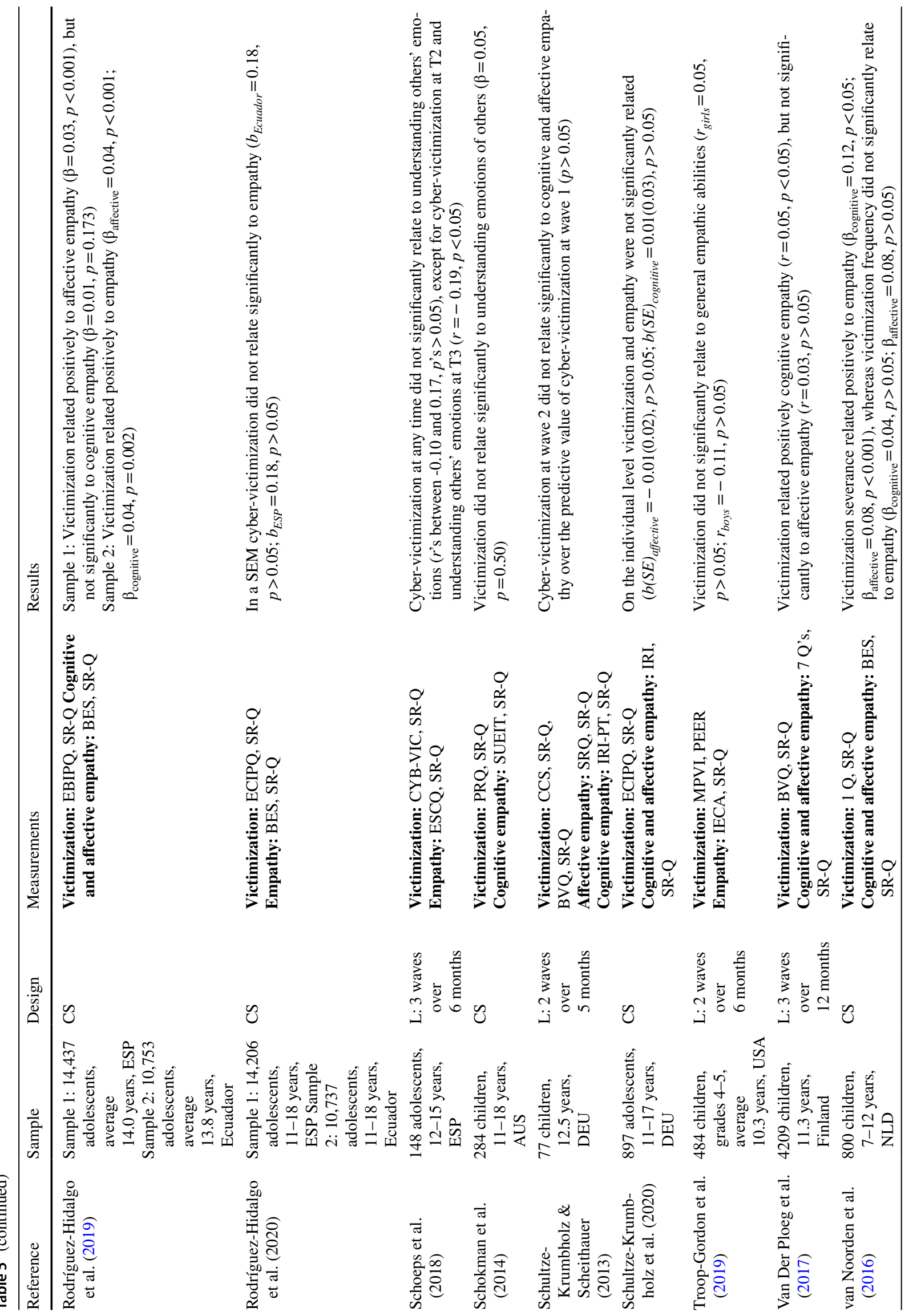




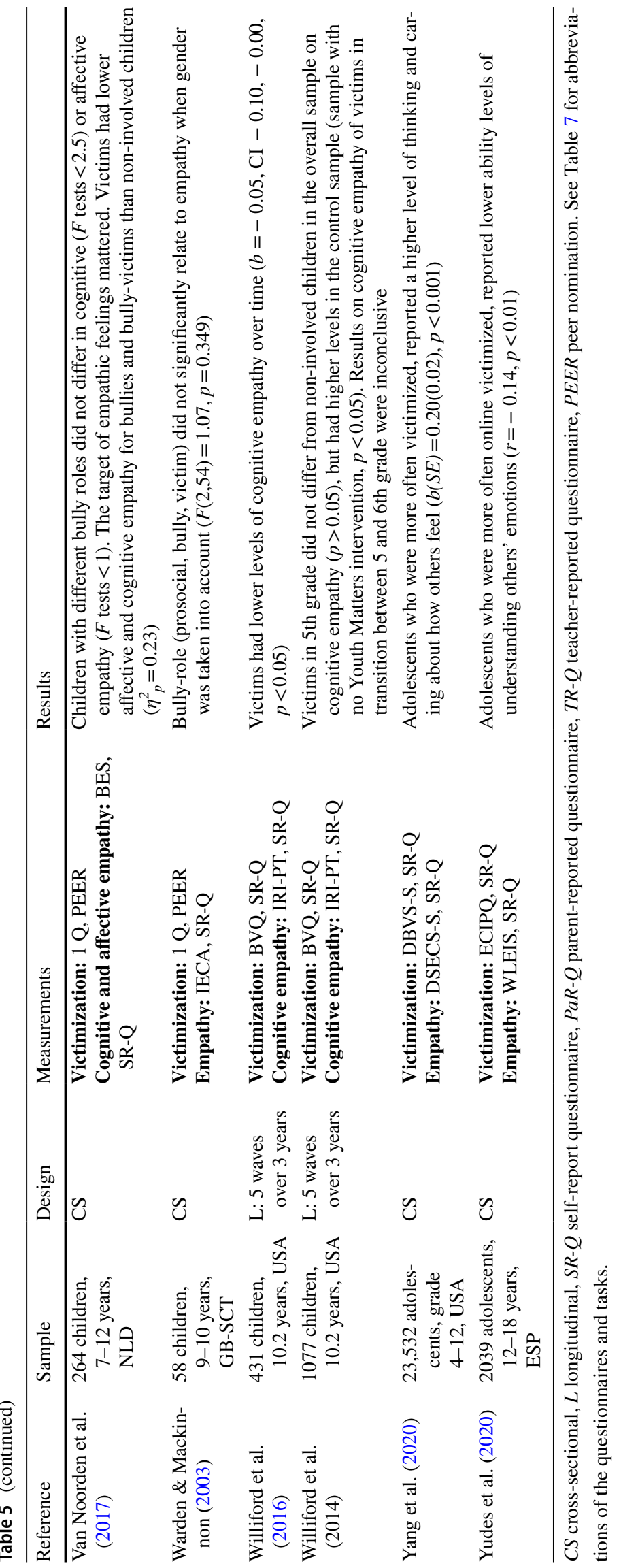




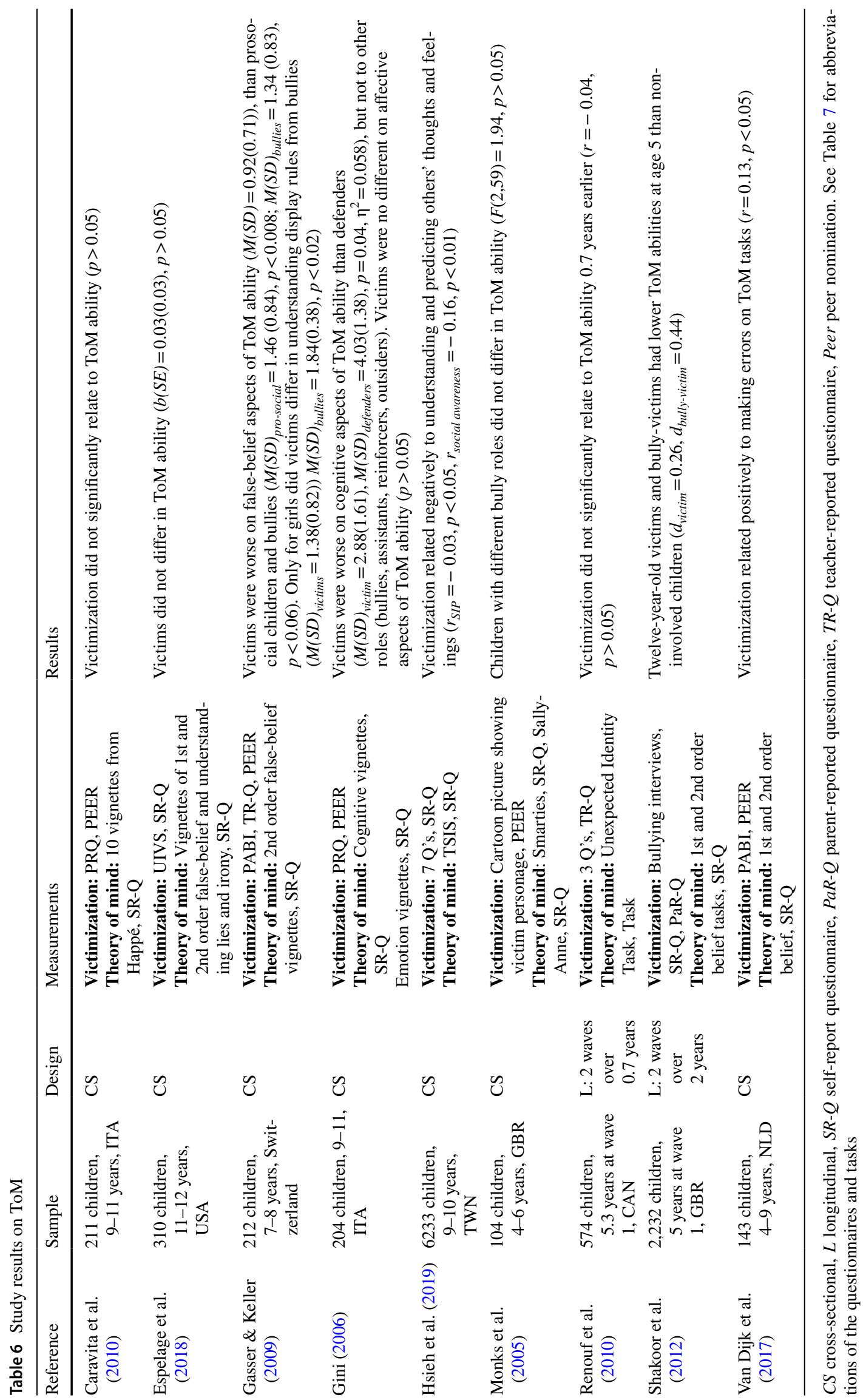




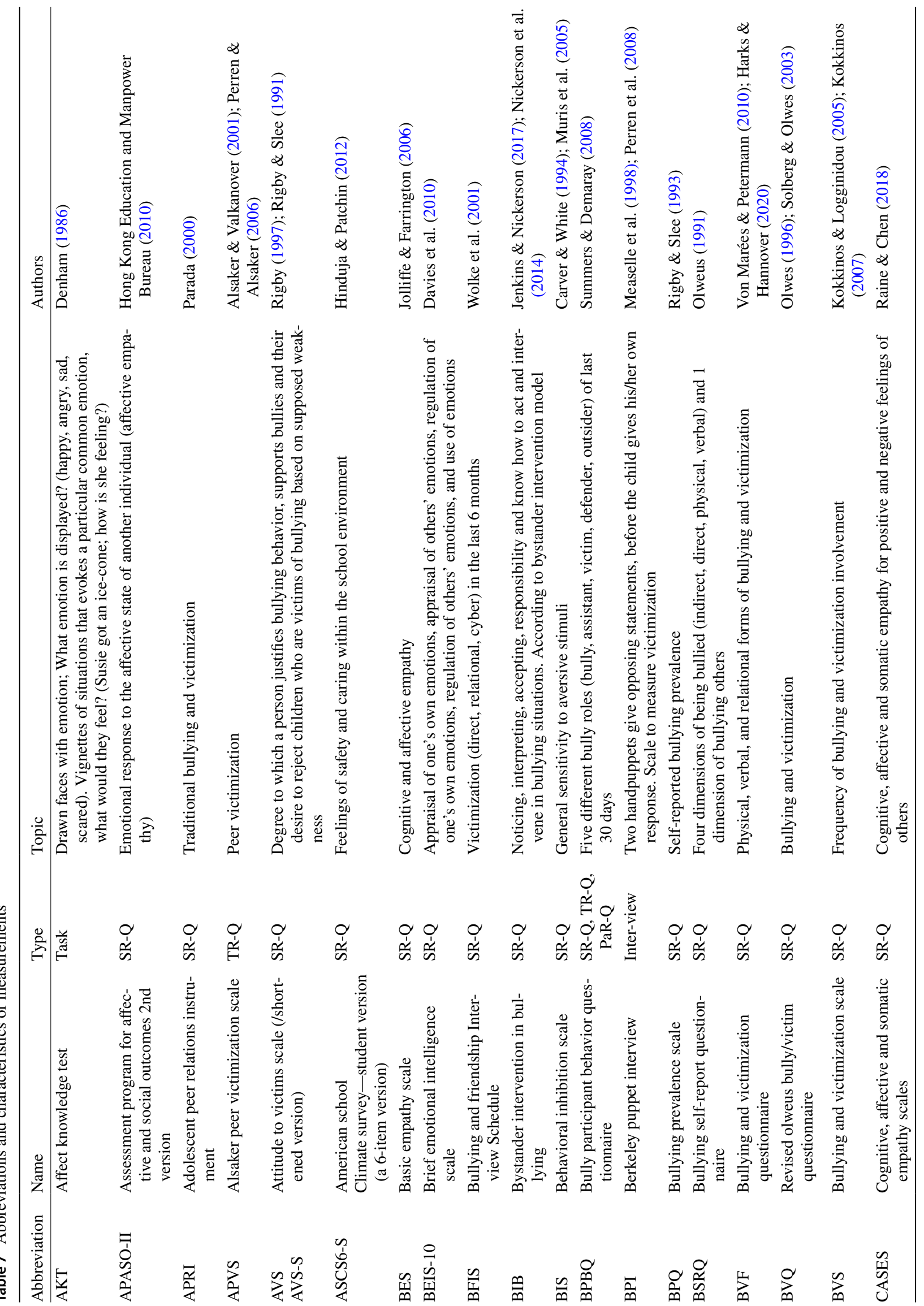




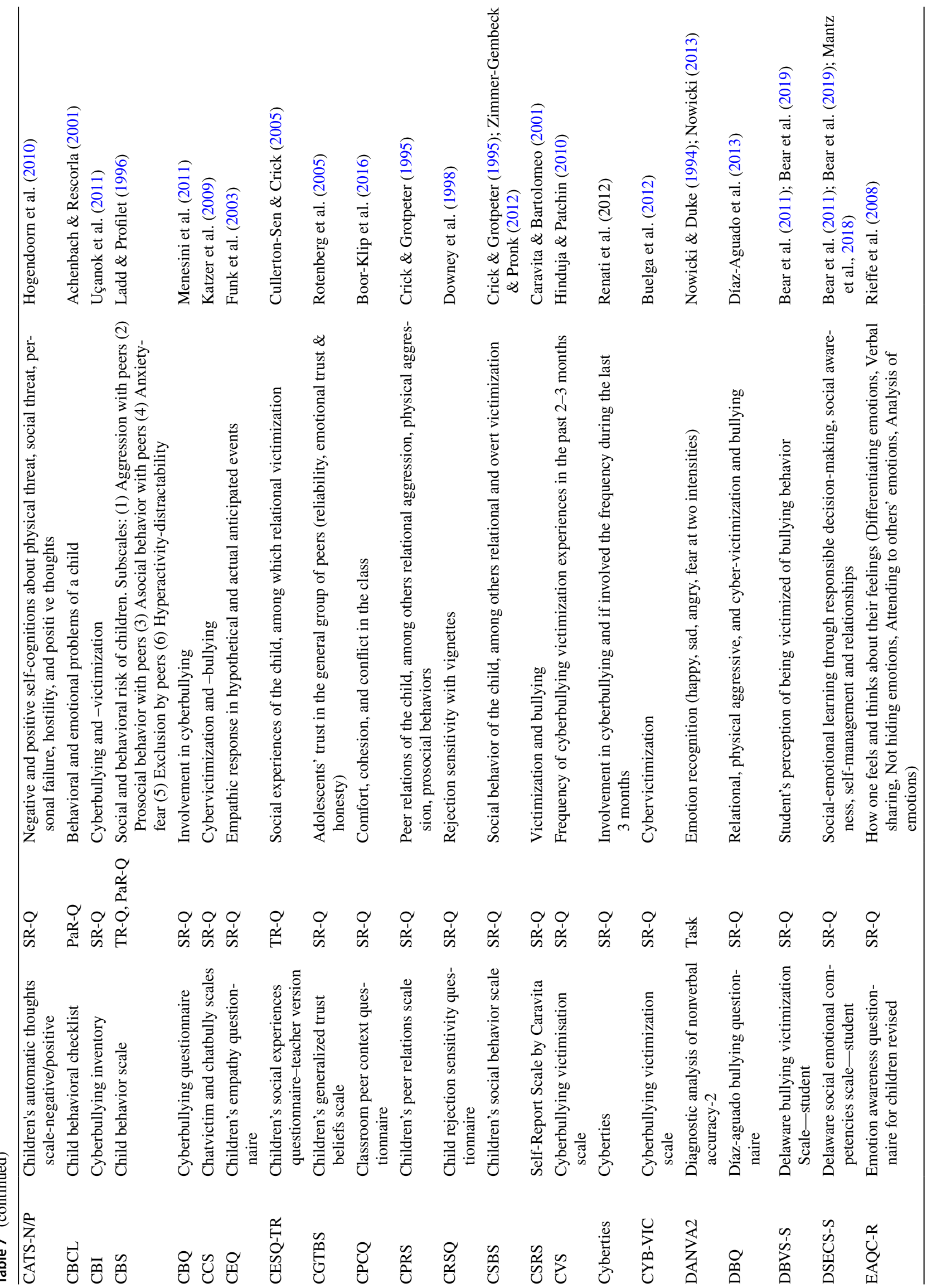




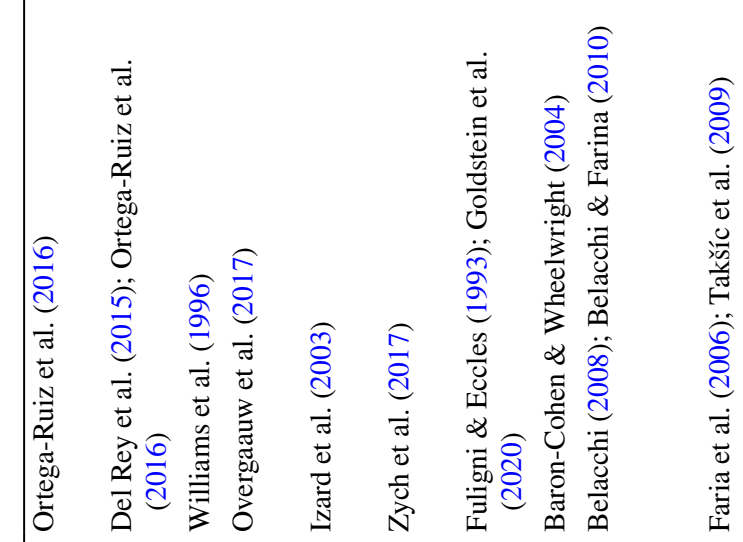

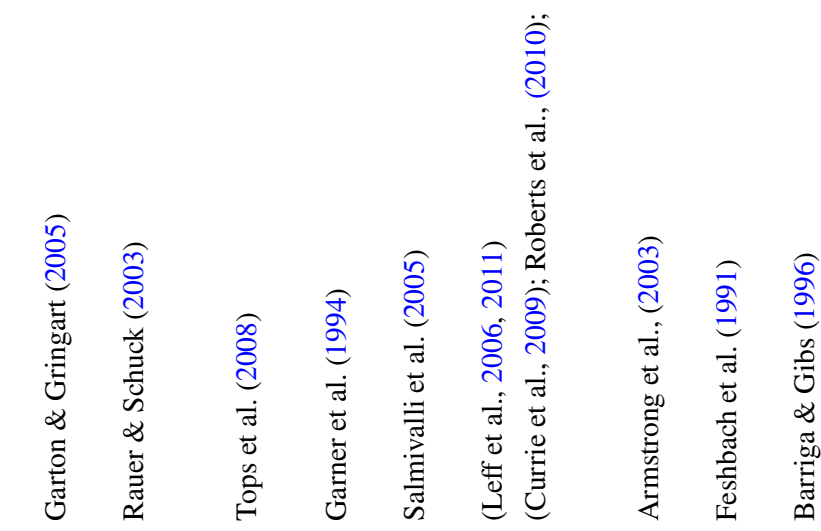

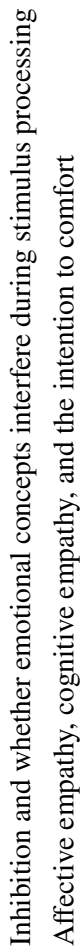

离育竞苛

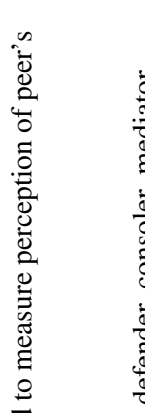

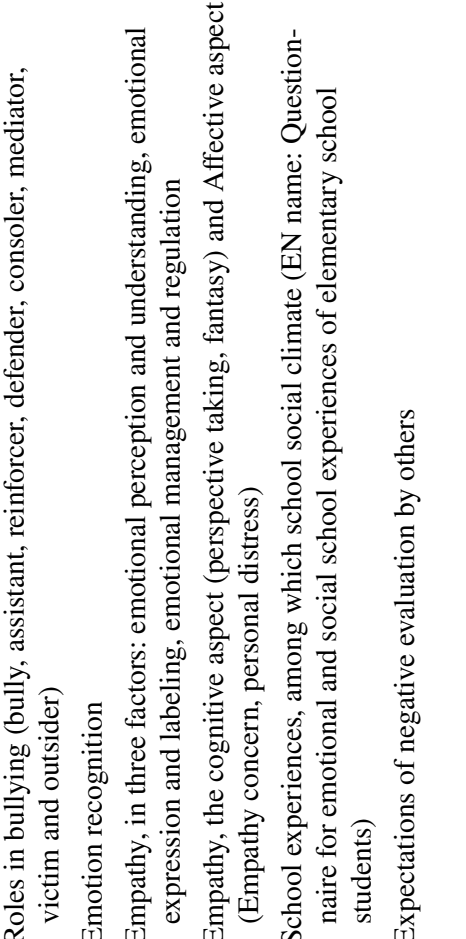

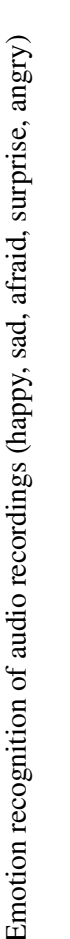

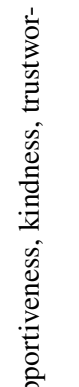

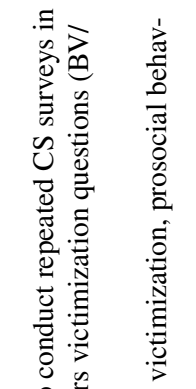

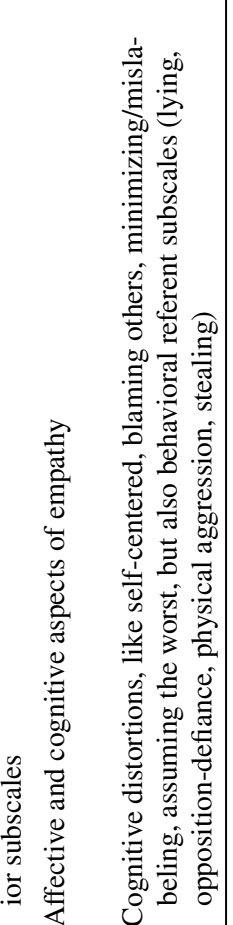

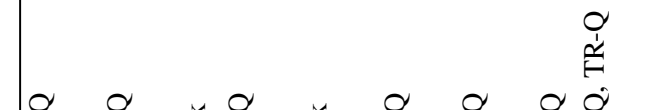

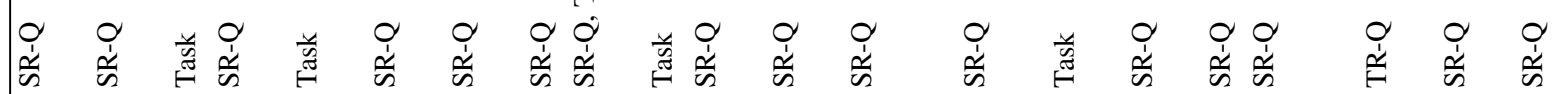
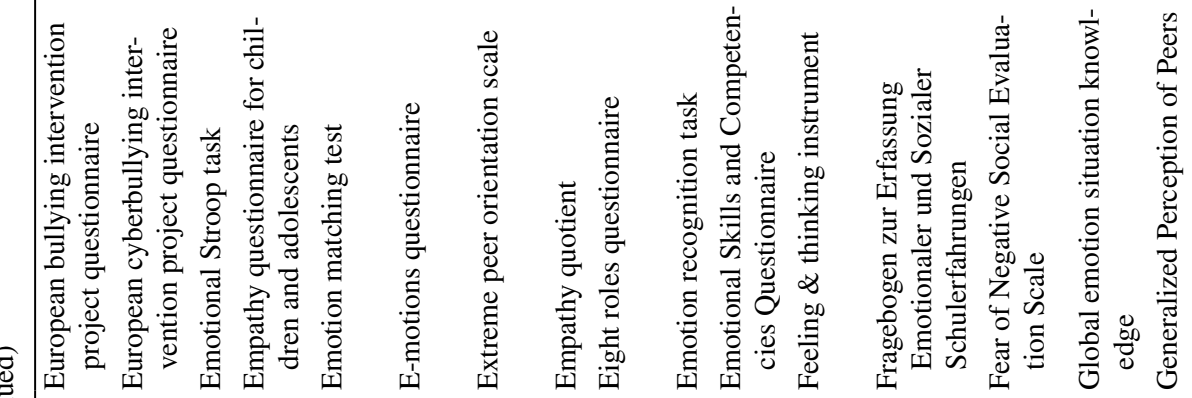

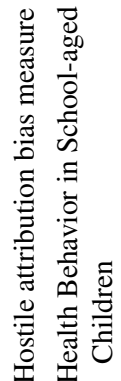

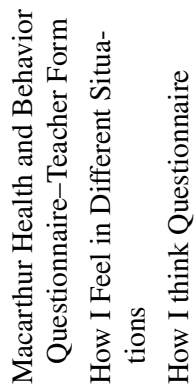




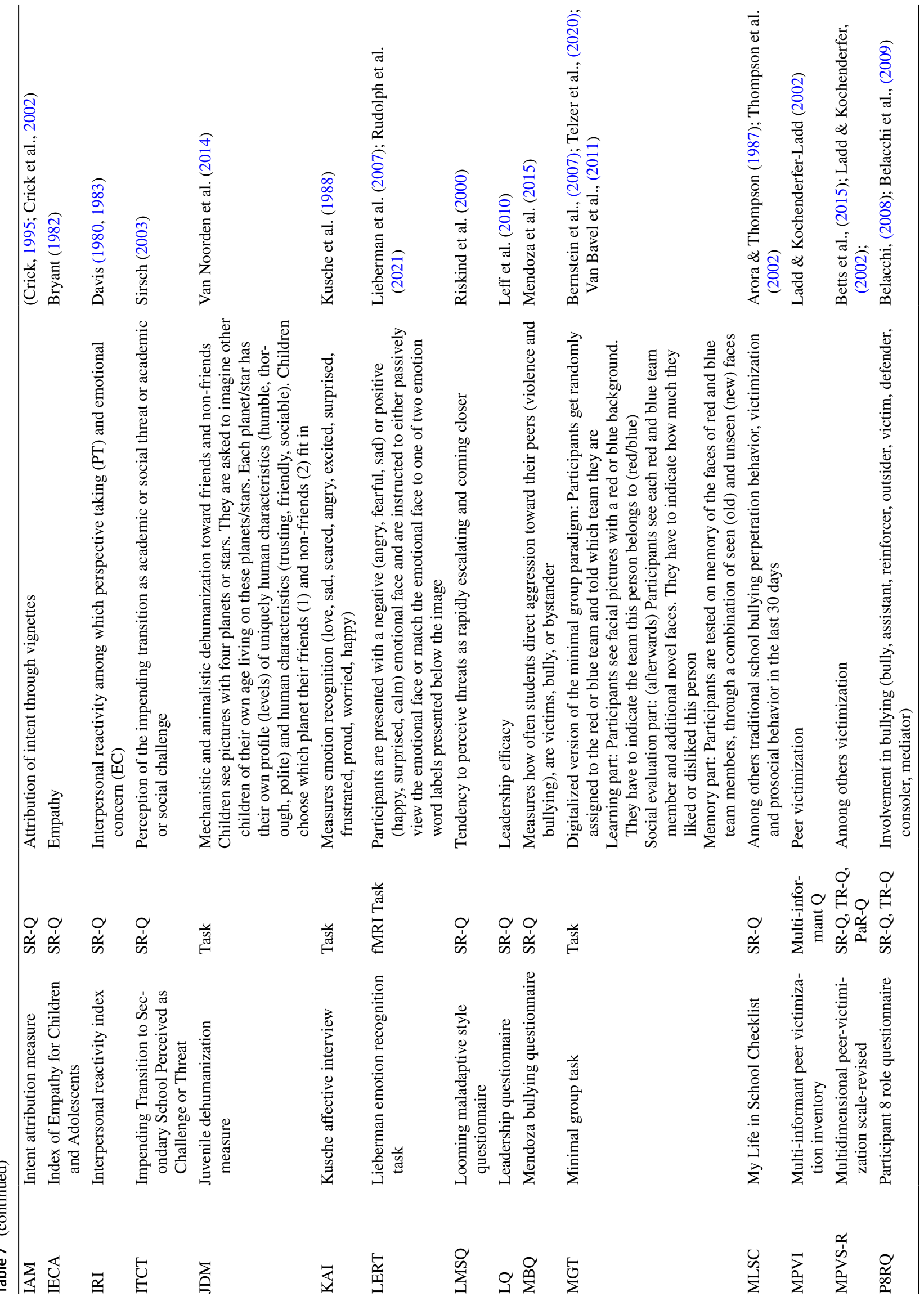




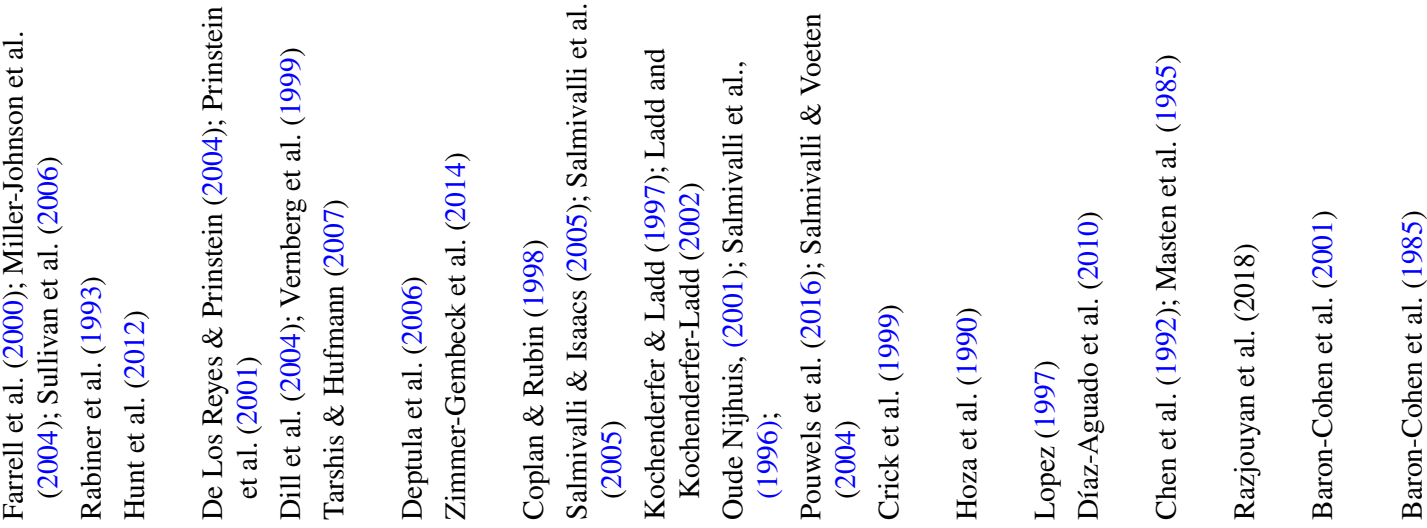

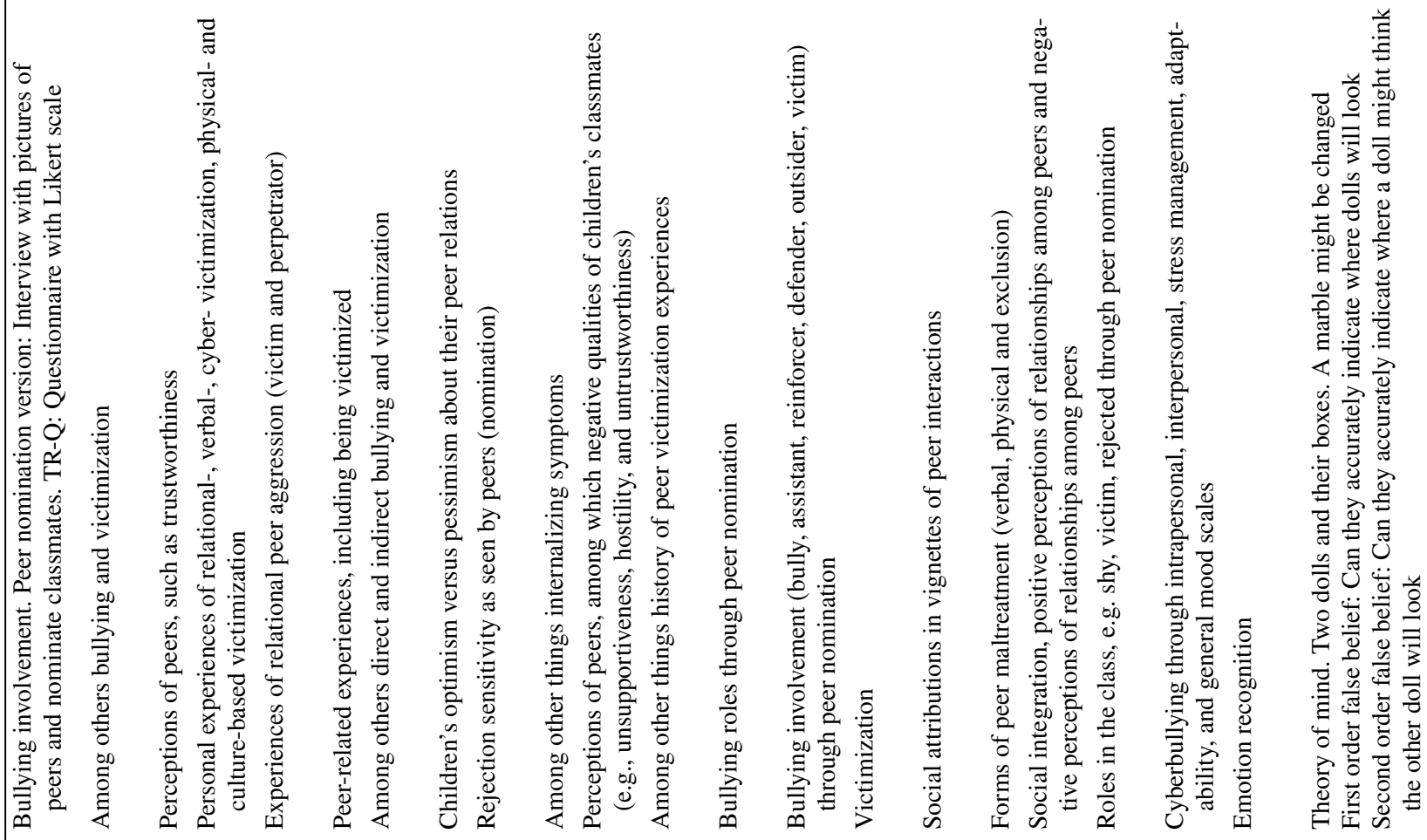

do

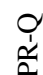

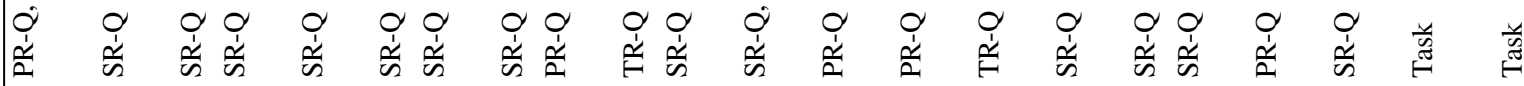

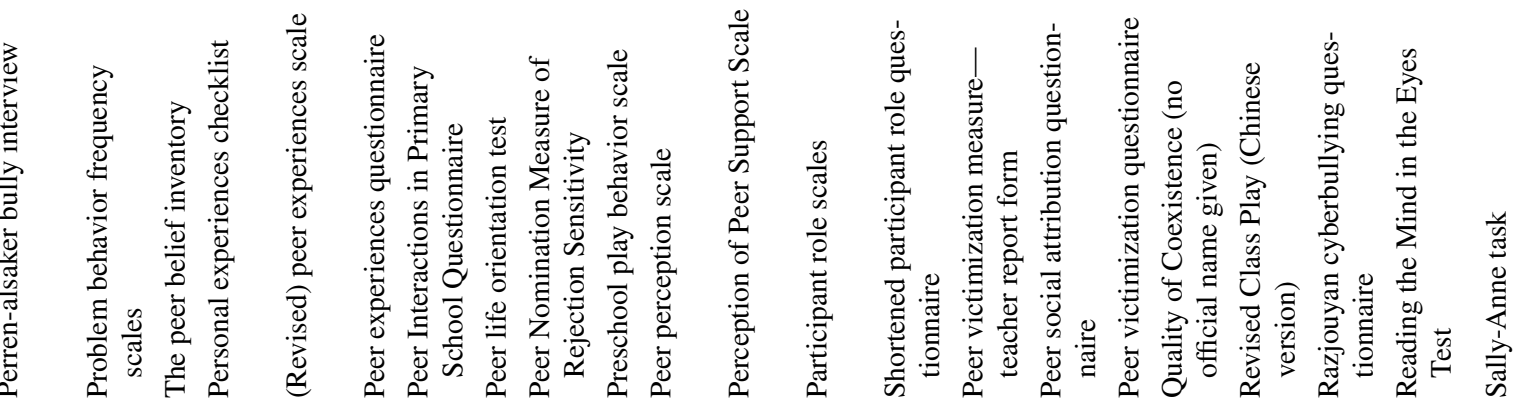

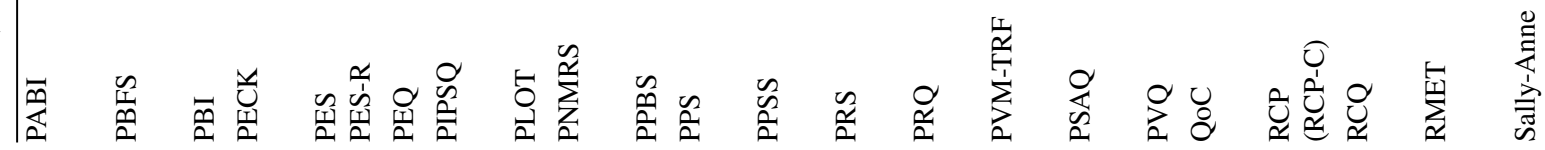




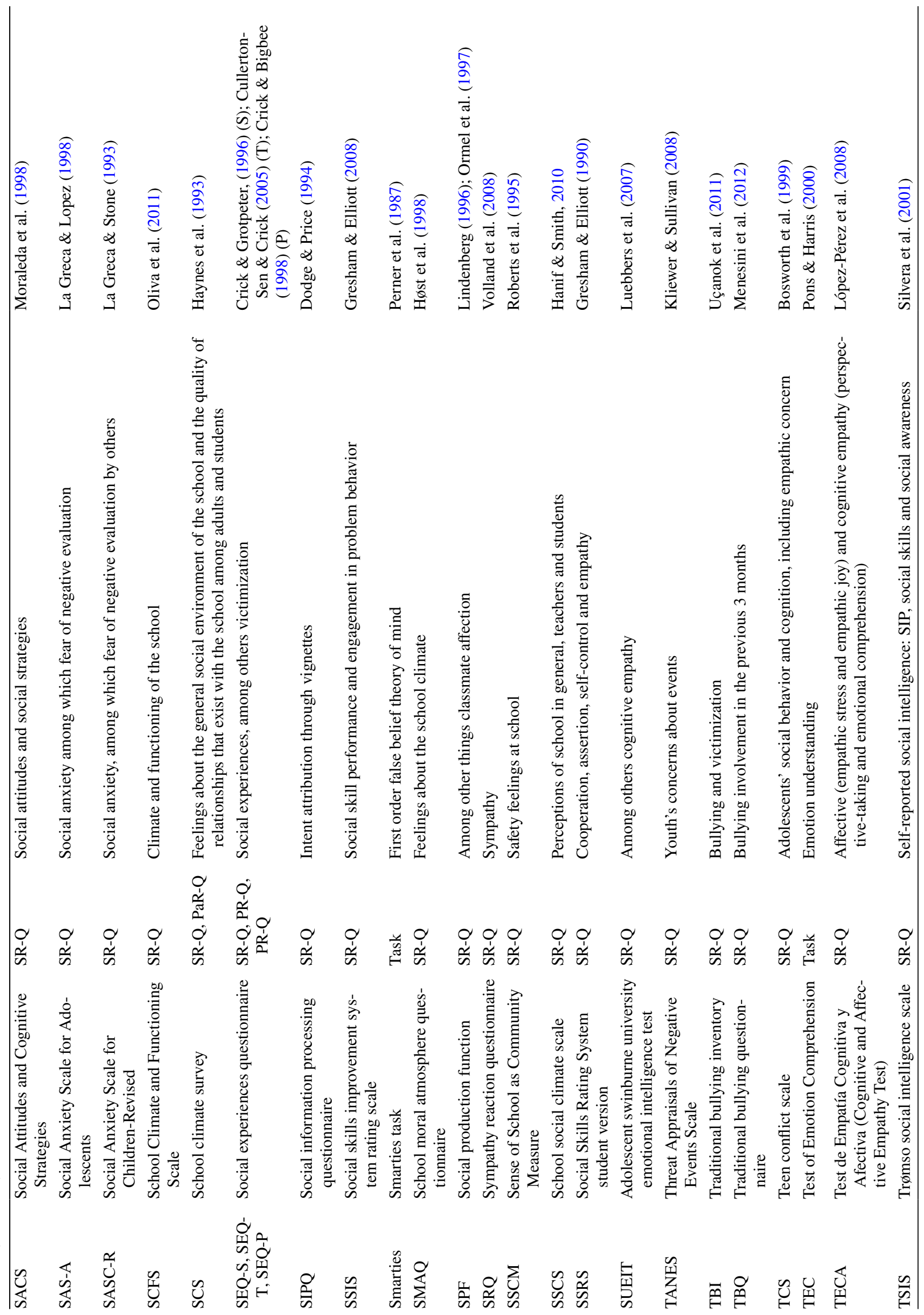




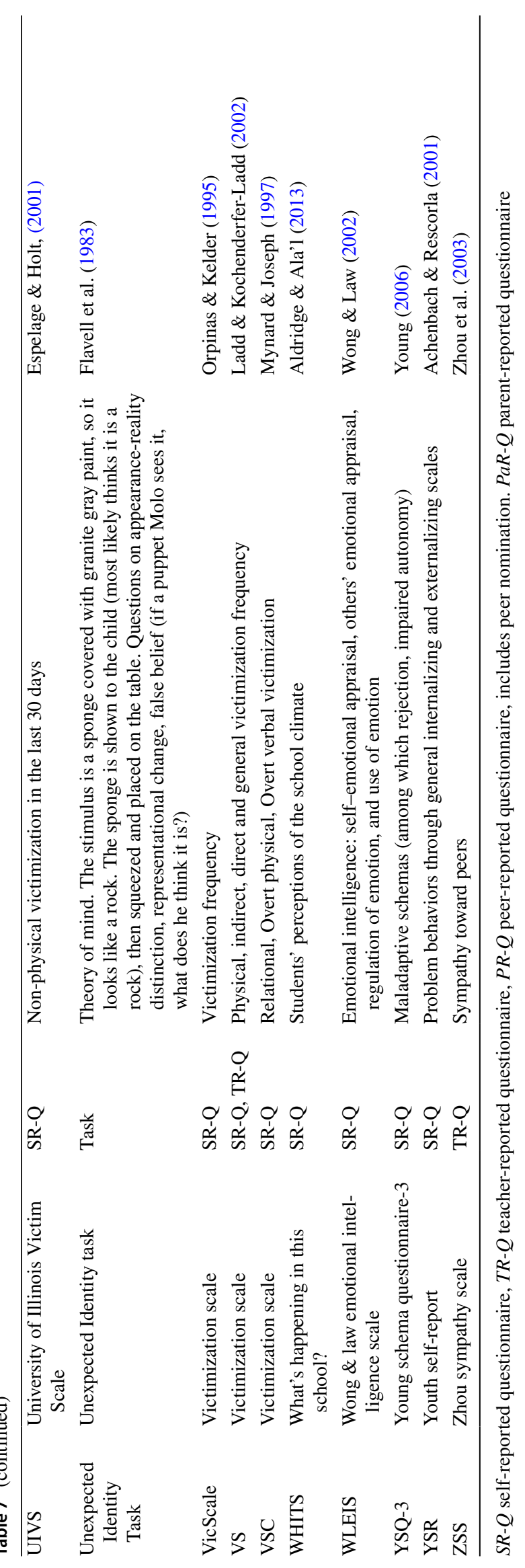

筜 Springer 
development of social-cognitive abilities. The development of social-cognitive abilities is backed by research findings such as that three year-olds do not pass ToM tasks on false belief, whereas five to six year-olds do (Wellman \& Peterson, 2013). In other words, perspective-taking abilities, as well as other social-cognitive abilities, such as language skills, develop with age. However, to date most research on social cognition and victims of bullying is cross-sectional, limiting the conclusions regarding causality or developmental trajectories of social-cognitive styles of (long-term) victims. Possibly, victims with a reaffiliation style can break negative spirals of sustained victimization, whereas victims with a prevention style may not be able to do so, and they might eventually develop a desensitization style over time. Without longitudinal studies such developmental patterns cannot be discerned. Similarly, without longitudinal studies it cannot be determined whether certain aspects of social cognition are precursors, consequences or both precursor and consequence of victimization. Knowledge on whether social-cognitive aspects adopted by victims result in subsequent (long-term) victimization is highly valuable for interventions that aim to increase resilience of victims. Whereas this systematic review provided evidence for a social-cognitive style that is in line with the prevention hypothesis, based on the desensitization hypothesis, long-term victims are expected to have a social-cognitive style marked by insensitivity to social cues.

A third limitation involves the examination of encoding. Studies on encoding often rely on recall and are therefore vulnerable for memory biases (alternations, enhancements, or impairments). Negative social events might be more emotionally impactful for victims than positive ones, and thus, have more leverage in recall (LaBar \& Cabeza, 2006; Roozendaal \& Mcgaugh, 2012). First, this might bias these results in favor of the prevention hypothesis. Second, the results might be more indicative of differences in the database and not of encoding.

A last limitation is related to the studies examining interpretation. Peer perception and attribution of situations are often examined in relation to school- or classmates, meaning that these studies examine the school-context and therefore the context in which victims are commonly bullied. Due to the limited number of studies on peer perception and situational attribution over different contexts (e.g., sport clubs, and new places), it is currently unknown whether victims also have a more negative social-cognitive style when they interact with unknown peers, are in other contexts, and whether it has consequences for future interactions (e.g., being able to trust others and invest in new relationships).

The underlying neurobiological processes of social cognition are a relevant aspect not examined in this review. Prior research shows that victims had blunted cortisol responses to stress compared with non-victims (Vaillancourt et al., 2013).
Because of such altered stress responses, victims might be more sensitive to threats and therefore adopt a prevention style. Along similar lines, neuroimaging studies showed that victimized or chronically rejected children had heightened neural responses to social exclusion, compared with nonvictimized (McIver et al., 2018) or non-rejected children (Will et al., 2016), suggesting stronger neural sensitivity to negative social interactions (see for an overview: Güroğlu \& Veenstra, 2021). Moreover, evidence exists that the strength of these neural responses is more strongly related to internalizing symptoms for long-term victims compared with non-victimized adolescents (Rudolph et al., 2016). In a recent large-scale study, it was found that bullying involvement related to brain structure. Victims differed in cortical thickness of the fusiform gyrus, a brain region involved in visual processing, from bullies, bully-victims and uninvolved children (Muetzel et al., 2019). Finally, it was shown that victimization experiences in childhood may modulate the relation between stress sensitivity and adolescent brain structure (Du Plessis et al., 2019), suggesting more complex relations between how early victimization experiences might influence future development. Despite evidence that victims have altered neural responses to social exclusion experiences, how these responses generalize across various processes of social cognition and differ for temporary versus long-term victims is largely unknown. Moreover, studies on neural processes of social cognition might inform on underlying motivational (Apps et al., 2016; Telzer, 2016) or regulatory processes (Sebastian et al., 2010), which might be difficult to assess using self-reports or observations of behavior. An example of possible underlying motivational processes is that victims were more empathetic toward noninvolved children and friends compared with bullies and non-friends (van Noorden et al., 2017). Although motivation is hard to measure behaviorally, neural measurements might prove fruitful. Furthermore, given existing evidence on the role of neurobiological processes in atypical social cognition (e.g., seen in persons with autism spectrum disorder), a developmental neuroscience perspective is an important avenue for further research (Happé \& Frith, 2014).

\section{Conclusion}

It had been unclear how victimization relates to social cognition, as many researchers only examined subcomponents of this complex construct. This systematic review reveals that victimization during childhood and adolescence relates to a stronger emphasis on negative events and a negative social-cognitive style, mostly in line with the prevention hypothesis. Victims appeared to have a heightened focus on negative or threatening social cues and represent social cues less accurately. Furthermore, they perceived peers more 
negatively, attributed more hostile intent and were more sensitive to rejection than non-victimized children. However, they did not differ in empathic or ToM skills. Further research is needed on the (neurobiological) development of social-cognitive styles and in particular on persistent victims and whether they, in line with the desensitization hypothesis, become insensitive to social cues because of the long period of victimization. For now, researchers and practitioners (e.g., who develop anti-bullying interventions) should realize that, in line with the prevention hypothesis, victims focus on negative social cues.

Supplementary Information The online version contains supplementary material available at https://doi.org/10.1007/s40894-022-00183-8.

Acknowledgements We would like to thank Anssi Bwalya for helping to update the search term and summarizing literature, and Ymke G. Riemersma for her help as second reader for the article selection.

Authors' Contributions SK conceived the study, article inclusion, draft and revision of the manuscript; GL conceived the study and manuscript revision; NB conceived the study and manuscript revision; BG conceived the study and manuscript revision; RV conceived the study and manuscript revision. All authors read and approved the final manuscript.

Funding This work was supported by The Netherlands Organization for Scientific Research (NWA Startimpuls 400.17.602 to BG and RV; 016.Veni.195.186 to GL).

\section{Declarations}

Conflict of interest The authors declare that they have no conflict of interest.

Open Access This article is licensed under a Creative Commons Attribution 4.0 International License, which permits use, sharing, adaptation, distribution and reproduction in any medium or format, as long as you give appropriate credit to the original author(s) and the source, provide a link to the Creative Commons licence, and indicate if changes were made. The images or other third party material in this article are included in the article's Creative Commons licence, unless indicated otherwise in a credit line to the material. If material is not included in the article's Creative Commons licence and your intended use is not permitted by statutory regulation or exceeds the permitted use, you will need to obtain permission directly from the copyright holder. To view a copy of this licence, visit http://creativecommons.org/licenses/by/4.0/.

\section{References}

\section{References marked with a Bullet indicate studies that were included in the systematic review}

Achenbach, T. M., \& Rescorla, L. A. (2001). Manual for the ASEBA school-age forms and profiles. University of Vermont, Research Center for Children, Youth, and Families.
Aldridge, J. M., \& Ala'i, K. (2013). Assessing students' views of school climate: Developing and validating the What's Happening In This School? (WHITS) questionnaire. Improving Schools, 16(1), 47-66.

-Aldridge, J. M., McChesney, K., \& Afari, E. (2020). Associations between school climate and student life satisfaction: Resilience and bullying as mediating factors. Learning Environments Research, 23(1), 129-150. https://doi.org/10.1007/ s10984-019-09296-9

Allen, J. R., \& Kinsey, K. (2013). Teaching Theory of Mind. Early Education and Development, 24(6), 865-876. https://doi.org/ 10.1080/10409289.2013.745182

Alsaker, F. D., \& Valkanover, S. (2001). Early diagnosis and prevention of victimization in kindergarten. In J. Juvonen \& S. Graham (Eds.), Peer harassment in school (pp. 175-195). Guilford.

Anderson, J. R. (2015). Cognitive psychology and its implications (8th ed.). Worth Publishers.

Apps, M. A. J., Rushworth, M. F. S., \& Chang, S. W. C. (2016). The anterior cingulate gyrus and social cognition: Tracking the motivation of others. Neuron, 90(4), 692-707. https://doi.org/ 10.1016/j.neuron.2016.04.018

•Arató, N., Zsidó, A. N., Lénárd, K., \& Lábadi, B. (2020). Cybervictimization and cyberbullying: The role of socio-emotional skills. Frontiers in Psychiatry, 11, 248. https://doi.org/10.3389/fpsyt. 2020.00248

Armstrong, J. M., Goldstein, L. H., \& The MacArthur Working Group on Outcome Assessment. (2003). Manual for the MacArthur Health and Behavior Questionnaire (HBQ 1.0). PA: MacArthur Foundation Research Network on Psychopathology and Development, University of Pittsburgh.

Arora, C. M. J., \& Thompson, D. A. (1987). Defining bullying for a secondary school. Educational and Child Psychology, 4(3-4), $110-120$.

Arseneault, L. (2018). Annual research review: The persistent and pervasive impact of being bullied in childhood and adolescence: Implications for policy and practice. Journal of Child Psychology and Psychiatry and Allied Disciplines, 59(4), 405-421. https:// doi.org/10.1111/jcpp. 12841

Astington, J. W. (2001). The future of theory-of-mind research: Understanding motivational states, the role of language, and real- world consequences. Commentary on "Meta-analysis of theory- ofmind development: The truth about false belief." Child Development, 72, 685-687.

-Audley, S., Hsueh, Y., \& Zhang, H. (2020). I'm respectful. Why don't they like me? Evaluator and gender effects of showing respect and children's social competence. Social Development, 29(1), 249-272. https://doi.org/10.1111/sode.12389

•Baird, A. A., Silver, S. H., \& Veague, H. B. (2010). Cognitive control reduces sensitivity to relational aggression among adolescent girls. Social Neuroscience, 5(5-6), 519-532. https://doi.org/10. 1080/17470911003747386

-Balan, R., Dobrean, A., \& Balazsi, R. (2018). Indirect effects of parental and peer attachment on bullying and victimization among adolescents: The role of negative automatic thoughts. Aggressive Behavior, 44(6), 561-570. https://doi.org/10.1002/ ab. 21775

Banerjee, R., Watling, D., \& Caputi, M. (2011). Peer relations and the understanding of faux pas: Longitudinal evidence for bidirectional associations. Child Development, 82(6), 1887-1905.

Bar-Haim, Y., Lamy, D., Pergamin-Hight, L., Bakermans-Kranenburg, M. J., \& van IJzendoorn, M. H. (2007). Threat-related attentional bias in anxious and nonanxious individuals: A meta-analytic study. Psychological Bulletin, 133(1), 1-24. https://doi.org/10. 1037/0033-2909.133.1.1 
Baron-Cohen, S., Leslie, A. M., \& Frith, U. (1985). Does the autistic child have a 'theory of mind'? Cognition, 21, 37-46.

Baron-Cohen, S., \& Wheelwright, S. (2004). The empathy quotient: An investigation of adults with Asperger syndrome or high functioning autism, and normal sex differences. Journal of Autism and Developmental Disorders, 34(2), 163-175.

Baron-Cohen, S., Wheelwright, S., Spong, A., Scahill, V., \& Lawson, J. (2001). Are intuitive physics and intuitive psychology independent? A test with children with Asperger syndrome. Journal of Developmental and Learning Disorders, 5, 47-78.

-Baroncelli, A., \& Ciucci, E. (2014). Unique effects of different components of trait emotional intelligence in traditional bullying and cyberbullying. Journal of Adolescence, 37(6), 807-815. https:// doi.org/10.1016/j.adolescence.2014.05.009

Barriga, A. Q., \& Gibbs, J. C. (1996). Measuring cognitive distortion in antisocial youth: Development and preliminary validation of the "How I Think" questionnaire. Aggressive Behavior, 22, 333-343.

-Barzeva, S. A., Richards, J. S., Meeus, W. H. J., \& Oldehinkel, A. J. (2020). The social withdrawal and social anxiety feedback loop and the role of peer victimization and acceptance in the pathways. Development and Psychopathology, 32(4), 1402-1417. https://doi.org/10.1017/S0954579419001354

-Bayar, Y., \& Uçanok, Z. (2012). School social climate and generalized peer perception in traditional and cyberbullying status. Educational Sciences: Theory \& Practice, 12(4), 2352-2358.

Bear, G. G., Gaskins, C., Blank, J., \& Chen, F. F. (2011). Delaware School Climate Survey-Student: Its factor structure, concurrent validity, and reliability. Journal of School Psychology, 49, 157-174. https://doi.org/10.1016/j.jsp.2011.01.001

Bear, G. G., Yang, C., Harris, A., Mantz, L., Boyer, D., \& Hearn, S. (2019). Technical Manual for the Delaware School Survey: Scales of school climate; bullying victimization; student engagement; positive, punitive, and social emotional learning techniques; and social and emotional competencies. University of Delaware and Delaware Department of Education.

Belacchi, C. (2008). I ruoli dei partecipanti nel bullismo: Una nuova proposta. Giornale Italiano Di Psicologia, 4, 885-911.

-Belacchi, C., \& Farina, E. (2010). Prosocial/hostile roles and emotion comprehension in preschoolers. Aggressive Behavior, 36(6), 371-389. https://doi.org/10.1002/ab.20361

Belacchi, C., Mei, V., Pierucci, V., Altoe, G. (2009, September). Ruoli dei partecipanti nel bullismo in eta adolescenziale: Validazione di un nuovo modello. Proceedings of XXV Congresso Nazionale AIP Sezione Psicologia sperimentale, Chieti, Italy.

-Berg, J. K., \& Aber, L. J. (2015). A multilevel view of predictors of children's perceptions of school interpersonal climate. Journal of Educational Psychology, 107(4), 1150-1170. https://doi.org/ $10.1037 / \mathrm{edu} 0000027$

Bernstein, M. J. (2003). Research in social psychology: Consequences of short- and long-term social exclusion. In P. Riva \& J. Eck (Eds.), Social exclusion: Psychological approaches to understanding and reducing its impact (pp. 51-72). Springer International Publishing. https://doi.org/10.1007/978-3-319-33033-4

Bernstein, M. J., Young, S. G., \& Hugenberg, K. (2007). The crosscategory effect. Psychological Science, 18, 706-712. https://doi. org/10.1111/j.1467-9280.2007.01964.x

Betts, L. R., Houston, J. E., \& Steer, O. L. (2015). Development of the Multidimensional Peer Victimisation Scale-Revised (MPVR-R) and the Multidimensional Peer Bullying Scale (MPVS-RB). The Journal of Genetic Psychology: Research and Theory on Human Development, 176, 93-109. https://doi.org/10.1080/00221325. 2015.1007915

-Betts, L. R., Houston, J. E., Steer, O. L., \& Gardner, S. E. (2017). Adolescents' experiences of victimization: The role of attribution style and generalized trust. Journal of School Violence, 16(1), 25-48. https://doi.org/10.1080/15388220.2015.1100117

Boor-Klip, H. J., Segers, E., Hendrickx, M. M. H. G., \& Cillessen, A. H. N. (2016). Development and psychometric properties of the classroom peer context questionnaire. Social Development, 25, 370-389.

Bosworth, K., Espelage, D. L., \& Simon, T. R. (1999). Factors associated with bullying behavior in middle school students. Journal of Early Adolescence, 19, 341-362.

Bryant, K. B. (1982). An index of empathy for children and adolescents. Child Development, 53, 413-425. https://doi.org/10. 2307/1128984

Buckner, J. D., DeWall, C. N., Schmidt, N. B., \& Maner, J. K. (2010). A tale of two threats: Social anxiety and attention to social threat as a function of social exclusion and non-exclusion threats. Cognitive Therapy and Research, 34(5), 449-455. https://doi.org/10.1007/s10608-009-9254-x

Buelga, S., Cava, M. J., \& Musitu, G. (2012). Validation of the adolescent victimization through mobile phone and internet scale [Validación de la Escala de Victimización entre Adolescentes a través del Teléfono Móvil y de Internet]. Revista Panamericana De Salud Publica, 32, 36-42. https://doi.org/10.1590/S102049892012000700006

-Calleja, R. L., \& Rapee, R. M. (2020). Social threat sensitivity and its relationships with peer victimisation and internalising symptoms among adolescent girls. Behaviour Research and Therapy, 133, 103710. https://doi.org/10.1016/j.brat.2020. 103710

•Calvete, E., Fernández-González, L., González-Cabrera, J. M., \& Gámez-Guadix, M. (2018). Continued bullying victimization in adolescents: Maladaptive schemas as a mediational mechanism. Journal of Youth and Adolescence, 47(3), 650-660. https://doi. org/10.1007/s10964-017-0677-5

-Camodeca, M., \& Goossens, F. A. (2005). Aggression, social cognitions, anger and sadness in bullies and victims. Journal of Child Psychology and Psychiatry and Allied Disciplines, 46(2), 186197. https://doi.org/10.1111/j.1469-7610.2004.00347.x

-Camodeca, M., Goossens, F. A., Schuengel, C., \& Terwogt, M. M. (2003). Links between social information processing in middle childhood and involvement in bullying. Aggressive Behavior, 29(2), 116-127. https://doi.org/10.1002/ab.10043

Caravita, S., \& Bartolomeo, A. (2001, August). Bullying and the use of violent videogames. Paper presented at the Tenth European Conference on Developmental Psychology, Uppsala, Sweden.

-Caravita, S. C. S., Di Blasio, P., \& Salmivalli, C. (2010). Early adolescents' participation in bullying: Is ToM involved? Journal of Early Adolescence, 30(1), 138-170. https://doi.org/10.1177/ 0272431609342983

-Caravita, S. C. S., Strohmeier, D., Salmivalli, C., \& Di Blasio, P. (2019). Bullying immigrant versus non-immigrant peers: Moral disengagement and participant roles. Journal of School Psychology, 75, 119-133. https://doi.org/10.1016/j.jsp.2019.07.005

Carver, C. S., \& White, T. L. (1994). Behavioral inhibition, behavioral activation, and affective responses to impending reward and punishment. Journal of Personality and Social Psychology, 67, 319-333.

•Chan, H. C. O., \& Wong, D. S. W. (2015). The overlap between school bullying perpetration and victimization: Assessing the psychological, familial, and school factors of Chinese adolescents in Hong Kong. Journal of Child and Family Studies, 24(11), 32243234. https://doi.org/10.1007/s10826-015-0125-7

$\bullet$ Chen, F. R., Fung, A. L. C., \& Raine, A. (2021). The cognitive, affective, and somatic empathy scales (CASES): Cross-cultural replication and specificity to different forms of aggression and victimization. Journal of Personality Assessment, 103(1), 80-91. https://doi.org/10.1080/00223891.2019.1677246 
Chen, X., Rubin, K. H., \& Sun, Y. (1992). Social reputation and peer relationships in Chinese and Canadian children: A cross-cultural study. Child Development, 63, 1336-1343.

-Choi, B., \& Park, S. (2018). Who becomes a bullying perpetrator after the experience of bullying victimization? The moderating role of self-esteem. Journal of Youth and Adolescence, 47(11), 2414-2423. https://doi.org/10.1007/s10964-018-0913-7

-Ciucci, E., Baroncelli, A., \& Nowicki, S. (2014). Emotion perception accuracy and bias in face-to-face versus cyberbullying. Journal of Genetic Psychology, 175(5), 382-400. https://doi.org/10.1080/ 00221325.2014 .934653

Coplan, R. J., \& Rubin, K. H. (1998). Exploring and assessing nonsocial play in the preschool: The development and validation of the Preschool Play Behavior Scale. Social Development, 7, 71-91.

Crick, N. R. (1995). Relational aggression: The role of intent attribution, feelings of distress, and provocation type. Development and Psychopathology, 7, 313-322. https://doi.org/10.1017/S0954 579400006520

Crick, N. R., \& Bigbee, M. A. (1998). Relational and overt forms of peer victimization: A multi informant approach. Journal of Consulting and Clinical Psychology, 66, 337-347. https://doi.org/10. 1037/0022-006X.66.2.337

Crick, N. R., Casas, J. F., \& Ku, H. Y. (1999). Relational and physical forms of peer victimization in preschool. Developmental Psychology, 35, 376-385.

Crick, N. R., \& Dodge, K. A. (1994). Review and reformulation of social information-processing mechanisms in children's social adjustment. Psychological Bulletin, 115(1), 74-101. https://doi. org/10.1037/0033-2909.115.1.74

Crick, N. R., \& Grotpeter, J. K. (1995). Relational aggression, gender, and social-psychological adjustment. Child Development, 66(3), 710-722. https://doi.org/10.1016/0169-555X(92)90033-K

Crick, N. R., \& Grotpeter, J. K. (1996). Children's treatment by peers: Victims of relational and overt aggression. Development and Psychopathology, 8, 367-380.

Crick, N. R., Grotpeter, J. K., \& Bigbee, M. A. (2002). Relationally and physically aggressive children's intent attributions and feelings of distress for relational and instrumental peer provocations. Child Development, 73, 1134-1142.

Cullerton-Sen, C., \& Crick, N. R. (2005). Understanding the effects of physical and relational victimization: The utility of multiple perspectives in predicting social emotional adjustment. School Psychology Review, 34, 147-160.

Currie, C., Nic Gabhainn, S., \& Godeau, E. (2009). The health behaviour in school-aged children: WHO collaborative cross-national (HBSC) study: Origins, concept, history and development 19822008. International Journal of Public Health, 54, 131-139.

Davies, K. A., Lane, A. M., Devonport, T. J., \& Scott, J. A. (2010). Validity and reliability of a brief emotional intelligence scale (BEIS-10). Journal of Individual Differences, 31, 198-208.

Davis, M. H. (1980). A multidimensional approach to individual differences in empathy. Catalog of Selected Documents in Psychology, 10, 1-19. https://doi.org/10.1037/0022-3514.44.1.113

Davis, M. H. (1983). Measuring individual differences in empathy: Evidence for a multidimensional approach. Journal of Personality and Social Psychology, 44, 113-126. https://doi.org/10.1037/ 0022-3514.44.1.113

De Los Reyes, A., \& Prinstein, M. J. (2004). Applying depressiondistortion hypotheses to the assessment of peer victimization in adolescents. Journal of Clinical Child and Adolescent Psychology, 33(2), 325-335. https://doi.org/10.1207/s15374424jccp33 $02 \_14$

Decety, J., Norman, G. J., Berntson, G. G., \& Cacioppo, J. T. (2012). A neurobehavioral evolutionary perspective on the mechanisms underlying empathy. Progress in Neurobiology, 98(1), 38-48. https://doi.org/10.1016/j.pneurobio.2012.05.001
Del Rey, R., Casas, J. A., Ortega-Ruiz, R., Schultze-Krumbholz, A., Scheithauer, H., Smith, P. K., \& Plichta, P. (2015). Structural validation and cross-cultural robustness of the European cyberbullying intervention project questionnaire. Computers in Human Behavior, 50, 141-147. https://doi.org/10.1016/j.chb.2015.03. 065

Denham, S. A. (1986). Social cognition, social behavior, and emotion in preschoolers: Contextual validation. Child Development, 57, 194-201.

•DePaolis, K. J., \& Williford, A. (2019). Pathways from cyberbullying victimization to negative health outcomes among elementary school students: A longitudinal investigation. Journal of Child and Family Studies, 28(9), 2390-2403. https://doi.org/10.1007/ s10826-018-1104-6

Deptula, D. P., Cohen, R., Phillipsen, L. C., \& Ey, S. (2006). Expecting the best: The relation between peer optimism and social competence. The Journal of Positive Psychology, 1, 130-141. https:// doi.org/10.1080/17439760600613685

DeWall, C. N., Twenge, J. M., Koole, S. L., Baumeister, R. F., Marquez, A., \& Reid, M. W. (2011). Automatic emotion regulation after social exclusion: Tuning to positivity. Emotion, 11(3), 623-636. https://doi.org/10.1037/a0023534

Díaz-Aguado, M. J., Martínez Arias, R., \& Babarro, J. M. (2013). El acoso entre adolescentes en España. Prevalencia, papeles adoptados por todo el grupo y características a las que atribuyen la victimización [Bullying among adolescents in Spain. Prevalence, participants' roles and characteristics attributable to victimization by victims and aggressors]. Revista De Educación, 362, 348-379. https://doi.org/10.4438/1988-592X-RE-2011-362-164

Díaz-Aguado, M. J., Martínez Arias, R., and Martín, J. (2010). Estudio estatal sobre la convivencia escolar en la Educación Secundaria Obligatoria [State study on school coexistence in Compulsory Secondary Education]. Observatorio Convivencia Escolar. Madrid: Ministerio de Educación.

Dill, E. J., Vernberg, E. M., Fonagy, P., Twemlow, S. W., \& Gamm, B. K. (2004). Negative affect in victimized children: The roles of social withdrawal, peer rejection, and attitudes towards bullying. Journal ofAbnormal Child Psychology, 32, 159-173. https://doi. org/10.1023/B:JACP.0000019768.31348.81

•Ding, X., Fu, R., Ooi, L. L., Coplan, R. J., Zheng, Q., \& Deng, X. (2020). Relations between different components of rejection sensitivity and adjustment in Chinese children. Journal of Applied Developmental Psychology, 67, 101119. https://doi.org/10. 1016/j.appdev.2020.101119

•Ding, Y., Li, D., Li, X., Xiao, J., Zhang, H., \& Wang, Y. (2020). Profiles of adolescent traditional and cyber bullying and victimization: The role of demographic, individual, family, school, and peer factors. Computers in Human Behavior, 111, 106439. https://doi.org/10.1016/j.chb.2020.106439

Dodge, K. A., \& Price, J. M. (1994). On the relation between social information processing and socially competent behavior in early school-aged children. Child Devevelopment, 65(5), 1385-1397.

-Donat, M., Rüprich, C., Gallschütz, C., \& Dalbert, C. (2020). Unjust behavior in the digital space: The relation between cyberbullying and justice beliefs and experiences. Social Psychology of Education, 23(1), 101-123. https://doi.org/10.1007/ s11218-019-09530-5

Downey, G., Lebolt, A., Rincón, C., \& Freitas, A. L. (1998). Rejection sensitivity and children's interpersonal difficulties. Child Development, 69(4), 1074-1091. https://doi.org/10.1111/j.1467-8624. 1998.tb06161.x

Du Plessis, M. R., Smeekens, S., Cillessen, A. H. N., Whittle, S., \& Güroglu, B. (2019). Bullying the brain? Longitudinal links between childhood peer victimization, cortisol, and adolescent brain structure. Frontiers in Psychology, 9, 2706. https://doi.org/ 10.3389/fpsyg. 2018.02706 
•Elsaesser, C., Gorman-Smith, D., \& Henry, D. (2013). The role of the school environment in relational aggression and victimization. Journal of Youth and Adolescence, 42(2), 235-249. https://doi. org/10.1007/s10964-012-9839-7

Espelage, D. L., \& Holt, M. L. (2001). Bullying and victimization during early adolescence: Peer influences and psychosocial correlates. Journal of Emotional Abuse, 2, 123-142. https://doi.org/ 10.1300/J135v02n02_08

*Espelage, D. L., Hong, J. S., Kim, D. H., \& Nan, L. (2018a). Empathy, attitude towards bullying, theory-of-mind, and non-physical forms of bully perpetration and victimization among U.S. middle school students. Child and Youth Care Forum, 47(1), 45-60. https://doi.org/10.1007/s10566-017-9416-z

-Espelage, D. L., Merrin, G. J., Hong, J. S., \& Resko, S. M. (2018). Applying social cognitive theory to explore relational aggression across early adolescence: A within- and between-person analysis. Journal of Youth and Adolescence, 47(11), 2401-2413. https:// doi.org/10.1007/s10964-018-0910-x

•Estévez, E., Estévez, J. F., Segura, L., \& Suárez, C. (2019). The influence of bullying and cyberbullying in the psychological adjustment of victims and aggressors in adolescence. International Journal of Environmental Research and Public Health, 16(12), 2080. https://doi.org/10.3390/ijerph16122080

Faria, L., Santos, N. L., Takši'c, V., Räty, H., Molander, B., Holmström, S., et al. (2006). Cross-cultural validation of the emotional skills and competence questionaire (ESCQ) [Validação intercultural do Emotional Skills and Competence Questionnaire (ESCQ)]. Psicologia, 20, 95-127. https://doi.org/10.17575/rpsic ol.v20i2.390

-Farrell, A. D., Goncy, E. A., Sullivan, T. N., \& Thompson, E. L. (2018). Evaluation of the problem behavior frequency scaleteacher report form for assessing behavior in a sample of urban adolescents. Psychological Assessment, 30(10), 1277-1291. https://doi.org/10.1037/pas0000571

Farrell, A. D., Kung, E. M., White, K. S., \& Valois, R. (2000). The structure of self-reported aggression, drug use, and delinquent behaviors during early adolescence. Journal of Clinical Child Psychology, 29, 282-292. https://doi.org/10.1207/S15374424j ccp2902_13

Feshbach, N. D., Caprara, G. V., Lo Coco, A., Pastorelli, C., Manna, G., \& Menzres, J. (1991). Empathy and its correlates: Cross cultural data from Italy. Oral communication presented at 11th Biennal Meeting of the International Society for the Study of Behavioral Development, Minneapolis.

Flavell, J. H., Flavell, E. R., \& Green, F. L. (1983). Development of the appearance-reality distinction. Cognitive Psychology, 15, 95-120

Fox, C. L., \& Boulton, M. J. (2005). The social skills problems of victims of bullying: Self, peer and teacher perceptions. British Journal of Educational Psychology, 75(2), 313-328. https://doi. org/10.1348/000709905X25517

Fuligni, A. J., \& Eccles, J. S. (1993). Perceived parent-child relationships and early adolescents' orientation toward peers. Developmental Psychology, 29(4), 622-632.

Funk, J., Elliott, R., Bechtoldt, H., Pasold, T., \& Tsavoussis, A. (2003). The attitudes toward violence scale. Journal of Interpersonal Violence, 18, 186-196. https://doi.org/10.1177/0886260502 238734

-Garandeau, C. F., \& Lansu, T. A. M. (2019). Why does decreased likeability not deter adolescent bullying perpetrators? Aggressive Behavior, 45(3), 348-359. https://doi.org/10.1002/ab.21824

Garner, P. W., Jones, D. C., \& Miner, J. (1994). Social competence among low-income preschoolers: Emotion socialization practices and social cognitive correlates. Child Development, 65, 622-637.

-Garner, P. W., \& Lemerise, E. A. (2007). The roles of behavioral adjustment and conceptions of peers and emotions in preschool children's peer victimization. Development and Psychopathology, 19(1), 57-71. https://doi.org/10.1017/S0954579407070046

Garton, A. F., \& Gringart, E. (2005). The development of a scale to measure empathy in 8-and 9-year old children. Australian Journal of Education and Developmental Psychology, 5, 17-25.

-Gasser, L., \& Keller, M. (2009). Are the competent the morally good? Perspective taking and moral motivation of children involved in bullying. Social Development, 18(4), 798-816. https://doi.org/ 10.1111/j.1467-9507.2008.00516.x

-Giannotta, F., Settanni, M., Kliewer, W., \& Ciairano, S. (2012). The role of threat appraisal in the relation between peer victimization and adjustment problems in early Italian adolescents. Journal of Applied Social Psychology, 42(9), 2077-2095. https://doi.org/ 10.1111/j.1559-1816.2012.00931.x

Giletta, M., Slavich, G. M., Rudolph, K. D., Hastings, P. D., Nock, M. K., \& Prinstein, M. J. (2018). Peer victimization predicts heightened inflammatory reactivity to social stress in cognitively vulnerable adolescents. Journal of Child Psychology and Psychiatry, 59(2), 129-139. https://doi.org/10.1111/jcpp.12804

-Gini, G. (2006). Social cognition and moral cognition in bullying: What's wrong? Aggressive Behavior, 32, 528-539.

-Gini, G. (2008). Italian elementary and middle school students' blaming the victim of bullying and perception of school moral atmosphere. The Elementary School Journal, 108(4), 335-354.

-Goldstein, S. E., Lee, C. Y. S., Gunn, J. F., Bradley, S., Lummer, S., \& Boxer, P. (2020). Susceptibility to peer influence during middle school: Links with social support, peer harassment, and gender. Psychology in the Schools, 57(1), 91-110. https://doi. org/10.1002/pits.22309

•Gómez-Ortiz, O., Roldán, R., Ortega-Ruiz, R., \& García-López, L. J. (2018). Social anxiety and psychosocial adjustment in adolescents: Relation with peer victimization, self-esteem and emotion regulation. Child Indicators Research, 11(6), 1719-1736. https:// doi.org/10.1007/s12187-017-9506-3

González-Díez, Z., Orue, I., \& Calvete, E. (2017). The role of emotional maltreatment and looming cognitive style in the development of social anxiety symptoms in late adolescents. Anxiety, Stress and Coping, 30(1), 26-38. https://doi.org/10.1080/10615 806.2016.1188920

Gresham, F. M., \& Elliott, S. N. (1990). Social skills rating system. American Guidance Service.

Gresham, F. M., \& Elliott, S. N. (2008). Social skills improvement system: Rating scales manual. Minneapolis, MN: Pearson Assessments.

•Guo, S., Liu, J., \& Wang, J. (2021). Cyberbullying roles among adolescents: A social-ecological theory perspective. Journal of School Violence, 20(2), 167-181. https://doi.org/10.1080/15388 220.2020 .1862674

Güroğlu, B., \& Veenstra, R. (2021). Neural underpinnings of peer experiences and interactions: A review of social neuroscience. Merrill-Palmer Quarterly, 67(4), 416-455.

-Guy, A., Lee, K., \& Wolke, D. (2017). Differences in the early stages of social information processing for adolescents involved in bullying. Aggressive Behavior, 43, 578-587. https://doi.org/10.1002/ ab. 21716

Hanif, R., \& Smith, P. K. (2010). Perceptions, attitudes and experiences concerning bullying and school social climate: A comparison of Pakistan and England. In K. Österman (Ed.), Indirect and direct aggression (pp. 159-169). Peter Lang Publishing.

Happé, F., \& Frith, U. (2014). Annual research review: Towards a developmental neuroscience of atypical social cognition. Journal of Child Psychology and Psychiatry, 55(6), 553-577. https://doi. org/10.1111/jcpp.12162

-Harks, M., \& Hannover, B. (2020). Feeling socially embedded and engaging at school: The impact of peer status, victimization experiences, and teacher awareness of peer relations in class. 
European Journal of Psychology of Education, 35(4), 795-818. https://doi.org/10.1007/s10212-019-00455-3

Haynes, N. M., Emmons, C. L., \& Comer, J. P. (1993). Elementary and middle school climate survey. Yale University Child Study Center.

-Heinze, J. E., Miller, A. L., Seifer, R., Dickstein, S., \& Locke, R. L. (2015). Emotion knowledge, loneliness, negative social experiences, and internalizing symptoms among low-income preschoolers. Social Development, 24(2), 240-265. https://doi. org/10.1111/sode. 12083

Hinduja, S., \& Patchin, J. W. (2010). Bullying, cyberbullying, and suicide. Archives of Suicide Research, 14(3), 206-221. https:// doi.org/10.1080/13811118.2010.494133

Hinduja, S., \& Patchin, J. W. (2012). School climate 2.0: preventing cyberbullying and sexting one classroom at a time. California, USA: Corwin Press, Sage Publications.

Hogendoorn, S. M., Wolters, L. H., Vervoort, L., Prins, P. J. M., Boer, F., Kooij, E., \& de Haan, E. (2010). Measuring negative and positive thoughts in children: An adaptation of the Children's Automatic Thoughts Scale (CATS). Cognitive Therapy and Research, 34, 467-478. https://doi.org/10.1007/ s10608-010-9306-2

-Hoglund, W. L., \& Leadbeater, B. J. (2007). Managing threat: Do social-cognitive processes mediate the link between peer victimization and adjustment problems in early adolescence? Journal of Research on Adolescence, 17(3), 525-540. https://doi.org/10. 1111/j.1532-7795.2007.00533.x

-Holfeld, B., \& Baitz, R. (2020). The mediating and moderating effects of social support and school climate on the association between cyber victimization and internalizing symptoms. Journal of Youth and Adolescence, 49(11), 2214-2228. https://doi.org/10. 1007/s10964-020-01292-0

Hong, I. K., Wang, W., Pepler, D. J., \& Craig, W. M. (2018). Peer victimization through a trauma lens: Identifying who is at risk for negative outcomes. Scandinavian Journal of Psychology. https:// doi.org/10.1111/sjop.12488

•Hong, J. S., Ryou, B., Wei, H. S., Allen-Meares, P., \& Espelage, D. L. (2019). Identifying protective factors that potentially buffer the association between peer victimization and weapon-carrying behavior among US adolescents. School Psychology International, 40(4), 381-402. https://doi.org/10.1177/0143034319 843964

-Hong, J. S., Yan, Y., Gonzalez-Prendes, A. A., Espelage, D. L., \& Allen-Meares, P. (2021). Correlates of school bullying victimization among Black/White biracial adolescents: Are they similar to their monoracial Black and White peers? Psychology in the Schools, 58(3), 601-621. https://doi.org/10.1002/pits.22466

Hong Kong Education and Manpower Bureau. (2010). Assessment program for affective and social outcomes (2nd version). The Education \& Manpower Bureau.

-Hood, M., \& Duffy, A. L. (2018). Understanding the relationship between cyber-victimisation and cyber-bullying on social network sites: The role of moderating factors. Personality and Individual Differences, 133, 103-108. https://doi.org/10.1016/j.paid. 2017.04.004

Høst, K., Brugman, D., Tavecchio, L., \& Beem, L. (1998). Students' perception of the moral at- mosphere in secondary school and the relationship between moral competence and moral atmosphere. Journal of Moral Education, 27, 47-70.

Hoza, B., Bukowski, W., \& Pelham, W. E. (1990). Attributions and self-perceptions of ADHD and normal children: A comparative study. Unpublished manual.

•Hsieh, Y. P., Wei, H. S., Hwa, H. L., Shen, A. C. T., Feng, J. Y., \& Huang, C. Y. (2019). The effects of peer victimization on children's internet addiction and psychological distress: The moderating roles of emotional and social intelligence. Journal of Child and Family Studies, 28(9), 2487-2498. https://doi.org/10.1007/ s10826-018-1120-6

Huitsing, G., Lodder, G. M. A., Oldenburg, B., Schacter, H. L., Salmivalli, C., Juvonen, J., \& Veenstra, R. (2019). The healthy context paradox: Victims' adjustment during an anti-bullying intervention. Journal of Child and Family Studies, 28(9), 24992509. https://doi.org/10.1007/s10826-018-1194-1

•Hung, A. H., Cassedy, A., Schultz, H. M., Yeates, K. O., Taylor, H. G., Stancin, T., Walz, N. C., \& Wade, S. L. (2017). Predictors of long-term victimization after early pediatric traumatic brain injury. Journal of Developmental and Behavioral Pediatrics, 38(1), 49-57. https://doi.org/10.1097/DBP.0000000000000366

Hunt, C., Rapee, R. M., \& Peters, L. (2012). Development of a measure of the experience of being bullied in youth. Psychological Assessment, 24(1), 156-165. https://doi.org/10.1037/a0025178

•Hunter, S. C., Durkin, K., Heim, D., Howe, C., \& Bergin, D. (2010). Psychosocial mediators and moderators of the effect of peervictimization upon depressive symptomatology. Journal of Child Psychology and Psychiatry and Allied Disciplines, 51(10), 11411149. https://doi.org/10.1111/j.1469-7610.2010.02253.x

-Hussein, M. H. (2013). The social and emotional skills of bullies, victims, and bully-victims of Egyptian primary school children. International Journal of Psychology, 48(5), 910-921. https://doi. org/10.1080/00207594.2012.702908

Imuta, K., Henry, J. D., Slaughter, V., Selcuk, B., \& Ruffman, T. (2016). Theory of mind and prosocial behavior in childhood: A meta-analytic review. Developmental Psychology, 52(8), 11921205. https://doi.org/10.1037/dev0000140

Izard, C. E., Haskins, F. W., Schultz, D., Trentacosta, C. J., \& King, K. A. (2003). Emotion matching task. University of Delaware.

•Jenkins, L. N., Demaray, M. K., Fredrick, S. S., \& Summers, K. H. (2016). Associations among middle school students' bullying roles and social skills. Journal of School Violence, 15(3), 259278. https://doi.org/10.1080/15388220.2014.986675

*Jenkins, L. N., Demaray, M. K., \& Tennant, J. (2017). Social, emotional, and cognitive factors associated with bullying. School Psychology Review, 46(1), 42-64. https://doi.org/10.17105/ SPR46-1.42-64

-Jenkins, L. N., \& Nickerson, A. B. (2017). Bullying participant roles and gender as predictors of bystander intervention. Aggressive Behavior, 43(3), 281-290. https://doi.org/10.1002/ab.21688

Jolliffe, D., \& Farrington, D. P. (2006). Examining the relationship between low empathy and bullying. Aggressive Behavior, 32, 540-550. https://doi.org/10.1002/ab.20154

Katzer, C., Fetchenhauer, D., \& Belschak, F. (2009). Cyberbullying: Who are the victims? A comparison of victimization in internet chatrooms and victimization in school. Journal of Media Psychology: Theories, Methods, and Applications, 21, 25-36.

Kaufman, T. M. L., Kretschmer, T., Huitsing, G., \& Veenstra, R. (2018). Why does a universal anti-bullying program not help all children? Explaining persistent victimization during an intervention. Prevention Science, 19(6), 822-832. https://doi.org/10. 1007/s11121-018-0906-5

-Kaufman, T. M. L., Lee, H. Y., Benner, A. D., \& Yeager, D. S. (2020), How school contexts shape the relations among adolescents' beliefs, peer victimization, and depressive symptoms. Journal of Research on Adolescence, 30(3), 769-786. https://doi.org/10. $1111 /$ jora. 12558

Kaukiainen, A., Salmivalli, C., Lagerspetz, K., Tamminen, M., Vauras, M., Mäki, H., \& Poskiparta, E. (2002). Learning difficulties, social intelligence, and self-concept: Connections to bully-victim problems. Scandinavian Journal of Psychology, 43(3), 269-278. https://doi.org/10.1111/1467-9450.00295

-Kawabata, Y., Crick, N. R., \& Hamaguchi, Y. (2013). The association of relational and physical victimization with hostile attribution bias, emotional distress, and depressive symptoms: A 
cross-cultural study. Asian Journal of Social Psychology, 16(4), 260-270. https://doi.org/10.1111/ajsp.12030

-Kiekens, W., la Roi, C., Bos, H. M. W., Kretschmer, T., van Bergen, D. D., \& Veenstra, R. (2020). Explaining health disparities between heterosexual and LGB adolescents by integrating the minority stress and psychological mediation frameworks: Findings from the TRAILS study. Journal of Youth and Adolescence, 49(9), 1767-1782. https://doi.org/10.1007/s10964-020-01206-0

Kliewer, W., \& Sullivan, T. N. (2008). Community violence exposure, threat appraisal, and adjustment in adolescents. Journal of Clinical Child and Adolescent Psychology, 37, 860-873.

Kochenderfer, B. J., \& Ladd, G. W. (1997). Victimized children's responses to peers' aggression: Behaviors associated with reduced versus continued victimization. Developmental Psychopathology, 9, 59-73.

Kokkinos, C. M. (2007). Elementary school children's involvement in bullying and victimization: The role of attachment style and internalizing and externalizing symptomatology. Scientia Paedagogica Experimentalis XLIV, 1, 33-49.

-Kokkinos, C. M., \& Kipritsi, E. (2012). The relationship between bullying, victimization, trait emotional intelligence, self-efficacy and empathy among preadolescents. Social Psychology of Education, 15(1), 41-58. https://doi.org/10.1007/s11218-011-9168-9

Kokkinos, C. M., \& Logginidou, E. (2005, July). Perceived parental rearing behaviors among elementary school children involved in bullying and victimization. Paper presented at the 27th international school psychology association (ISPA) colloquium, Athens, Greece.

•Kokkinos, C. M., \& Voulgaridou, I. (2018). Relational victimization, callous-unemotional traits, and hostile attribution bias among preadolescents. Journal of School Violence, 17(1), 111-122. https://doi.org/10.1080/15388220.2016.1222500

Kunter, M. (2005). Multiple ziele im mathematikunterricht [Multiple goals in math class]. Waxmann.

Kusche, C. A., Greenberg, M. T., \& Beilke, B. (1988). The Kusche affective interview. Unpublished manuscript, Seattle, WA: University of Washington.

La Greca, A. M., \& Lopez, N. (1998). Social anxiety among adolescents: Linkages with peer relations and friendships. Journal of Abnormal Child Psychology, 26, 83-94.

La Greca, A. M., \& Stone, W. L. (1993). Social Anxiety Scale for Children - Revised: Factor structure and concurrent validity. Journal of Clinical Child Psychology, 22, 17-27. https://doi.org/ 10.1207/s15374424jccp2201_2

LaBar, K. S., \& Cabeza, R. (2006). Cognitive neuroscience of emotional memory. Nature Reviews Neuroscience, 7(1), 54-64. https://doi.org/10.1038/nrn1825

Ladd, G. W., \& Kochenderfer-Ladd, B. (2002). Identifying victims of peer aggression from early to middle childhood: Analysis of cross-informant data for concordance, estimation of relational adjustment, prevalence of victimization, and characteristics of identified victims. Psychological Assessment, 14, 74-96.

Ladd, G. W., \& Profilet, S. M. (1996). The child behavior scale: A teacher-report measure of young children's aggressive, withdrawn, and prosocial behaviors. Developmental Psychology, 32, $1008-1024$.

-Ladd, G. W., \& Troop-Gordon, W. (2003). The role of chronic peer difficulties in the development of children's psychological adjustment problems. Child Development, 74(5), 1344-1367. https:// doi.org/10.1111/1467-8624.00611

-Lansu, T. A. M., van Noorden, T. H. J., \& Deutz, M. H. F. (2017). How children's victimization relates to distorted versus sensitive social cognition: Perception, mood, and need fulfillment in response to cyberball inclusion and exclusion. Journal of
Experimental Child Psychology, 154, 131-145. https://doi.org/ 10.1016/j.jecp.2016.10.012

•Laurent, G., Hecht, H. K., Ensink, K., \& Borelli, J. L. (2018). Emotional understanding, aggression, and social functioning among preschoolers. American Journal of Orthopsychiatry, 90(1), 9-21. https://doi.org/10.1037/ort0000377

-Lázaro-Visa, S., Palomera, R., Briones, E., Fernández-Fuertes, A. A., \& Fernández-Rouco, N. (2019). Bullied adolescent's life satisfaction: Personal competencies and school climate as protective factors. Frontiers in Psychology. https://doi.org/10.3389/fpsyg. 2019.01691

•Leadbeater, B., Sukhawathanakul, P., Smith, D., \& Bowen, F. (2015). Reciprocal associations between interpersonal and values dimensions of school climate and peer victimization in elementary school children. Journal of Clinical Child and Adolescent Psychology, 44(3), 480-493. https://doi.org/10.1080/15374416. 2013.873985

Leahy, R. L., \& Rego, S. A. (2012). Cognitive Restructuring. In W. O’Donohue \& J. E. Fisher (Eds.), Cognitive Behavior Therapy: Core Principles for Practice (pp. 133-158). John Wiley \& Sons, Inc. https://doi.org/10.1002/9781118470886.ch6

•Lee, H. Y., Jamieson, J. P., Reis, H. T., Beevers, C. G., Josephs, R. A., Mullarkey, M. C., O’Brien, J. M., \& Yeager, D. S. (2020). Getting fewer "Likes" than others on social media elicits emotional distress among victimized adolescents. Child Development, 91(6), 2141-2159. https://doi.org/10.1111/cdev.13422

•Leff, S. S., Baker, C. N., Waasdorp, T. E., Vaughn, N. A., Bevans, K. B., Thomas, N. A., Guerra, T., Hausman, A. J., \& Monopoli, W. J. (2014). Social cognitions, distress, and leadership self-efficacy: Associations with aggression for high-risk minority youth. Development and Psychopathology, 26(3), 759-772. https://doi. org/10.1017/S0954579414000376

Leff, S. S., Crick, N. R., Angelucci, J., Haye, K., Jawad, A. F., Grossman, M., et al. (2006). Social cognition in context: Validating a cartoon-based attributional measure for urban girls. Child Development, 77, 1351-1358. https://doi.org/10.1111/j.14678624.2006.00939.x

Leff, S. S., Lefler, E., Khera, G., Paskewich, B., \& Jawad, A. (2011). Preliminary examination of a cartoon-based hostile attributional bias measure for urban African American boys. American Journal of Community Psychology. Advance online publication. https://doi.org/10.1007/s10464-011-9461-y

Leff, S. S., Thomas, D. E., Vaughn, N. A., Thomas, N. A., MacEvoy, J. P., Freedman, M. A., et al. (2010). Using community-based participatory research to develop the PARTNERS youth violence prevention program. Progress in Community Health Partnerships: Research, Education, and Action, 4, 207-216. https://doi. org/10.1353/cpr.2010.0005

Lereya, S. T., Copeland, W. E., Zammit, S., \& Wolke, D. (2015). Bully/victims: A longitudinal, population-based cohort study of their mental health. European Child and Adolescent Psychiatry, 24(12), 1461-1471. https://doi.org/10.1007/s00787-015-0705-5

Lieberman, M. D., Eisenberg, N. I., Crockett, M. J., Tom, S. M., Pfeifer, J. H., \& Way, B. M. (2007). Putting feelings into words: Affect labeling disrupts amygdala activity in response to affective stimuli. Psychological Science, 18(5), 421-428.

Lindenberg, S. (1996). Continuities in the theory of social production functions. In H. Ganzeboom \& S. Lindenberg (Eds.), Verklarende Sociologie: Opstellen voor Reinhard Wippler (pp. 169184). Amsterdam: Thela Thesis.

Lopez, C. (1997). Peer victimization: Preliminary validation of a multidimensional self-report measure for children and young adolescents. Unpublished Master's thesis, University of Missouri-Columbia. 
López-Pérez, B., Fernández-Pinto, I., \& Abad, F.J. (2008). TECA, Test. de Empatía Cognitiva y Afectiva. Tea Ediciones: Madrid, Spain.

Luebbers, S., Downey, L. A., \& Stough, C. (2007). The development of an adolescent measure of EI. Personality and Individual Differences, 42, 999-1009.

Mantz, L. S., Bear, G. G., Yang, C., \& Harris, A. (2018). The Delaware social-emotional competency scale (DSECS-S): Evidence of validity and reliability. Child Indicators Research, 11(1), 137-157. https://doi.org/10.1007/s12187-016-9427-6

-Malti, T., Perren, S., \& Buchmann, M. (2010). Children's peer victimization, empathy, and emotional symptoms. Child Psychiatry and Human Development, 41(1), 98-113. https://doi.org/10. 1007/s10578-009-0155-8

-Martínez, J., Rodríguez-Hidalgo, A. J., \& Zych, I. (2020). Bullying and cyberbullying in adolescents from disadvantaged areas: Validation of questionnaires; prevalence rates; and relationship to self-esteem, empathy and social skills. International Journal of Environmental Research and Public Health, 17, 6199. https:// doi.org/10.3390/ijerph17176199

Masten, A. S., Morrison, P., \& Pellegrini, D. S. (1985). A revised class play method of peer assessment. Developmental Psychology, 3, 523-533.

-Mathieson, L. C., Murray-Close, D., Crick, N. R., Woods, K. E., Zimmer-Gembeck, M., Geiger, T. C., \& Morales, J. R. (2011). Hostile intent attributions and relational aggression: The moderating roles of emotional sensitivity, gender, and victimization. Journal of Abnormal Child Psychology, 39(7), 977-987. https:// doi.org/10.1007/s10802-011-9515-5

McIver, T. A., Bosma, R. L., Sandre, A., Goegan, S., Klassen, J. A., Chiarella, J., Booij, L., \& Craig, W. (2018). Peer victimization is associated with neural response to social exclusion. MerrillPalmer Quarterly, 64(1), 135-161.

-McQuade, J. D., Murray-Close, D., Breslend, N. L., Balda, K. E., Kim, M. M., \& Marsh, N. P. (2019). Emotional underarousal and overarousal and engagement in relational aggression: Interactions between relational victimization, physiological reactivity, and emotional sensitivity. Journal of Abnormal Child Psychology, 47(10), 1663-1676. https://doi.org/10.1007/s10802-019-00544-3

Measelle, J. R., Ablow, J. C., Cowan, P. A., \& Cowan, C. P. (1998). Assessing young children's views of their academic, social, and emotional lives: An evaluation of the self-perception scales of the Berkeley Puppet Interview. Child Development, 69, 1556-1576.

Mehrabian, A., \& Epstein, N. (1972). A measure of emotional empathy. Journal of Personality, 40, 525-543.

Mendoza, B., Cervantes, A., Pedroza, F. J., \& Aguilera, S. J. (2015). Estructura factorial y consistencia interna del Cuestionario para medir Bullying y Vio- lencia Escolar [Factorial structure and internal consistency of the Questionnaire to measure Bullying and School Violence]. Revista Ciencia UAT, 10(1), 6-16.

•Mendoza-González, B., Nieto, I. D., \& Mandujano, M. A. G. (2020). Student profile not involved in bullying: Description based on gender stereotypes, parenting practices, cognitive-social strategies and food over-intake. Anales De Psicologia, 36(3), 483-491. https://doi.org/10.6018/analesps.337011

Menesini, E., Calussi, P., \& Nocentini, A. (2012). Cyberbullying and traditional bullying: unique, additive and synergistic effects on psychological health symptoms. In Q. Li, D. Cross, \& P. K. Smith (Eds.), Cyberbullying in the global playground: Research from international perspectives (pp. 245e262). London: Wiley-Blackwell.

Menesini, E., Nocentini, A., \& Calussi, P. (2011). The measurement of cyberbullying: Dimensional structure and relative item severity and discrimination. Cyberpsychology, Behavior, and Social Networking, 14, 267-274.

-Mertens, E. C. A., Deković, M., Van Londen, M., \& Reitz, E. (2021). The role of classmates' modeling and reinforcement in adolescents' perceived classroomp peer context. Journal of Youth and Adolescence, 50(2), 260-270. https://doi.org/10.1007/ s10964-020-01325-8

-Miller, A. L., Gouley, K. K., Seifer, R., Zakriski, A., Eguia, M., \& Vergnani, M. (2005). Emotion knowledge skills in low-income elementary school children: Associations with social status and peer experiences. Social Development, 14(4), 637-651. https:// doi.org/10.1111/j.1467-9507.2005.00321.x

Miller-Johnson, S., Sullivan, T. N., Simon, T. R., The Multisite Violence Prevention Project. (2004). Evaluating the impact of interventions in the multisite violence prevention study: Samples, procedures, and measures. American Journal of Preventive Medicine, 26, 48-61. https://doi.org/10.1016/j.amepre.2003.09.015

Moher, D., Liberati, A., Tetzlaff, J., \& Altman, D. G. (2009). Preferred reporting items for systematic reviews and meta-analyses: The PRISMA statement. BMJ, 339(7716), 332-336. https://doi.org/ 10.1136/bmj.b2535

•Monks, C. P., Smith, P. K., \& Swettenham, J. (2005). Psychological correlates of peer victimisation in preschool: Social cognitive skills, executive function and attachment profiles. Aggressive Behavior, 31(6), 571-588. https://doi.org/10.1002/ab.20099

Moraleda, M., González, A., \& García-Gallo, J. (1998). AECS, Actitudes y Estrategias Cognitivas Sociales [AECS, Social Cognitive Strategies and Attitudes]. Madrid, España: TEA Ediciones.

-Morrow, M. T., Hubbard, J. A., \& Sharp, M. K. (2019). Preadolescents' internal attributions for negative peer experiences: Links to child and classroom peer victimization and friendship. Journal of Abnormal Child Psychology, 47(3), 393-404. https://doi.org/ 10.1007/s10802-018-0460-4

•Moyano, N., Ayllón, E., Antoñanzas, J. L., \& Cano, J. (2019). Children's social integration and low perception of negative relationships as protectors against bullying and cyberbullying. Frontiers in Psychology, 10, 643. https://doi.org/10.3389/fpsyg.2019. 00643

Muris, P., Meesters, C., de Kanter, E., \& Timmerman, P. E. (2005). Behavioural inhibition and behavioural activation system scales for children: Relationships with Eysenck's personality traits and psychopathological symptoms. Personality and Individual Differences, 38(4), 831-841. https://doi.org/10.1016/j.paid.2004. 06.007

Mynard, H., \& Joseph, S. (1997). Bully/victim problems and their association with Eysenck's personality dimensions in 8 to 13 yearolds. The British Journal of Educational Psychology, 67, 51-54.

Muetzel, R. L., Mulder, R. H., Lamballais, S., Hidalgo, A. P. C., Jansen, P., Güroğlu, B., Vernooiji, M. W., Hillegers, M., White, T., El Marroun, H., \& Tiemeier, H. (2019). Frequent bullying involvement and brain morphology in children. Frontiers in Psychiatry. https://doi.org/10.3389/fpsyt.2019.00696

•Nasaescu, E., Marín-López, I., Llorent, V. J., Ortega-Ruiz, R., \& Zych, I. (2018). Abuse of technology in adolescence and its relation to social and emotional competencies, emotions in online communication, and bullying. Computers in Human Behavior, 88, 114-120. https://doi.org/10.1016/j.chb.2018.06.036

Nickerson, A. B., Singleton, D., Schnurr, B., \& Collen, M. H. (2014). Perceptions of school climate as a function of bullying involvement. Journal of Applied School Psychology, 30, 157-181. https://doi.org/10.1080/15377903.2014.888530

Nowicki, S. (2013). Manual for the receptive tests of the diagnostic analysis of nonverbal accuracy 2 (DANVA2). Unpublished manuscript, Emory University, Atlanta, Georgia.

Nowicki, S., \& Duke, M. P. (1994). Individual differences in the nonverbal communication of affect: The diagnostic analysis of nonverbal accuracy scale. Journal of Nonverbal Behavior, 18, 9-35.

-Ogelman, H. G., \& Seven, S. (2012). The effect social information processing in six-year-old children has on their social competence and peer relationships. Early Child Development and 
Care, 182(12), 1623-1643. https://doi.org/10.1080/03004430. 2011.636810

Oliva Delgado, A., Antolín Suárez, L., Pertegal Vega, M. Á., Ríos Bermúdez, M., Parra Jiménez, Á., Hernando Gómez, Á., del Carmen Reina Flores, M. (2011). Instrumentos para la evaluación de la salud mental y el desarrollo positivo adolescente y los activos que lo promueven. Seville, Spain: Junta de Andalucía. Consejería de Salud. Retrived from http://www.formajoven.org/AdminFJ/ doc_recursos/201241812465364.pdf

Olweus, D. (1991). Bully/victim problems among schoolchildren: Basic facts and effects of a school based intervention program. In D. Papler, \& K. Rubin (Eds.), The developmental and treatment of childhood aggression. Hillsdale, $\mathrm{NJ}$ : Lawrence Edbaum.

Olweus, D. (1993). Bullying at school. Blackwell.

Olweus, D. (1996). The Revised Olweus Bully/Victim Questionnaire. Mimeo. Bergen, Norway: Research Center for Health Promotion (HEMIL Center), University of Bergen.

Ormel, J., Lindenberg, S., Steverink, N., \& Vonkorff, M. (1997). Quality of life and social production functions: A framework for understanding health effects. Social Science and Medicine, $45,1051-1063$.

Orpinas, P., \& Kelder, S. (1995). Students for Peace Project: Second student evaluation. Unpublished manuscript, University of Texas Health Science Center at Houston, School of Public Health, Houston, TX.

Ortega-Ruiz, R., Del Rey, R., \& Casas, J. A. (2016). Evaluar el bullying y el cyberbullying validación española del EBIP-Q y del ECIPQ. Psicología Educativa, 22, 71-79. https://doi.org/10.1016/j. pse.2016.01.004

Ostrom, T. M. (1984). The sovereignty of social cognition. In R. S. Wyer \& T. K. Srull (Eds.), Handbook of Social Cognition (1st ed., pp. 1-38). Lawrence Erlbaum Associates Publicers.

Oude Nijhuis, M. (2001). Pesten als groepsproces. Een onderzoek naar validering van de Participant Role Scales. [Bullying as a group process. A study into the validity of the Participant Role Scales]. Unpublished master's thesis, Free University, Amsterdam, The Netherlands.

Overgaauw, S., Rieffe, C., Broekhof, E., Crone, E. A., \& Güroğlu, B. (2017). Assessing empathy across childhood and adolescence: Validation of the empathy questionnaire for children and adolescents (EmQue-CA). Frontiers in Psychology, 8, 870-870. https:// doi.org/10.3389/fpsyg.2017.00870

-Pabian, S. (2019). An investigation of the effectiveness and determinants of seeking support among adolescent victims of cyberbullying. Social Science Journal, 56(4), 480-491. https://doi.org/ 10.1016/j.soscij.2018.09.011

Parada, R. (2000). Adolescent Peer Relations Instrument: A theoretical and Empirical Basis for the Measurement of Participant Roles. In Bullying and Victimisation of Adolescence: An Interim Test Manual and a Research Monograph: A Test Manual. Penright South: Publication Unit, Self-concept Enhancement and Learning Facilitation (SELF) Research Centre, University of Western Sydney.

Perren, S., \& Alsaker, F. D. (2006). Social behavior and peer relationships of victims, bully-victims, and bullies in kindergarten. Journal of Child Psychology and Psychiatry and Allied Disciplines, 47(1), 45-57. https://doi.org/10.1111/j.1469-7610.2005.01445.x

Perner, J., Leekam, S. R., \& Wimmer, H. (1987). 2-year-olds difficulty with false belief-The case for a conceptual deficit. British Journal of Developmental Psychology, 5, 125-137.

Perren, S., Stadelmann, S., Lüdin, J., von Wyl, A., \& von Klitzing, K. (2008). Kindergartenkinder schätzen ihre symptome und stärken ein: Das Berkeley Puppet Interview in forschung und praxis [kindergarten children report their symptoms and strengths: The
Berkeley Puppet Interview in research and practice]. Kinderanalyse, 16(1), 1-22.

Perner, J., \& Wimmer, H. (1985). "John thinks that Mary thinks that..." attribution of second-order beliefs by 5- to 10-year-old children. Journal of Experimental Child Psychology, 39, 437-471.

-Perren, S., Ettekal, I., \& Ladd, G. (2013). The impact of peer victimization on later maladjustment: Mediating and moderating effects of hostile and self-blaming attributions. Journal of Child Psychology and Psychiatry and Allied Disciplines, 54(1), 46-55. https://doi.org/10.1111/j.1469-7610.2012.02618.x

Pickett, C. L., \& Gardner, W. L. (2005). The social monitoring system: Enhanced sensitivity to social cues and information as an adaptive response to social exclusion and belonging need. In $\mathrm{K}$. D. Williams, J. P. Forgas, \& W. von Hippel (Eds.), The social outcast: Ostracism, social exclusion, rejection, and bullying (pp. 213-226). Psychology Press.

•Pistella, J., Zava, F., Sette, S., Baumgartner, E., \& Baiocco, R. (2020). Peer victimization, social functioning, and temperament traits in preschool children: The role of gender, immigrant status and sympathy. Child Indicators Research, 13(6), 2135-2156. https:// doi.org/10.1007/s12187-020-09736-6

Pons, F., \& Harris, P. (2000). Test of Emotion Comprehension-TEC. Oxford University Press.

•Pornari, C. D., \& Wood, J. (2010). Peer and cyber aggression in secondary school students: The role of moral disengagement, hostile attribution bias, and outcome expectancies. Aggressive Behavior, 36, 81-94.

Pouwels, J. L., Lansu, T. A. M., \& Cillessen, A. H. N. (2016). Participant roles of bullying in adolescence: Status characteristics, social behavior, and assignment criteria. Aggressive Behavior, 42, 239-253.

•Pouwels, J. L., Lansu, T. A. M., \& Cillessen, A. H. N. (2017). Adolescents' explicit and implicit evaluations of hypothetical and actual peers with different bullying participant roles. Journal of Experimental Child Psychology, 159, 219-241. https://doi.org/ 10.1016/j.jecp.2017.02.008

•Pouwels, J. L., Scholte, R. H. J., van Noorden, T. H. J., \& Cillessen, A. H. N. (2016). Interpretations of bullying by bullies, victims, and bully-victims in interactions at different levels of abstraction. Aggressive Behavior, 42(1), 54-65. https://doi.org/10.1002/ab. 21605

•Pozzoli, T., Gini, G., \& Altoè, G. (2017). Associations between facial emotion recognition and young adolescents' behaviors in bullying. PLoS ONE, 12(11), 1-23. https://doi.org/10.1371/journal. pone. 0188062

Prinstein, M. J., Boergers, J., \& Vernberg, E. M. (2001). Overt and relational aggression in adolescents: Social- psychological adjustment of aggressors and victims. Journal of Clinical Child Psychology, 30, 479-491.

•Prinstein, M. J., Cheah, C. S. L., \& Guyer, A. E. (2005). Peer victimizaiton, cue interpretation, and internalizing symptoms: Preliminary concurrent and longitudinal findings for children and adolescents. Journal of Clinical Child \& Adolescent Psychology, 34(1), 11-24. https://doi.org/10.1207/s15374424jccp3401_2

•Purcell, V. L., Andrews, J. J. W., \& Nordstokke, D. (2021). Peer victimization and anxiety in youth: A moderated mediation of peer perceptions and social self-efficacy. Canadian Journal of School Psychology, 36(1), 9-22. https://doi.org/10.1177/08295 73520951041

Rabiner, D. L., Keane, S. P., \& MacKinnon-Lewis, C. (1993). Children's beliefs about familiar and unfamiliar peers in relation to their sociometric status. Developmental Psychology, 29, 236-243.

Raine, A., \& Chen, F. R. (2018). The cognitive, affective, and somatic empathy scales (CASES) for children. Journal of Clinical Child 
\& Adolescent Psychology, 47(1), 24-37. https://doi.org/10.1080/ 15374416.2017.1295383

Rapee, R. M., \& Heimberg, R. G. (1997). A cognitive-behavioral model of anxiety in social phobia. Behaviour Research and Therapy, 35, 741-756.

Rauer, W., \& Schuck, K. D. (2003). FEESS 3-4: Fragebogen zur Erfassung emotionaler und sozialer Schulerfahrungen von Grundschulkindern dritter und vierter Klassen. Manual [questionnaire for emotional and social school experiences of elementary school students]. Goettingen, Germany: Beltz Test. https://doi.org/10. 1024/1422-4917/a000363

-Renouf, A., Brendgen, M., Séguin, J. R., Vitaro, F., Boivin, M., Dionne, G., Tremblay, R. E., \& Pérusse, D. (2010). Interactive links between theory of mind, peer victimization, and reactive and proactive aggression. Journal of Abnormal Child Psychology, 38, 1109-1123. https://doi.org/10.1007/s10802-010-9432-z

Rieffe, C., Oosterveld, P., Miers, A. C., Meerum Terwogt, M. M., \& Ly, V. (2008). Emotion awareness and internalizing symptoms in children and adolescents: The emotion awareness questionnaire revised. Personality and Individual Differences, 45, 756-761. https://doi.org/10.1016/j.paid.2008.08.001

Rigby, K. (1997). Bullying in schools: And what to do about it. Jessica Kingsley.

Rigby, K., \& Slee, P. T. (1991). Bullying among Australian school children: Reported behavior and attitudes toward victims. The Journal of Social Psychology, 13, 615-627.

Rigby, K., \& Slee, P. T. (1993). Dimensions of interpersonal relation among Australian children and implications for psychological well-being. The Journal of Social Psychology, 133, 33-42.

Riskind, J. H., Williams, N. L., Gessner, T. L., Chrosniak, L. D., \& Cortina, J. M. (2000). The looming maladaptive style: Anxiety, danger, and schematic processing. Journal of Personality and Social Psychology, 79, 837-852. https://doi.org/10.1037/00223514.79.5.837

Roberts, C., Freeman, J., Samdal, O., Schnohr, C., Looze, M., Gabhainn, S. N., \& Iannotti, R. (2010). The Health Behaviour in School-aged Children (HBSC) study: Methodological developments and current tensions. International Journal of Public Health, 54, 140-150. https://doi.org/10.1007/s00038-009-5405-9

Roberts, W., Horn, A., \& Battistich, V. (1995, April). Assessing students' and teachers' sense of the school as a caring community. Paper presented at the meeting of the American Educational Research Association, San Francisco, CA.

*Röder, M., \& Müller, A. R. (2020). Social competencies and expectations regarding the impending transition to secondary school. International Journal of Educational Psychology, 9(1), 82-102. https://doi.org/10.17583/ijep.2020.4463

-Rodríguez-Hidalgo, A. J., Pantaleón, Y., \& Calmaestra, J. (2019). Psychological predictors of bullying in adolescents from pluricultural schools: A transnational study in Spain and Ecuador. Frontiers in Psychology, 10, 1383. https://doi.org/10.3389/fpsyg. 2019.01383

-Rodríguez-Hidalgo, A. J., Solera, E., \& Calmaestra, J. (2018). Psychological predictors of cyberbullying according to ethnic-cultural origin in adolescents: A national study in Spain. Journal of Cross-Cultural Psychology, 49(10), 1506-1522. https://doi.org/ $10.1177 / 0022022118795283$

Roozendaal, B., \& Mcgaugh, J. L. (2012). Memory modulation. Behavioral Neuroscience, 125(6), 797-824. https://doi.org/10.1037/ a0026187.MEMORY

$\bullet$ Rosen, P. J., Milich, R., \& Harris, M. J. (2007). Victims of their own cognitions: Implicit social cognitions, emotional distress, and peer victimization. Journal of Applied Developmental Psychology, 28(3), 211-226. https://doi.org/10.1016/j.appdev.2007.02. 001
•Rotenberg, K. J., \& Boulton, M. (2013). Interpersonal trust consistency and the quality of peer relationships during childhood. Social Development, 22(2), 225-241. https://doi.org/10.1111/ sode. 12005

Rotenberg, K. J., Boulton, M. J., \& Fox, C. L. (2005). Cross-Sectional and longitudinal relations among children's trust beliefs, psychological maladjustment and social relationships: Are very high as well as very low trusting children at risk? Journal of Abnormal Child Psychology, 33(5), 595-610.

•Rowe, S. L., Zimmer Gembeck, M. J., Rudolph, J., \& Nesdale, D. (2015). A longitudinal study of rejecting and autonomyrestrictive parenting, rejection sensitivity, and socioemotional symptoms in early adolescents. Journal of Abnormal Child Psychology, 43(6), 1107-1118. https://doi.org/10.1007/ s10802-014-9966-6

-Rudolph, K. D. (2010). Implicit theories of peer relationships. Social Development, 19(1), 113-129. https://doi.org/10.1111/j.14679507.2008.00534.x

-Rudolph, K. D., Miernicki, M. E., Troop-Gordon, W., Davis, M. M., \& Telzer, E. H. (2016). Adding insult to injury: Neural sensitivity to social exclusion is associated with internalizing symptoms in chronically peer-victimized girls. Social Cognitive and Affective Neuroscience, 11(5), 829-842. https://doi.org/10.1093/scan/ nsw021

-Rudolph, K. D., Skymba, H. V., Modi, H. H., Davis, M. M., Yan Sze, W., Rosswurm, C. P., \& Telzer, E. H. (2021). How does peer adversity "Get inside the brain?" Adolescent girls' differential susceptibility to neural dysregulation of emotion following victimization. Developmental Psychobiology, 63(3), 481-495. https://doi.org/10.1002/dev.22022

$\bullet$ Rudolph, K. D., Troop-Gordon, W., \& Flynn, M. (2009). Relational victimization predicts children's social-cognitive and self-regulatory responses in a challenging peer context. Developmental Psychology, 45(5), 1444-1454. https://doi.org/10.1037/a0014858

•Sainio, M., Veenstra, R., Little, T. D., Kärnä, A., Rönkkö, M., \& Salmivalli, C. (2013). Being bullied by same- versus other-sex peers: Does it matter for adolescent victims? Journal of Clinical Child and Adolescent Psychology, 42(4), 454-466. https://doi. org/10.1080/15374416.2013.769172

Salmivalli, C. (2010). Bullying and the peer group: A review. Aggression and Violent Behavior, 15(2), 112-120. https://doi.org/10. 1016/j.avb.2009.08.007

-Salmivalli, C., \& Isaacs, J. (2005). Prospective relations among victimization, rejection, friendlessness, and children's self- And peer-perceptions. Child Development, 76(6), 1161-1171. https:// doi.org/10.1111/j.1467-8624.2005.00841.x-i1

Salmivalli, C., Lagerspetz, K., Björkqvist, K., Österman, K., \& Kaukiainen, A. (1996). Bullying as a group process: Participant roles and their relations to social status within the group. Aggressive Behavior, 22, 1-15.

Salmivalli, C., Ojanen, T., Haanpää, J., \& Peets, K. (2005). "I'm OK but you're not" and other peer-relational schemas: Explaining individual differences in children's social goals. Developmental Psychology, 41(2), 363-375.

Salmivalli, C., \& Voeten, M. (2004). Connections between attitudes, group norms, and behaviour in bullying situations. International Journal of Behavioral Development, 28, 246-258.

-Schacter, H. L., \& Juvonen, J. (2018). You've got a friend(ly school): Can school prosocial norms and friends similarly protect victims from distress? Social Development, 27(3), 636-651. https://doi. org/10.1111/sode.12281

-Schwartz, D., Dodge, K. A., Coie, J. D., Hubbard, J. A., Cillessen, A. H. N., Lemerise, E. A., \& Bateman, H. (1998). Social-cognitive and behavioral correlates of aggression and victimization in boys' play groups. Journal of Abnormal Child Psychology, 26(6), 431-440. https://doi.org/10.1023/A:1022695601088 
Sebastian, C., Viding, E., Williams, K. D., \& Blakemore, S.-J. (2010). Social brain development and the affective consequences of ostracism in adolescence. Brain and Cognition, 72(1), 134-145. https://doi.org/10.1016/j.bandc.2009.06.008

-Shakoor, S., Jaffee, S. R., Bowes, L., Ouellet-Morin, I., Andreou, P., Happé, F., Moffitt, T. E., \& Arseneault, L. (2012). A prospective longitudinal study of children's theory of mind and adolescent involvement in bullying. Journal of Child Psychology and Psychiatry, 53(3), 254-261. https://doi.org/10.1111/j.1469-7610. 2011.02488.x

Silvera, D., Martinussen, M., \& Dahl, T. I. (2001). The Troms $\varnothing$ social intelligence scale, a self-report measure of social intelligence. Scandinavian Journal of Psychology, 42, 313-319.

Sirsch, U. (2003). The impending transition from primary to secondary school: Challenge or threat? International Journal of Behavioral Development, 27, 385-395. https://doi.org/10.1080/0165025034 4000082

-Smalley, D., \& Banerjee, R. (2014). The role of social goals in bullies' and victims' social information processing in response to ambiguous and overtly hostile provocation. Social Development, 23(3), 593-610. https://doi.org/10.1111/sode.12067

-Smorti, A., \& Ciucci, E. (2000). Narrative strategies in bullies and victims in Italian schools. Aggressive Behavior, 26(1), 33-48. https://doi.org/10.1002/(SICI)1098-2337(2000)26:1\%3c33:: AID-AB3\%3e3.0.CO;2-Y

Solberg, M. E., \& Olweus, D. (2003). Prevalence estimation of school bullying with the Olweus bully/victim questionnaire. Aggressive Behavior, 29(3), 239-268. https://doi.org/10.1002/ab.10047

Spithoven, A. W. M., Bijttebier, P., \& Goossens, L. (2017). It is all in their mind: A review on information processing bias in lonely individuals. Clinical Psychology Review, 58, 97-114. https://doi. org/10.1016/j.cpr.2017.10.003

-Stubbs-Richardson, M., \& May, D. C. (2020). Social contagion in bullying: An examination of strains and types of bullying victimization in peer networks. American Journal of Criminal Justice. https://doi.org/10.1007/s12103-020-09572-y

Sullivan, T. N., Farrell, A. D., \& Kliewer, W. (2006). Peer victimization in early adolescence: Associations between physical and relational victimization and drug use, aggression, and delinquent behaviors among urban middle school students. Development and Psychopathology, 18, 119-137. https://doi.org/10.1017/ S095457940606007X

Summers, K. H., \& Demaray, M. K. (2008). Bully Participant Role Survey. IL, Northern Illinois University.

Takšíc, V., Mohoriæ, T., \& Duran, M. (2009). Emotional skills and competence questionnaire (ESCQ) as a self-report measure of emotional intelligence [Vprašalnik emocionalne inteligentnosti ESCQ kot samoocenjevalna mera emocionalne inteligentnosti]. Horizons of Psychology, 18, 7-21.

Tarshis, T. P., \& Huffman, L. C. (2007). Psychometric properties of the peer interactions in primary school (PIPS) questionnaire. Journal of Development \& Behavioral Pediatrics, 28, 125-132.

-Taylor, K. A., Sullivan, T. N., \& Kliewer, W. (2013). A longitudinal path analysis of peer victimization, threat appraisals to the self, and aggression, anxiety, and depression among urban African American adolescents. Journal of Youth and Adolescence, 42(2), 178-189. https://doi.org/10.1007/s10964-012-9821-4

Telzer, E. H. (2016). Dopaminergic reward sensitivity can promote adolescent health: A new perspective on the mechanism of ventral striatum activation. Developmental Cognitive Neuroscience, 17, 57-67. https://doi.org/10.1016/j.den.2015.10.010

-Telzer, E. H., Fowler, C. H., Davis, M. M., \& Rudolph, K. D. (2020). Hungry for inclusion: Exposure to peer victimization and heightened social monitoring in adolescent girls. Development and Psychopathology, 32(4), 1495-1508. https://doi.org/10.1017/S0954 579419001433
Thompson, D., Arora, T., \& Sharp, S. (2002). Bullying: Effective strategies for long-term improvement. Routledge.

Thornberg, R. (2010). Schoolchildren's social representions on bullying causes. Psychology in the Schools, 47(4), 311-327. https://doi. org/10.1002/pits.20472

Tops, M., Riese, H., Oldehinkel, A. J., Rijsdijk, F. V., \& Ormel, J. (2008). Rejection sensitivity relates to hypocortisolism and depressed mood state in young women. Psychoneuroendocrinology, 33(5), 551-559.

Trevisan, D. A., \& Birmingham, E. (2016). Are emotion recognition abilities related to everyday social functioning in ASD? A metaanalysis. Research in Autism Spectrum Disorders, 32, 24-42. https://doi.org/10.1016/j.rasd.2016.08.004

-Troop-Gordon, W., Gordon, R. D., Schwandt, B. M., Horvath, G. A., Ewing Lee, E., \& Visconti, K. J. (2019). Allocation of attention to scenes of peer harassment: Visual-cognitive moderators of the link between peer victimization and aggression. Development and Psychopathology, 31(2), 525-540. https://doi.org/10.1017/ S0954579418000068

-Troop-Gordon, W., \& Ladd, G. W. (2005). Trajectories of peer victimization and perceptions of the self and schoolmates: Precursors to internalizing and externalizing problems. Child Development, 76(5), 1072-1091.

Ttofi, M. M., \& Farrington, D. P. (2011). Effectiveness of school-based programs to reduce bullying: A systematic and meta-analytic review. Journal of Experimental Criminology, 7(1), 27-56. https://doi.org/10.1007/s11292-010-9109-1

Uçanok, Z., Karasoy, D., \& Durmuş, E., (2011). Yeni bir akran

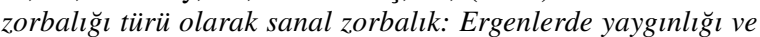
önemi (108K424 no'lu TUBİTAK Projesi).

Van Bavel, J. J., Packer, D. J., \& Cunningham, W. A. (2011). Modulation of the fusiform face area following minimal exposure to motivationally relevant faces: Evidence of in-group enhancement (not out-group disregard). Journal of Cognitive Neuroscience, 23, 3343-3354. https://doi.org/10.1162/jocn_a_00016

Vaillancourt, T., Hymel, S., \& McDougall, P. (2013). The biological underpinnings of peer victimization: Understanding why and how the effects of bullying can last a lifetime. Theory into Practice, 52(4), 241-248. https://doi.org/10.1080/00405841.2013. 829726

-van der Ploeg, R., Kretschmer, T., Salmivalli, C., \& Veenstra, R. (2017). Defending victims: What does it take to intervene in bullying and how is it rewarded by peers? Journal of School Psychology, 65(2015), 1-10. https://doi.org/10.1016/j.jsp.2017. 06.002

•van Dijk, A., Poorthuis, A. M. G., \& Malti, T. (2017). Psychological processes in young bullies versus bully-victims. Aggressive Behavior, 43(5), 430-439. https://doi.org/10.1002/ab.21701

-van Noorden, T. H. J., Bukowski, W. M., Haselager, G. J. T., Lansu, T. A. M., \& Cillessen, A. H. N. (2016). Disentangling the frequency and severity of bullying and victimization in the association with empathy. Social Development, 25(1), 176-192. https://doi.org/ $10.1111 /$ sode. 12133

•van Noorden, T. H. J., Cillessen, A. H. N., Haselager, G. J. T., Lansu, T. A. M., \& Bukowski, W. M. (2017). Bullying involvement and empathy: Child and target characteristics. Social Development, 26(2), 248-262. https://doi.org/10.1111/sode.12197

•van Noorden, T. H. J., Haselager, G. J. T., Cillessen, A. H. N., \& Bukowski, W. M. (2014). Dehumanization in children: The link with moral disengagement in bullying and victimization. Aggressive Behavior, 40(4), 320-328. https://doi.org/10.1002/ab.21522

•van Noorden, T. H. J., Haselager, G. J. T., Lansu, T. A. M., Cillessen, A. H. N., \& Bukowski, W. M. (2016). Attribution of human characteristics and bullying involvement in childhood: Distinguishing between targets. Aggressive Behavior, 42(4), 394-403. https:// doi.org/10.1002/ab.21634 
van Reemst, L., Fischer, T. F. C., \& Zwirs, B. W. C. (2016). Social information processing mechanisms and victimization: A literature review. Trauma, Violence, and Abuse, 17(1), 3-25. https:// doi.org/10.1177/1524838014557286

Vernberg, E. M., Jacobs, A. K., \& Hershberger, S. L. (1999). Peer victimization and attitudes about violence during early adolescence. Journal of Clinical Child Psychology, 28, 386-395.

Volland, C., Ulich, D., Kienbaum, J., \& Hölzle, E. (2008). Doing gender by doing emotion? Die geschlechtsspezifische Entwick- lung der Mitgef "uhlsbereitschaft im Jugendalter [Doing gender by doing emotion? Gender-specific development of the tendency to show sympathy in adolescence]. Psychologie in Erziehung Und Unterricht, 55, 27-38.

Von Marées, N., \& Petermann, F. (2010). Bullying in German primary schools gender differences, age trends and influence of parents' migration and educational backgrounds. School Psychology International, 31, 178-198.

-Warden, D., \& Mackinnon, S. (2003). Prosocial children, bullies and victims: An investigation of their sociometric status, empathy and social problem-solving strategies. British Journal of Developmental Psychology, 21(3), 367-385. https://doi.org/10.1348/ 026151003322277757

Wellman, H. M., \& Peterson, C. C. (2013). Theory of mind, development, and deafness. In S. Baron-Cohen, M. Lombardo, \& H. Tager-Flusberg (Eds.), Understanding Other Minds: Perspectives from developmental social neuroscience (3rd ed., pp. 603-610). Oxford University Press. https://doi.org/10.1093/acprof

Wells, G. A., Shea, B., O'Connell, D., Peterson, J., Welch, V., Losos, M., \& Tugwell, P. (2000). The Newcastle-Ottawa Scale (NOS) for assessing the quality of nonrandomised studies in meta-analyses. Available from: http://www.ohri.ca/programs/clinical_epide miology/oxford.asp. Accessed Oct 2021.

Will, G.-J., van Lier, P. A. C., Crone, E. A., \& Güroğlu, B. (2016). Chronic childhood peer rejection is associated with heightened neural responses to social exclusion during adolescence. Journal of Abnormal Child Psychology, 44(1), 43-55. https://doi.org/10. 1007/s10802-015-9983-0

Williams, J. M. G., Mathews, A., \& MacLeod, C. (1996). The emotional stroop task and psychopathology. Psychological Bulletin, 120(1), 3-24.

-Williford, A., Boulton, A. J., Forrest-Bank, S. S., Bender, K. A., Dieterich, W. A., \& Jenson, J. M. (2016). The effect of bullying and victimization on cognitive empathy development during the transition to middle school. Child and Youth Care Forum, 45(4), 525-541. https://doi.org/10.1007/s10566-015-9343-9

Wolke, D., Woods, S., Bloomfield, L., \& Karstadt, L. (2001). Bullying involvement in primary school and common health problems. Archives of Disease in Childhood, 85(3), 197-201.

Wong, C., \& Law, K. S. (2002). The effects of leader and follower emotional intelligence on performance and attitude. The Leadership Quarterly, 13, 243-274.

-Yang, C., Chan, M. K., \& Ma, T. L. (2020). School-wide social emotional learning (SEL) and bullying victimization: Moderating role of school climate in elementary, middle, and high schools.
Journal of School Psychology, 82, 49-69. https://doi.org/10. 1016/j.jsp.2020.08.002

-Yeung, R. S., \& Leadbeater, B. J. (2007). Does hostile attributional bias for relational provocations mediate the short-term association between relational victimization and aggression in preadolescence? Journal of Youth and Adolescence, 36(8), 973-983. https://doi.org/10.1007/s10964-006-9162-2

Young, J. (2006). Schema therapy: A practitioner's guide. Guilford.

Ykema, F. (2002). Het Rots en Water perspectief. Een psychofysieke training voor jongens. Basisboek [The Rock and Water perspective. A psychophysical training for boys. Basic book]. Uitgeverij SWP.

*Yudes, C., Rey, L., \& Extremera, N. (2020). Predictive factors of cyberbullying perpetration amongst Spanish adolescents. International Journal of Environmental Research and Public Health, 17(3967). https://doi.org/10.3390/ijerph17113967

-Zimmer-Gembeck, M. J. (2015). Emotional sensitivity before and after coping with rejection: A longitudinal study. Journal of Applied Developmental Psychology, 41, 28-37. https://doi.org/ 10.1016/j.appdev.2015.05.001

-Zimmer-Gembeck, M. J., \& Duffy, A. L. (2014). Heightened emotional sensitivity intensifies associations between relational aggression and victimization among girls but not boys: A longitudinal study. Development and Psychopathology, 26(3), 661673. https://doi.org/10.1017/S0954579414000303

•Zimmer-Gembeck, M. J., Nesdale, D., McGregor, L., Mastro, S., Goodwin, B., \& Downey, G. (2013). Comparing reports of peer rejection: Associations with rejection sensitivity, victimization, aggression, and friendship. Journal of Adolescence, 36(6), 1237-1246. https://doi.org/10.1016/j.adolescence.2013.10.002

Zimmer-Gembeck, M. J., \& Pronk, R. (2012). Relation of depression and anxiety to self- and peer-reported relational aggression. Aggressive Behavior, 38, 16-30. https://doi.org/10.1002/ab. 20416

-Zimmer-Gembeck, M. J., Trevaskis, S., Nesdale, D., \& Downey, G. A. (2014). Relational victimization, loneliness and depressive symptoms: Indirect associations via self and peer reports of rejection sensitivity. Journal of Youth and Adolescence, 43(4), 568-582. https://doi.org/10.1007/s10964-013-9993-6

-Ziv, Y., Leibovich, I., \& Shechtman, Z. (2013). Bullying and victimization in early adolescence: Relations to social information processing patterns. Aggressive Behavior, 39(6), 482-492. https:// doi.org/10.1002/ab.21494

Zhou, Q., Valiente, C., \& Eisenberg, N. (2003). Empathy and its measurement. In S. J. Lopez \& C. R. Snyder (Eds.), Positive psychological assessment: A handbook of models and measures (pp. 269-284). American Psychological Association.

Zych, I., Ortega-Ruiz, R., \& Marín-López, I. (2017). Emotional content in cyberspace: Development and validation of E-motions Questionnaire in adolescents and young people. Psicothema, 29, 563-569. https://doi.org/10.7334/psicothema2016.340

Publisher's Note Springer Nature remains neutral with regard to jurisdictional claims in published maps and institutional affiliations. 